Stephen M. Horan, CFA

St. Bonaventure University

\title{
Tax-Advantaged Savings Accounts and Tax-Efficient Wealth Accumulation
}

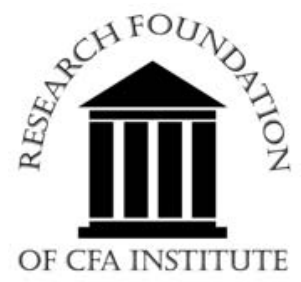


The Research Foundation of CFA Institute and the Research Foundation logo are trademarks owned by The Research Foundation of CFA Institute. CFA ${ }^{\circledast}$, Chartered Financial Analyst ${ }^{\circledast}$, AIMR-PPS $^{\oplus}$, and GIPS ${ }^{\circledast}$ are just a few of the trademarks owned by CFA Institute. To view a list of CFA Institute trademarks and a Guide for the Use of CFA Institute Marks, please visit our website at www.cfainstitute.org.

\section{(C) 2005 The Research Foundation of CFA Institute}

All rights reserved. No part of this publication may be reproduced, stored in a retrieval system, or transmitted, in any form or by any means, electronic, mechanical, photocopying, recording, or otherwise, without the prior written permission of the copyright holder.

This publication is designed to provide accurate and authoritative information in regard to the subject matter covered. It is sold with the understanding that the publisher is not engaged in rendering legal, accounting, or other professional service. If legal advice or other expert assistance is required, the services of a competent professional should be sought.

ISBN 0-943205-73-5

Printed in the United States of America

22 June 2005

\section{Editorial Staff}

Elizabeth A. Collins

Book Editor

Christine E. Kemper

Assistant Editor
Kara H. Morris

Production Manager

Lois Carrier

David VanNoy

Composition and Production 
Tax-Advantaged Savings Accounts and Tax-Efficient Wealth Accumulation 



\section{Biography}

Stephen M. Horan, CFA, is professor of finance at St. Bonaventure University. His areas of expertise include securities brokerage, trading, institutional money management, and financial and economic consulting. Dr. Horan has co-authored two editions of the Forbes Stock Market Course, a comprehensive guide to investing and wealth management, and has authored articles for various academic journals, including the Journal of Financial Research and Financial Services Review. His awardwinning research has been profiled in leading practitioner publications, including the CFA Digest and Barron's. Dr. Horan is an associate editor for Financial Services Review, and he serves on the editorial board of the CFA Digest. He also serves on several community boards and has served as education chair for the Buffalo Chapter of the New York Society of Security Analysts. Dr. Horan is a member of the American Finance Association, the Financial Management Association, and the Academy of Financial Services. He holds a BBA in finance from St. Bonaventure University and a $\mathrm{PhD}$ in finance with a concentration in economics from the State University of New York at Buffalo. 



\section{Contents}

Foreword $\ldots \ldots \ldots \ldots \ldots \ldots \ldots \ldots \ldots \ldots \ldots \ldots \ldots$, viii

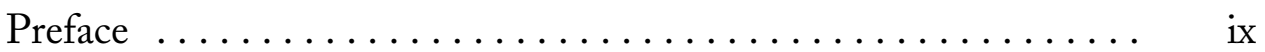

Chapter 1. Introduction $\ldots \ldots \ldots \ldots \ldots \ldots \ldots \ldots \ldots . \ldots \ldots$

Chapter 2. Choosing between Traditional IRAs and

Roth IRAs: The Basics ................ 5

Chapter 3. Employer Matching and Converting a

Traditional IRA to a Roth IRA............. 26

Chapter 4. Choosing between Nondeductible IRAs

and Taxable Investments ................ 38

Chapter 5. Valuing Tax-Sheltered Assets on an

After-Tax Basis ...................... $\quad 45$

Chapter 6. Early Withdrawal Penalties and

Breakeven Time Horizons.................. 64

Chapter 7. Asset Location between Taxable and Tax-Deferred Savings Accounts ............. $\quad 75$

Chapter 8. Implications for Financial Analysts ........... 86

Appendix A. Proof of Equivalency for Standardized

Pretax and After-Tax Investments............. 91

Appendix B. Simplification When Tax Savings

Are Reinvested in $401(\mathrm{k}) \ldots \ldots \ldots \ldots \ldots \ldots . .65$

Appendix C. Derivation of Breakeven Withdrawal Tax Rate for Nondeductible IRA ................... 98

Appendix D. Derivation of Future Value Interest

Factor of a Taxable Annuity ............... 99

Appendix E. Breakeven Investment Horizon for a Traditional IRA .................... 100






\section{Foreword}

Academics and practitioner researchers have developed a large body of impressive research for determining optimal investment strategies and valuation models, yet much of this research abstracts from real-world complexities, such as transaction costs, liquidity constraints, limitations on access to credit, and of particular importance, taxes. Indeed, the standard by which many scholars evaluate research is neither relevance nor reality but, rather, mathematical elegance. This attitude is jokingly summarized by the aphorism, the real world is an uninteresting, special case of my model. Thankfully, Stephen M. Horan, CFA, is well grounded in the real world as evidenced by this outstanding monograph, Tax-Advantaged Savings Accounts and Tax-Efficient Wealth Accumulation.

As corporations shift from defined-benefit pension plans to 401(k) plans and the government offers a wider menu of tax-deferred accounts, individual investors and their financial advisors are faced with a more complex set of investment choices. How they direct the flow of their savings and where they locate their assets is now a first-order consideration for wealth accumulation. Horan artfully disentangles this new and more complex reality with a fine balance of mathematical precision, accessibility, and pragmatism.

The time value of money serves as the foundation of Horan's analysis, which focuses mainly on retirement savings. Horan uses this familiar methodology to evaluate a variety of investment choices including, for example, alternative investment vehicles, front-end versus back-end tax benefits, employer-matching contributions, investment in nondeductible IRAs versus taxable investments, and early withdrawal penalties. Of necessity in a piece of this size, he abstracts from tax minutiae and concentrates on the important issues. He uses clear examples to demonstrate the advantage of one approach versus another, and he provides numerous tables to illustrate and generalize his points. For those unwilling to engage in mathematical detail, Horan summarizes many of these topics with clearly and concisely stated guidelines. And for those who demand more mathematical detail, he includes of variety of technical appendices.

The essential concepts and tools of investment management were developed primarily in the sterile world of tax-exempt investing, and perhaps justifiably so given the dominance of institutional investors, such as pension funds and eleemosynary institutions. But that is not the world we live in today. Individual investors control vast sums of wealth, and they demand tax-efficient investment strategies. The Research Foundation is especially pleased to contribute this excellent monograph to the cause of developing a more robust framework for tax-efficient investing.

Mark Kritzman, CFA Research Director

The Research Foundation of CFA Institute 


\section{Preface}

Taxing investment returns is largely a 20th century phenomenon. The first temporary federal income tax in U.S. history was passed in the early 1860s to subsidize the Civil War and included a tax on interest and dividends paid to investors of insurance companies and banks. ${ }^{1}$ Originally accepted as an emergency wartime measure, the 3 percent tax on income of more than $\$ 800$ was allowed to expire in 1872. After a series of conflicting U.S. Supreme Court decisions and tax acts, the income tax regained its foothold in U.S. fiscal policy in 1913 with the passage of the Sixteenth Amendment, which serves as the basis for a permanent, progressive income tax. Modest as the income tax may have been initially (1-2 percent on income of more than $\$ 3,000)$, World War I transformed it into the centerpiece of federal finance, raising the top rate to 6 percent. By 1919, the top rate had risen to 77 percent, and in 1921, Congress passed a preferential tax rate for capital gains.

Despite a long history of high tax rates for investment returns, most modern portfolio theory is grounded in a pretax framework. Only recently have researchers investigated the impact of taxes and tax-preferred savings accounts on risk and return characteristics of a portfolio and wealth accumulation. Nonetheless, a fundamental issue facing investors, particularly those investing for retirement, is how to invest funds in a tax-efficient manner. Using tax incentives, the U.S. federal government encourages retirement savings through many different tax-advantaged savings programs. The proliferation of traditional individual retirement accounts (IRAs), defined-contribution plans, 401(k) plans, 403(b) plans, Keogh plans, Roth IRAs, and other tax-preferred savings accounts expands opportunities for efficient wealth accumulation but also adds complexity to the investor's decision. These programs offer tax-deferred accumulation of savings and allow the taxpayer to either contribute to or withdraw from the account on a tax-exempt basis.

Often called tax-deferred accounts, or TDAs, these investment vehicles are quite popular. According to the U.S. Department of Labor, almost half of all fulltime U.S. workers in 2003 used payroll deductions to make contributions to definedcontribution plans. ${ }^{2}$ The assets held in defined-benefit and defined-contribution plans totaled $\$ 4.2$ trillion in 2003 , most of which was held in defined-contribution plans controlled, at least to some extent, by the employee. ${ }^{3}$ Another $\$ 3$ trillion was

1 Historical tax information can be accessed online from the Tax History Project at www.tax.org/ Museum.

2 Bureau of Labor Statistics, "National Compensation Survey: Employee Benefits in Private Industry in the United States, 2002-2003," Table 1, p. 5. This survey can be accessed online at www.bls.gov/ ncs/ebs/sp/ebb10020.pdf.

3 Federal Reserve Board, "Flow of Funds Accounts of the United States, First Quarter 2004" (10 June 2004), Tables L.119.b and L.119.c, p. 113. This study can be accessed online at www.federalreserve.gov/ releases/z1/20040610/z1.pdf. 
invested in IRAs, which are becoming more popular than employer-sponsored plans. Contributions to IRAs in 2003, for example, were three times larger than contributions to defined-benefit and defined-contribution plans combined. ${ }^{4}$ Another indication of the IRA's popularity is that net contributions to employersponsored plans have fallen by more than half in the past 10 years, whereas the amount in IRAs has more than doubled over the same time period. 5 These trends reflect the growing responsibility borne by individual investors and their financial advisors to invest tax efficiently. They also emphasize the need for developing methods that can be used to evaluate various tax-advantaged investment alternatives.

The problem of tax-efficient investing is aggravated by the complexity and instability of the tax code. Since 1997 alone, investors in the United States have experienced three major tax reforms that significantly affect an investor's optimal decision making regarding the use of tax-deferred savings accounts: the Taxpayer Relief Act (TRA) of 1997, the Economic Growth Tax Relief Reconciliation Act (EGTRRA) of 2001, and the Jobs and Growth Tax Relief Reconciliation Act (JGTRRA) of 2003. The TRA of 1997 created the Roth IRA, which has been the forerunner of many different types of back-end-loaded, tax-advantaged savings accounts. The EGTRRA of 2001 lowered marginal tax rates and lowered the tax rate on realized capital gains to 20 percent. The JGTRRA of 2003 accelerated the implementation of marginal tax rate reductions and further eroded the double taxation of equity returns by reducing the tax rate on realized capital gains, as well as dividends, to 15 percent. All of these measures affect an investor's decisions regarding tax-efficient wealth accumulation.

The issue of tax-efficient investing is not unique to U.S. investors. Most industrialized and developing countries have tax incentives to encourage retirement savings. An international survey of 24 industrialized and developing countries commissioned by the American Council for Capital Formation (ACCF) indicates that tax-advantaged savings accounts are offered to taxpayers by two-thirds of the countries surveyed, including Australia, Canada, Germany, Italy, the Netherlands, and the United Kingdom. 6 All but one of these countries permits tax-deductible contributions. In addition, a related survey commissioned by the ACCF indicates that many countries have tax investment income much like the United States, albeit at a generally lower level. 7 For example, all but two countries surveyed have different tax rates for interest income and capital gains. Therefore, the analysis developed herein has international applicability.

4 Federal Reserve Board, "Flow of Funds Accounts of the United States, First Quarter 2004" (10 June 2004), Table L.225.i., p. 113. This study can be accessed online at www.federalreserve.gov/releases/ z1/20040610/z1.pdf.

5 Ibid.

6 American Council for Capital Formation, "An International Comparison of Incentives for Retirement Saving and Insurance” (June 1999). This study can be accessed online at www.accf.org/ publications/reports/sr-intcompretirement1999.html. 
Until recently, the issue of tax-efficient investing has been largely overlooked by the mainstream literature. And simple heuristics to guide investors and their advisors are not always as obvious as they might initially seem. The pages that follow provide a compendium of the recent advances in this area, as well as some updates and extensions. The ultimate aim is to lay a foundation that yields practical rules of thumb that can be used as a basis for analyzing a series of investment decisions in an individual's unique circumstance.

This monograph explores central issues surrounding the use of tax-deferred investment accounts as a means of accumulating wealth. Most of the monograph focuses on retirement savings. As the reader will discover, however, it also examines nonretirement savings issues, including using tax-deferred retirement accounts for nonretirement purposes and using education savings accounts for noneducational purposes. Much of the literature analyzing the tax implications of tax-efficient investment strategies involves sophisticated methods. My aim is to present a useful framework, grounded in basic time-value-of-money concepts, that can be readily implemented by investment professionals. Using basic algebra, I dissect and package the model into intuitive components, emphasize important relationships, and derive practical rules of thumb. Another practical feature of this framework is its flexibility. Because the model is based on general time-value-of-money and tax principles, it can be adapted easily to different tax environments. Therefore, non-U.S. investors will find the framework equally applicable in their home countries. The framework will also remain relevant to investors over time as they respond to endless changes in the tax code.

The initial chapters of this monograph lay the analytical foundations for examining a series of common financial decisions that are explored in later chapters. Chapter 1 introduces different types of investment vehicles and reviews their salient characteristics. Chapter 2 lays the foundation for evaluating taxadvantaged investment decisions. By introducing a framework for calculating future values in different tax environments, this fundamental chapter addresses the question of choosing between TDAs with front-end tax benefits, such as traditional IRAs, and those with back-end tax benefits, such as Roth IRAs. Armed with these basic tools, I examine other TDA investment decisions in Chapters 3 through 6. Chapter 3 examines the implications of employer-matching arrangements that are often found as part of $401(\mathrm{k})$ plans or other defined-contribution plans. The results show that it is rarely optimal for an investor to forgo the benefits of employer matching. Chapter 4 applies a similar analysis to the choice between nondeductible IRA investments and taxable investments. Perhaps surprisingly, taxable investments are preferred to nondeductible IRA investments in many

7 American Council for Capital Formation, "Small Saver Incentives: An International Comparison of the Taxation of Interest, Dividends, and Capital Gains" (October 1998). This study can be accessed online at www.accf.org/publications/reports/sr-smallsaver-oct1998.html. 
instances. Chapter 5 uses basic technology to determine the after-tax value of assets held in tax-sheltered accounts. Depending on the circumstance, the after-tax value of a dollar held in a TDA may be more or less than $\$ 1.00$. I then examine the notion of early withdrawal penalties in Chapter 6. The analysis helps determine when an investor might rationally use a TDA and knowingly incur an early withdrawal penalty rather than use a taxable account.

In Chapter 7, I move beyond the investment analysis among and within TDAs to take a somewhat broader view, examining the interaction between asset allocation and asset location. Asset allocation, of course, refers to how an investor allocates his or her investment portfolio among different asset classes. Asset location refers to how assets are distributed among taxable accounts and TDAs. A strictly formal analysis of this issue is prohibitively complicated, but I review the recent research and provide intuitive and sometimes counterintuitive rules of thumb. I conclude in Chapter 8 with some general guidance for financial professionals seeking to make investment decisions that are informed by an understanding of the tax implications of wealth accumulation in tax-advantaged savings accounts.

The reader should note that this monograph does not include an exhaustive treatment of all the nuances in the U.S. tax code associated with tax-advantaged savings accounts. Such publications already exist and do not lend themselves to economic analysis and practical application. Instead, I focus on salient features of TDA investing and incorporate them into the analysis. Consequently, I abstract from some of the seemingly infinite loopholes and tax minutiae. This document also does not contain a macroeconomic analysis of the impact of tax incentives on aggregate savings, the pension system, or tax receipts. These questions have fiscal policy implications more than investment decision-making implications. I present useful tools that financial analysts can readily apply to the investment decisionmaking process.

I am grateful to the many people who have directly and indirectly helped make this monograph a reality. I am indebted to my wife, Connie, who has been a constant source of encouragement, enduring endless hours of my absence and contributing her editing prowess. I am also grateful to those who have encouraged and sharpened my thinking on many of these issues over the years, including Robert McLeod, Jeffrey Peterson, Karen Eilers Lahey, Conrad Ciccotello, and William Jennings. The Research Foundation of CFA Institute deserves special recognition as well. In supporting this endeavor, it has demonstrated leadership and courage in helping to set a research agenda that has only begun to find its way into mainstream financial literature. 


\section{Introduction}

The United States has a long history of encouraging retirement savings by providing tax incentives for investors. ${ }^{1}$ Although individual retirement accounts (IRAs) were first introduced in 1974 for employees without pension plans, fewer than 3 percent of taxpayers contributed to such plans that year. The Economic Recovery Tax Act of 1981 increased contribution limits and expanded eligibility requirements for IRAs, allowing almost all working taxpayers to contribute. As a result, contributions to IRA accounts increased substantially until the Tax Reform Act of 1986 excluded higher-income taxpayers with employer-provided pension plans from making taxdeductible contributions. The 401(k) savings program, which also became popular in the early 1980s, permits tax-deductible contributions and tax deferral on accumulated earnings until funds are withdrawn, much like the traditional IRA. And like the IRA, withdrawals from $401(\mathrm{k})$ plans prior to age $59 \frac{1}{2}$ are subject to a 10 percent early withdrawal penalty. ${ }^{2}$ In addition, the investor is generally required to make minimum withdrawals starting at age 701/2. But unlike IRAs, 401(k) plans are sponsored by an employer, have much higher contribution limits, and permit employers to make additional contributions to supplement employees' contributions. Traditional IRA, 401(k), 403(b), 457, and Keogh plans are sometimes said to have front-end-loaded tax benefits because the initial contribution is tax deductible in many cases and the withdrawal is taxed as ordinary income. ${ }^{3}$

The Taxpayer Relief Act (TRA) of 1997 introduced a variation on this themethe Roth IRA. Named after the Delaware senator William Roth, who sponsored the bill, Roth IRAs are sometimes said to have back-end-loaded tax benefits because, although the investor enjoys no tax deduction for the initial contribution, accumulated earnings and withdrawals are free from tax. This new type of IRA reignited investor interest in IRAs, as evidenced by annual contributions nearly doubling over the 1996-2003 period. ${ }^{4}$ The U.S. Congress, as well, must have liked

1 Hubbard and Skinner (1996) and Crain and Austin (1997) have good reviews, from which some of this section is drawn, of legislative developments designed to encourage retirement savings.

2 401(k) plans and IRAs are somewhat distinct from each other in their access to savings before age 591/2.

3 403(b) plans, which Congress introduced in 1958, are similar to 401(k) plans but are designed for certain employees of public schools, employees of certain tax-exempt organizations, and certain ministers. Keogh plans allow self-employed workers opportunities for tax-deferred retirement savings and have significantly higher contribution limits than IRAs, 401(k) plans, or 403(b) plans. Similar to 401(k) and 403(b) plans, Section 457 plans offer government employees and employees of nonchurch-controlled tax-exempt organizations opportunities for retirement savings with front-endloaded tax benefits.

4 Federal Reserve Board, "Flow of Funds Accounts of the United States, First Quarter 2004" (10 June 2004), Table F.225.i, p. 112. This study can be accessed online at www.federalreserve.gov/releases/ z1/20040610/z1.pdf. 
the idea of encouraging savings with back-end-loaded tax benefits. And why not? Legislators forgo no tax revenue for the initial contribution and leave it to future Congresses to handle the forgone tax revenue created by tax-exempt withdrawals. As a result, taxpayers are witnessing the introduction and proposal of similar targeted savings accounts, including Section 529 College Savings plans, new Roth 401(k) plans, health care savings accounts, and lifetime savings accounts (LSAs). Introduced in 2001, Section 529 plans are designed to encourage higher education saving and are nearly equivalent to the Roth IRA from a tax perspective: Withdrawals for noneducational purposes are subject to a 10 percent withdrawal penalty. Congress created the Roth 401(k) in the Economic Growth Tax Relief Reconciliation Act (EGTRRA) of 2001. Although the Roth 401(k) is scheduled to take effect 1 January 2006, as of this writing, the Bush administration has proposed accelerating its availability a year and renaming it Roth Employee Retirement Savings Accounts (ERSAs). The same budget proposal includes a provision for LSAs that would be nearly identical to Roth IRAs but would have more liberal contribution and withdrawal policies.

Tax law is ever changing; contribution limits, eligibility requirements, and withdrawal policies vary from plan to plan. But the basic theme is that all accounts offer the opportunity to accumulate earnings in a tax-deferred manner. Some accounts allow tax-free contributions, and others permit tax-free withdrawals. The salient tax features of the most popular TDAs and taxable accounts are summarized in Table 1.1, which separates the investment horizon of a savings account into three phases: the initial contribution, the accumulation phase, and withdrawal. The taxable account is taxed in all three phases. During the accumulation and withdrawal phases, the timing of taxable events and the associated tax rate for the taxable account depend on the proportion of return that is ordinary income dividend, realized capital gain, or unrealized capital gain. Withdrawals from traditional IRAs

\section{Table 1.1. Tax Treatment of Different Savings Accounts}

\begin{tabular}{|c|c|c|c|c|}
\hline Item & $\begin{array}{l}\text { Traditional IRA, } \\
\text { 401(k), 403(b), 457, } \\
\text { and Keogh Plans }\end{array}$ & $\begin{array}{c}\text { Roth IRA, 529, and } \\
\text { Roth 401(k) Plans } \\
\text { and LSAs }\end{array}$ & Nondeductible IRA & Taxable Account \\
\hline $\begin{array}{l}\text { Initial } \\
\text { contribution }\end{array}$ & Tax deductible & Not deductible & Not deductible & Not deductible \\
\hline $\begin{array}{l}\text { Accumulated } \\
\text { earnings }\end{array}$ & Tax deferred & Tax exempt & Tax deferred & $\begin{array}{l}\text { Taxable as ordinary } \\
\text { income, dividend, } \\
\text { or capital gain as } \\
\text { realized }\end{array}$ \\
\hline Withdrawal & $\begin{array}{l}\text { Taxable as ordinary } \\
\text { income }\end{array}$ & Tax exempt & $\begin{array}{l}\text { Accumulated } \\
\text { earnings taxable } \\
\text { as ordinary } \\
\text { income }\end{array}$ & $\begin{array}{l}\text { Previously unrealized } \\
\text { gains taxed as capital } \\
\text { gain }\end{array}$ \\
\hline
\end{tabular}


are taxed as ordinary income, whereas contributions to Roth IRAs are taxed as ordinary income. One could say that the nominal taxes paid upon withdrawal for a traditional IRA will be greater than those paid upon contribution for a Roth IRA. But properly discounting these future taxes at the opportunity cost of capital exactly offsets their nominal growth. So, the present value of the traditional IRA tax liability upon withdrawal is exactly equal to the additional tax paid on a Roth IRA contribution, depending on how tax rates change over time. This assumption is pivotal, and I examine it in detail in the pages that follow.

Taxpayers who do not qualify for tax-deductible IRA contributions may be allowed to make nondeductible IRA contributions. These funds enjoy the same taxdeferral status for earnings as other IRAs and are taxed as ordinary income upon withdrawal. The initial contribution, however, does not lower the investor's tax bill. In some circumstances, an investor may optimally forgo a nondeductible IRA investment in favor of a taxable investment that might have some inherent tax advantages of its own, such as tax deferral through unrealized capital gain and lower tax rates on realized capital gains. Unlike a nondeductible IRA, a taxable investment is not taxed as ordinary income upon withdrawal and may receive preferential tax treatment in the form of capital gains and dividends. The trade-off between the tax advantages of these two strategies is examined in Chapter 4.

Table 1.2 highlights some other features of tax-advantaged savings accounts. The EGTRRA of 2001 increased the contribution limits on these accounts and set a schedule for future increases. Prior to its passage, the contribution limit for IRAs stood at $\$ 2,000$ for many years. This legislation also created “catch up" contributions for taxpayers 50 years of age or older. Table 1.2 also shows that employer-sponsored plans have much higher contribution limits than IRA accounts. Income limitations for the traditional IRA are much lower than those for the Roth IRA or employersponsored plans, which can be somewhat complicated. Because the income limits for married couples are less than twice the limits for single filers, some may say a "marriage penalty" exists in this part of the tax code. Withdrawals before age 591/2 are generally subject to a 10 percent penalty unless an exemption applies, such as disability, medical expenses, or a first-time home purchase. Early withdrawals from 401(k)s are a bit more restrictive, but investors can often borrow funds from their account or use their account as collateral for a loan, which is not allowed for IRA accounts. In any case, investors are required to make mandatory withdrawals starting at age $70 \frac{1}{2}$.

The next chapter abstracts a bit from these details and lays the foundation for analyzing the best choice among different tax-advantaged savings plans. This framework considers the salient features outlined in Tables 1.1 and 1.2 and is based on fundamental concepts of time value of money, which are familiar to all investment professionals. 
Table 1.2. Contribution, Eligibility, and Withdrawal Policies of Tax-Advantaged Savings Accounts

\begin{tabular}{|c|c|c|c|}
\hline Item & Traditional IRA & Roth IRA & 401(k) and 403(b) \\
\hline \multicolumn{4}{|l|}{ A. Contribution limits } \\
\hline 2004 & $\$ 3,000^{a}$ & $\$ 3,000^{a}$ & $\$ 13,000^{b}$ \\
\hline 2005 & $\$ 4,000^{a}$ & $\$ 4,000^{a}$ & $\$ 14,000 \mathrm{~b}$ \\
\hline 2006 & $\$ 4,000^{a}$ & $\$ 4,000^{a}$ & $\$ 15,000^{b}$ \\
\hline 2007 & $\$ 4,000^{a}$ & $\$ 4,000^{a}$ & Indexedc \\
\hline 2008 & $\$ 5,000^{a}$ & $\$ 5,000^{a}$ & \\
\hline 2009 & Indexedc & Indexedc & \\
\hline \multicolumn{4}{|c|}{ B. Income limitations for 2005} \\
\hline \multicolumn{4}{|l|}{ Single } \\
\hline Full contribution & $\$ 50,000 \mathrm{~d}$ & $\$ 95,000 \mathrm{e}$ & $\$ 90,000^{f}$ \\
\hline Partial contribution & $\$ 60,000 \mathrm{~d}$ & $\$ 110,000 \mathrm{e}$ & \\
\hline \multicolumn{4}{|l|}{ Married filing joint } \\
\hline Full contribution & $\$ 70,000 \mathrm{~d}$ & $\$ 150,000 \mathrm{e}$ & $\$ 90,000^{f}$ \\
\hline Partial contribution & $\$ 80,000 \mathrm{~d}$ & $\$ 160,000$ e & \\
\hline \multicolumn{4}{|l|}{ C. Withdrawal policies } \\
\hline Minimum age & $59 \frac{1}{2}$ & $591 / 2$ & $591 / 2$ \\
\hline Mandatory age & $701 / 2$ & None & $701 / 2$ \\
\hline Early withdrawal penalty & $10 \%$ of withdrawal & $10 \%$ of earnings & $10 \%$ of withdrawal \\
\hline Penalty exemptions & $\begin{array}{l}\text { Disability, death, } \\
\text { medical expenses, } \\
\text { first-time home } \\
\text { purchase, higher } \\
\text { education expenses }\end{array}$ & $\begin{array}{l}\text { Disability, death, } \\
\text { medical expenses, } \\
\text { first-time home } \\
\text { purchase, higher } \\
\text { education expenses }\end{array}$ & $\begin{array}{l}\text { Disability, death, } \\
\text { medical expenses, } \\
\text { separation of service } \\
\text { after age } 55\end{array}$ \\
\hline
\end{tabular}

a Taxpayers 50 years of age or older can contribute an additional $\$ 500$ through 2005 and an additional $\$ 1,000$ through 2008.

b Taxpayers 50 years of age or older can contribute an additional $\$ 3,000$ in $2004, \$ 4,000$ in 2005 , and $\$ 5,000$ in 2006. These "catch up" contributions will be indexed for inflation in $\$ 500$ increments.

cIndexed for inflation in $\$ 500$ increments.

dincome limitations for the traditional IRA relate to the tax deductibility of the contribution and do not apply if a taxpayer does not participate in a qualified employer-sponsored retirement plan.

eIncome limitations for the Roth IRA relate to contribution eligibility.

fAn income limitation applies only if the percentage of income that highly compensated employees defer into the plan is more than 2 percentage points higher than non-highly compensated employees. A highly compensated employee owns more than 5 percent of the business or earned more than $\$ 90,000$ the previous year. 


\section{Choosing between Traditional IRAs and Roth IRAs: The Basics}

Motivated by the passage of the TRA of 1997, Crain and Austin (1997) modeled the choice between a traditional IRA and a Roth IRA. Their analysis, and most of the following analysis in this monograph, should be interpreted with the understanding that the term "traditional IRA" generically represents all TDAs with frontloaded tax benefits, including 401(k), 403(b), 457, and Keogh plans. Likewise, the term "Roth IRA" can most often be understood as omnibus vernacular representing TDAs with back-loaded tax benefits, such as Section 529, Roth 401(k), and LSA plans. This chapter focuses on the choice between TDA accounts having front-end tax benefits and those having back-end tax benefits. The analysis, therefore, has much broader applicability than merely IRA accounts, despite the fact that I proceed using the IRA nomenclature for simplicity.

Another point of taxonomy is in order. One might think of this chapter's central issue as an "asset location" question. This term, however, is generally understood to mean something different. It relates to where an investor might optimally hold stocks or bonds (or some other asset class) when both taxable and TDA accounts are used for investing. This chapter, in contrast, focuses on the investor's choice between different types of TDA accounts for a given investment. For the sake of clarity, I avoid using the term "asset location" until Chapter 7, which addresses it directly.

This chapter establishes that comparing traditional IRA and Roth IRA investments by equalizing the pretax investment is equivalent to equalizing the after-tax investment as long as one is consistent in making assumptions about how tax savings are invested. Using this insight to establish a general framework, this chapter shows that traditional IRAs become relatively more attractive than Roth IRAs when an investor's withdrawal tax rate declines. The intuition is simple: The tax shelter of the traditional IRA is greatest when contribution tax rates are high, and the tax shelter of the Roth IRA is greatest when withdrawal tax rates are high.

When an investor maximizes the pretax contribution, however, part of the traditional IRA strategy must include a taxable investment, which hampers its performance compared with the Roth IRA. In this case, if the investor drops two tax brackets during retirement, the traditional IRA is almost always preferred to the Roth IRA because the benefit of the low-withdrawal tax rate outweighs the disadvantage of the taxable investment associated with the traditional IRA strategy. 
When the same investor drops only one tax bracket, the traditional IRA is optimal only for short time horizons or for investments with low rates of return.

\section{Equalizing the Investment}

Crain and Austin compared the after-tax accumulations of traditional IRAs and Roth IRAs for various returns and investment horizons. For a meaningful comparison, they held the pretax investment constant for the two investment choices and implicitly assumed that it was less than the after-tax contribution limit. ${ }^{1}$ Under the premise that investors are better advised to make investment decisions net of taxes, other authors have standardized the after-tax investment. ${ }^{2}$ As it turns out, Horan (2003) showed that the two seemingly contrasting approaches are reconcilable and can be combined into one cohesive framework. The issue is best understood by way of example.

Consider an investor currently in the 25 percent tax bracket (denoted as $T_{0}$ ) who wishes to make a $\$ 3,000$ investment before taxes $\left(I_{B T}\right)$. The contribution limit $(L)$ for both traditional and Roth IRAs in the 2004 tax year is $\$ 3,000$. The entire $\$ 3,000$ may be invested in the traditional IRA and escape taxation; withdrawals from this account will be taxed as ordinary income. For the Roth IRA, only $\$ 2,250$ [i.e., $\$ 3,000(1-0.25)$ ] can be invested because contributions are taxable. Although the after-tax investment is lower for the Roth IRA than the traditional IRA, withdrawals from the Roth IRA are not taxed. Panel A of Table 2.1 displays the instance in which the pretax contribution is less than the contribution limit (i.e., $I_{B T} \leq L$ ).

One can equivalently view the scenario in Panel $A$ as a standardized $\$ 2,250$ after-tax investment. Doing so, however, requires one to make an assumption about how tax savings are to be invested. Contributing $\$ 2,250$ to the traditional IRA generates an initial tax savings of $\$ 562.50$ (i.e., $\$ 2,250 \times 0.25$ ). Because the IRA contribution limit is $\$ 3,000$ and has not yet been reached, these tax savings can be reinvested in the traditional IRA, which creates more tax savings. The total amount of tax savings that can be reinvested in the traditional IRA is $\$ 750$ [i.e., $\$ 562.50$ / $(1-0.25)$, yielding a total investment for the traditional IRA of $\$ 3,000$, which is identical to the standardized pretax investment scenario. This equivalency between the two approaches holds for any pretax investment up to and including the IRA contribution limit $\left(I_{B T} \leq L\right) .{ }^{3}$ Therefore, a standardized pretax investment less than or equal to the IRA contribution limit is equivalent to a standardized after-tax investment in which tax savings are assumed to be reinvested in the deductible IRA.

1 Horan, Peterson, and McLeod (1997) took a similar approach in their analysis. Stout and Barker (1998) also held the pretax investment constant but allowed the pretax contribution to exceed the after-tax contribution limit, which required them to make an assumption about how the pretax investment in excess of the after-tax contribution was invested.

2 Examples include Krishnan and Lawrence (2001) and Horan and Peterson (2001).

3 See Appendix A for a proof. 
Table 2.1. Example of Standardized Pretax Investments in a Traditional IRA and Roth IRA

\begin{tabular}{|c|c|c|}
\hline Item & Traditional IRA & Roth IRA \\
\hline \multicolumn{3}{|l|}{ A. $I_{B T} \leq L$} \\
\hline Pretax investment $\left(I_{B T}\right)$ & $\$ 3,000$ & $\$ 3,000$ \\
\hline \multicolumn{3}{|l|}{ After-tax investment } \\
\hline IRA investment & 3,000 & 2,250 \\
\hline Non-IRA investment & $\underline{0}$ & 二 \\
\hline Total after-tax investment & $\$ 3,000$ & $\$ 2,250$ \\
\hline \multicolumn{3}{|l|}{ B. $I_{B T}=L /\left(1-T_{0}\right)$} \\
\hline Pretax investment $\left(I_{B T}\right)$ & $\$ 4,000$ & $\$ 4,000$ \\
\hline \multicolumn{3}{|l|}{ After-tax investment } \\
\hline IRA investment & 3,000 & 3,000 \\
\hline Non-IRA investment $\left[\left(I_{B T}-L\right) /\left(1-T_{o}\right)\right]$ & 750 & 二 \\
\hline Total after-tax investment & $\$ 3,750$ & $\$ 3,000$ \\
\hline \multicolumn{3}{|l|}{ C. $L<I_{B T}<L /\left(1-T_{o}\right)$} \\
\hline Pretax investment $\left(I_{B T}\right)$ & $\$ 3,500$ & $\$ 3,500$ \\
\hline \multicolumn{3}{|l|}{ After-tax investment } \\
\hline IRA investment & 3,000 & 2,625 \\
\hline Non-IRA investment $\left[\left(I_{B T}-L\right) /\left(1-T_{o}\right)\right]$ & 375 & 二 \\
\hline Total after-tax investment & $\$ 3,375$ & $\$ 2,625$ \\
\hline
\end{tabular}

Note: The investor faces a 25 percent tax bracket $\left(T_{o}\right)$ and a $\$ 3,000$ after-tax contribution limit $(L)$.

Source: Horan (2003).

A similar equivalence exists when one maximizes the pretax contribution. This hypothetical investor can contribute up to $\$ 4,000$ pretax into the traditional IRA [i.e., $\$ 3,000 /(1-0.25)]$. In this case, a non-IRA investment in some kind of taxable investment is required for the $\$ 1,000$ above the contribution limit. The exact type of taxable investment is considered below, but in any case, it is initially taxed as ordinary income, leaving $\$ 750$ after taxes [i.e., $\$ 1,000(1-0.25)$ ] to be invested in a non-IRA vehicle. As Panel B illustrates, the $\$ 4,000$ pretax traditional IRA investment comprises a $\$ 3,000$ tax-sheltered investment, a $\$ 750$ taxable investment, and $\$ 250$ in taxes. For the Roth IRA alternative, the $\$ 4,000$ pretax investment comprises the $\$ 3,000$ contribution and $\$ 1,000$ of taxes.

One can equivalently view the scenario in Panel B as a standardized after-tax investment of $\$ 3,000$. An investor contributing $\$ 3,000$ after-tax dollars into a traditional IRA will generate $\$ 750$ of tax savings that can be invested in some kind of taxable investment. In a standardized after-tax framework, the $\$ 750$ is the tax savings from the IRA strategy. In a pretax framework, it is the after-tax investment 
in excess of the IRA contribution limit. The main point is that a standardized pretax investment equal to the maximum allowable pretax allocation to an IRA is equivalent to a standardized after-tax investment equal to the IRA contribution limit in which the tax savings are invested in some kind of taxable account.

A similar equivalence holds when the pretax investment is greater than the contribution limit but less than the maximum pretax Roth IRA investment, such as the $\$ 3,500$ pretax contribution illustrated in Panel $\mathrm{C}$ of Table 2.1. In this case, $\$ 2,625$ [i.e., \$3,500(1-0.25)] is invested in the Roth IRA. Because the contribution limit is $\$ 3,000$, only a portion of the $\$ 3,500$ pretax investment can be allocated to the traditional IRA, leaving $\$ 500$ pretax for a taxable investment. The result is a $\$ 375$ [i.e., \$500(1 - 0.25)] non-IRA investment. Any marginal pretax investment greater than $\$ 4,000$ is treated identically under both the traditional IRA and Roth IRA alternatives in that it must be invested in a taxable investment and does not, therefore, affect the decision between the traditional and Roth IRA.

Notice that the total after-tax investment for the traditional IRA strategy is always $\$ 750$ greater than that for a Roth IRA. The difference between the three cases rests in how the $\$ 750$ is invested. In the first case, the entire $\$ 750$ can be reinvested in the traditional IRA. In the second case, the $\$ 750$ is invested in a taxable, non-IRA account. In this last case, a portion can be allocated to the traditional IRA (\$375) and the remainder (\$375) invested in a non-IRA vehicle. This last scenario represents a hybrid of the first two scenarios. A proof of this equivalency for all scenarios is located in Appendix A. The main point, however, is that whether the pretax investment is held constant or the after-tax investment is held constant, one must make an assumption about how the tax savings are invested in the pretax framework or how the pretax investment in excess of the contribution limit is invested in the after-tax framework. The two approaches are equivalent as long as their respective assumptions are consistent.

With this foundation, the next section presents a flexible model that considers all the scenarios just presented. It is also general enough to accommodate different tax structures for the non-IRA investment. For instance, the taxable return could be fully taxed each year as ordinary income (e.g., fixed-income investments), tax deferred until withdrawal as a capital gain (e.g., non-dividend-paying stocks), or taxed as some combination of ordinary income, dividend, unrealized capital gain, and realized capital gain (e.g., mutual funds). It is important to recognize that the typical mutual fund has inherent tax-deferral characteristics in this regard, making it a relatively tax-efficient investment in many cases. (The precise impact of these tax-deferral characteristics will be discussed later in this monograph.) In addition to capturing salient features of the tax code, the following framework permits variation in tax rates over time, which allows one to assess the effect of increasing or decreasing tax rates. 


\section{The Basic Framework}

For a given pretax investment $\left(I_{B T}\right)$, the after-tax investment for a Roth IRA is $I_{B T}\left(1-T_{o}\right)$, where $T_{o}$ is the initial marginal tax rate on ordinary income at the time of the contribution. The standard future value formula shows that the after-tax future value of a Roth IRA after $n$ years is

$$
\mathrm{FV}_{\text {Roth }}=I_{B T}\left(1-T_{o}\right)(1+r)^{n} \text {, }
$$

where $r$ is the expected annual pretax return on the investment. Now, consider the future value of a traditional IRA when the after-tax contribution is less than or equal to the contribution limit. Because an investor does not pay tax on the contribution, the entire pretax investment will accumulate earnings. The investor pays tax when withdrawing funds at the then-prevailing tax rate, $T_{n}$. Therefore,

$$
\mathrm{FV}_{\text {Trad }}=I_{B T}(1+r)^{n}\left(1-T_{n}\right) \text {. }
$$

The asterisk on the subscript "Trad" denotes this as a special case where the after-tax contribution is less than the contribution limit. A more general approach follows. In any case, a straightforward comparison of Equation 2.1 and Equation 2.2 reveals that the only difference between the future values of the Roth IRA and the traditional IRA is the tax rate, which yields the following rule of thumb: If the prevailing tax rate when funds are withdrawn is less than the tax rate when funds are invested, then the traditional IRA will accumulate more after-tax wealth. Otherwise, the Roth IRA is a better investment.

This fundamental result carries two important caveats. First, this analysis is limited to situations in which the pretax contribution is less than or equal to the contribution limit. The previous example only applied to pretax contributions up to $\$ 3,000$. The hypothetical investor, however, can contribute up to $\$ 4,000$ pretax, and investors in higher tax brackets can contribute even more. So, the analysis is incomplete. The second caveat is that the tax rate ultimately prevailing when the investor withdraws funds from a traditional IRA is uncertain. Nonetheless, one can say something about an investor's marginal tax rate during retirement at least in relation to his or her preretirement tax rate. On average, retirement income is about 64 percent of preretirement income, suggesting that marginal tax rates for retirees are likely to fall over their investment horizon. ${ }^{4}$ For example, according to the 2004 tax code, a married couple filing jointly with an adjusted gross income of $\$ 180,000$ has a marginal tax rate of 33 percent. At a 64 percent average replacement rate, retirement income would be $\$ 115,000$ and the marginal tax rate becomes 25 percent, or a drop of two tax brackets. Although it may be more likely for retirees to drop one tax bracket rather than two, tax rates probably decline as most investors enter retirement. I will discuss more about the uncertainty of the withdrawal tax rate later.

${ }^{4}$ See Bernheim, Skinner, and Weinberg (2001) for a discussion of a panel study of income dynamics. 
Despite these limitations, both of which I will address in turn, this analysis produces an important heuristic result that permeates this chapter: Traditional IRAs become relatively more attractive as future tax rates decline, and Roth IRAs become more attractive as future tax rates increase.

\section{A More General Foundation}

As demonstrated earlier, an investment in a traditional IRA strategy potentially has two components: an IRA contribution up to the contribution limit $(L)$ and a nonIRA contribution for any pretax investment in excess of the limit. These two components of the after-tax traditional IRA investment can be expressed as

$$
I_{A T, \text { Trad }}=\min \left(I_{B T}, L\right)+\max \left[0,\left(I_{B T}-L\right)\left(1-T_{0}\right)\right] .
$$

At first glance, this equation looks a bit onerous, but the first term is simply the after-tax investment in the traditional IRA up to the contribution limit, $L$. The second term represents the after-tax investment, if any, applied to a non-IRA taxable account when the pretax contribution exceeds the contribution limit. If the pretax investment is less than the contribution limit, the second term drops out leaving just $I_{B T}$.

If, however, the pretax contribution is greater than the contribution limit, then one must choose how the excess (i.e., the second term) will be invested. To draw a reliable comparison between the traditional IRA strategy and the Roth IRA, both strategies must have similar investment risk so that the tax structure differences between the two can be isolated as determining factors. Therefore, any taxable investment of tax savings associated with the traditional IRA strategy must be similar to the investment of the IRAs. ${ }^{5}$ Under the current tax code, the return on a taxable investment, such as a mutual fund or equity portfolio, can be taxed using three ways. First, interest and short-term capital gains are taxed annually as ordinary income. Second, for a mutual fund or equity portfolio, a significant portion of earnings is typically unrealized capital gains that are not taxed until the fund sells the appreciated securities or until shareholders sell their fund shares. As a result, mutual funds have an inherent, albeit partial, tax-deferral feature. Third, according to the Jobs and Growth Tax Relief Reconciliation Act (JGTRRA) of 2003, the portion of earnings distributed as realized capital gains or dividends is typically taxed at 15 percent, which is substantially lower than the marginal tax rate on ordinary

5 I note in Chapter 7, as does Reichenstein (2001), that an identical investment has different riskreturn characteristics to the investor depending on whether it is held in a taxable or tax-deferred account. Because the government taxes these accounts differently, it also shares in their risk and return differently. The residual risk for the investor is, therefore, affected. I abstract from that notion here to retain the tractability of the analysis. 
income. 6 As a result, mutual funds have significant tax advantages over investments having returns that are taxed each year as ordinary income.

If the taxable portion of the traditional IRA investment strategy is invested instead in a mutual fund, then a portion of the annual return is distributed to shareholders as ordinary income $\left(p_{o i}\right)$ and taxed at $t_{o i}$. Another portion is distributed to shareholders as capital gains $\left(p_{c g}\right)$ and taxed at $t_{c g}$. Using this notion, I can express the future value of an after-tax dollar in a taxable investment earning a return with these different taxable components as

$$
\operatorname{FVIF}_{T X}=\left(1+r^{*}\right) n\left(1-T^{*}\right)+T^{*},
$$

where $r^{*}=r-r p_{o i} t_{o i}-r p_{c g} t_{c g}=r\left(1-p_{o i} t_{o i}-p_{c g} t_{c g}\right)$, or the effective annual after-tax return, and $T^{*}=t_{c g}\left(1-p_{o i}-p_{c g}\right) /\left(1-p_{o i} t_{o i}-p_{c g} t_{c g}\right)$, which is the effective capital gains tax rate after adjusting the basis for previously paid taxes on ordinary income and realized capital gain. It is worth taking a moment to understand this expression because it serves as the bedrock for much that follows.

The effective annual after-tax return $\left(r^{*}\right)$ reflects the tax erosion caused by a portion of the return being taxed as ordinary income and another portion being taxed as realized capital gain or dividend. The form of the effective capital gains tax rate $\left(T^{*}\right)$ is less intuitive, but it incorporates the notion that only price appreciation is taxed as a capital gain and that the gain is calculated against an adjusted basis. An investor who automatically reinvests returns and sells mutual fund shares beyond an 18-month holding period does not typically pay tax on the entire appreciation of the mutual fund's net asset value because a portion of that appreciation was already taxed as either ordinary income or capital gain in a prior tax year. Therefore, the adjusted basis used for calculating the capital gain is stepped up by the taxes previously paid on ordinary income or capital gain, and $T^{*}$ reflects this stepped-up basis. Appendix A contains a derivation. The important realization is that this expression is essentially a future value interest factor like those used in introductory finance courses, except it is adapted for a broad range of taxable environments. ${ }^{7}$

Another way to understand Equation 2.4 is to consider the future value of an investment that is taxed entirely as capital gain at the end of the investment horizon, $n$. In this case, the after-tax future value is $(1+r)^{n}-t_{c g}\left[(1+r)^{n}-1\right]$. The first term is the pretax accumulation. The second term is the capital gains tax rate times the capital gain. Rearranging terms simplifies this expression to $(1+r)^{n}\left(1-t_{c g}\right)+t_{c g}$,

6 For taxpayers in the 10 percent and 15 percent tax brackets, the JGTRRA of 2003 reduces the tax rate on dividends and capital gains to 5 percent.

7 This after-tax future value interest factor can be easily adapted to accommodate returns partitioned into even more taxable components simply by adding terms to $r^{*}$ and $T^{*}$. It also reduces to more simple forms when the tax structure is less complex. For example, when the return is fully taxed as ordinary income, then $p_{o i}=100 \%$ and $p_{c g}=0$, in which case $r^{*}$ reduces to $r\left(1-t_{o i}\right)$ and $T^{*}$ reduces to zero. See Appendix A for a more complete discussion. 
which is analogous to Equation 2.4. In fact, Equation 2.4 reduces to this expression when none of the investment return is distributed as ordinary income or capital gain until the end of the investment period, at which time it is taxed entirely as capital gain (see Appendix A for a proof). Therefore, $T^{*}$ can be thought of as an effective deferred capital gains tax rate after an adjustment for taxes paid on returns previously distributed as ordinary income or realized capital gains.

Appendix A also shows that if the entire return is taxed annually as ordinary income, then the future value expression reduces to $\left[1+r\left(1-t_{o i}\right)\right]^{n}$, which is the familiar future value expression when one substitutes an after-tax rate of return for the pretax rate of return. The more general expression in Equation 2.4, although less familiar, accommodates more typical and complex taxing schemes, as well as their more simple counterparts. It is used frequently in the pages that follow.

This taxable future value interest factor allows one to calculate the after-tax accumulation of the traditional IRA investment strategy when the pretax contribution exceeds the contribution limit by applying the future value operators in Equations 2.2 and 2.4 to the investment in Equation 2.3. I have already considered contributions below the limit and discovered that the optimal choice involves a simple comparison of the contribution and withdrawal tax rates. For pretax investments above the contribution limit, the future value of a traditional IRA investment is

$$
\mathrm{FV}_{\text {Trad }}=L(1+r)^{n}\left(1-T_{n}\right)+\left(I_{B T}-L\right)\left(1-T_{o}\right)\left(\mathrm{FVIF}_{T X}\right) .
$$

The first term is the future value of the maximized IRA contribution. The second term is the future value of the taxable investment in excess of the contribution limit. $T_{n}$ and $t_{o i}$ are similar to each other in that they are both ordinary income tax rates. They are different in that $t_{o i}$ applies over the term of the investment and $T_{n}$ is the prevailing tax rate upon withdrawal. Consequently, the model permits some variation in the tax rate over time. This expression requires one to know the proportion of return that is taxed as ordinary income, dividend, realized capital gain, and unrealized capital gain. For equity mutual funds, these proportions depend in part on the investment style and whether the fund is passively managed or actively managed. As I will show, the tax structure of the non-IRA investment is important when choosing between a traditional IRA and Roth IRA.

Table 2.2 displays the proportion of distributed ordinary income and capital gains for typical equity mutual funds. Distribution practices vary widely. In Panel A, average distribution rates for ordinary income range from 5 percent of the total pretax return to about 38 percent, and distribution rates for realized capital gains range from about 30 percent to more than 60 percent of the total pretax return. Growth funds tend to distribute less return as ordinary income probably because of a tendency for growth stocks to be low-dividend-yielding stocks. Balanced funds, of course, tend to distribute more ordinary income. In Panel B, actively managed funds tend to make more taxable distributions; index funds tend to make less. 


\section{Table 2.2. Proportion of Return Distributed as Ordinary Income and Capital Gain for Equity Mutual Funds}

\begin{tabular}{lccc}
\hline & Ordinary & Realized & \\
Fund Style & $\left(p_{o i}\right)$ & Capital Gain & Unrealized \\
& $\left(p_{c g}\right)$ & Capital Gain \\
\hline
\end{tabular}

A. Mean of 10 randomly selected mutual funds $\mathrm{a}$

$\begin{array}{llll}\text { Aggressive growth } & 5.2 \% & 63.5 \% & 31.3 \% \\ \text { Growth } & 7.0 & 44.2 & 48.8 \\ \text { Growth and income } & 20.5 & 45.4 & 34.2 \\ \text { Balanced } & 37.9 & 30.7 & 31.4\end{array}$

B. Large mutual funds $\mathrm{b}$

\begin{tabular}{|c|c|c|}
\hline & & \\
\hline & & \\
\hline \multicolumn{3}{|c|}{$\begin{array}{l}\text { from } 10 \text { randomly selected active and passive funds for } 1992-96 \\
\text { rted in Crain and Austin (1997). Short-term capital gains are included } \\
\text { alized capital gains. } \\
\text { edian distribution rates from the five largest actively managed funds } \\
\text { the greatest total assets beginning in } 1979 \text {, as reported by Shoven and } \\
\text { (2003). Short-term capital gains and dividends are included as } \\
\text { nary income distributions because of their tax treatment during the } \\
\text { ple period. The distribution rates are the average rates for each fund for } \\
\text { 9-98. }\end{array}$} \\
\hline
\end{tabular}
1979-98.

Although index funds tend to be tax efficient and distribute little realized capital gain, they are almost always weighted by market capitalization, which increases their exposure to stocks that tend to have higher dividend yields than small stocks. Therefore, index funds distribute a fair amount of their return as ordinary income. In the illustrative examples that follow, I use a 20 percent distribution rate for ordinary income and a 45 percent distribution rate for realized capital gains.

Two salient features of the JGTRRA of 2003 are revised lower tax brackets for ordinary income and lower taxes on dividends and capital gains. The new tax rates for ordinary income are 10,15, 25, 28, 33, and 35 percent. In addition, tax rates on dividends and capital gains have been reduced to 15 percent for taxpayers in all but the two lowest tax brackets. The tax reduction on equity returns decreases the double taxation of equity and increases the tax efficiency of equity investment so that potentially all distributions from equity mutual funds are taxed at 15 percent. It is worth noting that the distribution rates in Table 2.2 treat dividends as ordinary income because the then-prevailing tax law did so. Today, dividends might be better grouped with capital gains because JGTRRA of 2003 taxes them similarly. As a result, the distribution rates for ordinary income in Table 2.2 might be overstated, and the distribution rates for capital gains might be understated. Nonetheless, with 
these figures as inputs, Table 2.3 displays the relative values of a traditional IRA and a Roth IRA for investors in the 28 percent tax bracket seeking to maximize

\section{Table 2.3. After-Tax Future Value Ratios of a Traditional IRA and Roth IRA for an Investor in the 28 Percent Tax Bracket}

\begin{tabular}{|c|c|c|c|c|c|c|c|c|}
\hline \multirow[b]{2}{*}{$r$} & \multicolumn{8}{|c|}{ Investment Horizon in Years $(n)$} \\
\hline & 5 & 10 & 15 & 20 & 25 & 30 & 35 & 40 \\
\hline \multicolumn{9}{|c|}{ A. 28 percent withdrawal tax rate } \\
\hline $2 \%$ & 0.996 & 0.992 & 0.988 & 0.985 & 0.981 & 0.978 & 0.975 & 0.972 \\
\hline $4 \%$ & 0.992 & 0.985 & 0.978 & 0.972 & 0.966 & 0.961 & 0.955 & 0.950 \\
\hline $6 \%$ & 0.989 & 0.979 & 0.970 & 0.961 & 0.953 & 0.946 & 0.939 & 0.933 \\
\hline $8 \%$ & 0.985 & 0.973 & 0.962 & 0.952 & 0.942 & 0.934 & 0.926 & 0.918 \\
\hline $10 \%$ & 0.982 & 0.968 & 0.955 & 0.943 & 0.933 & 0.923 & 0.914 & 0.905 \\
\hline $12 \%$ & 0.979 & 0.963 & 0.948 & 0.935 & 0.924 & 0.913 & 0.903 & 0.893 \\
\hline $14 \%$ & 0.977 & 0.958 & 0.942 & 0.928 & 0.916 & 0.904 & 0.893 & 0.883 \\
\hline $16 \%$ & 0.974 & 0.954 & 0.937 & 0.922 & 0.908 & 0.896 & 0.884 & 0.873 \\
\hline $18 \%$ & 0.972 & 0.950 & 0.932 & 0.916 & 0.902 & 0.888 & 0.876 & 0.865 \\
\hline \multicolumn{9}{|c|}{ B. 25 percent withdrawal tax rate } \\
\hline $2 \%$ & 1.026 & 1.022 & 1.018 & 1.015 & 1.011 & 1.008 & 1.005 & 1.002 \\
\hline $4 \%$ & 1.022 & 1.015 & 1.008 & 1.002 & 0.996 & 0.991 & 0.985 & 0.980 \\
\hline $6 \%$ & 1.019 & 1.009 & 1.000 & 0.991 & 0.983 & 0.976 & 0.969 & 0.963 \\
\hline $8 \%$ & 1.015 & 1.003 & 0.992 & 0.982 & 0.972 & 0.964 & 0.956 & 0.948 \\
\hline $10 \%$ & 1.012 & 0.998 & 0.985 & 0.973 & 0.963 & 0.953 & 0.944 & 0.935 \\
\hline $12 \%$ & 1.009 & 0.993 & 0.978 & 0.965 & 0.954 & 0.943 & 0.933 & 0.923 \\
\hline $14 \%$ & 1.007 & 0.988 & 0.972 & 0.958 & 0.946 & 0.934 & 0.923 & 0.913 \\
\hline $16 \%$ & 1.004 & 0.984 & 0.967 & 0.952 & 0.938 & 0.926 & 0.914 & 0.903 \\
\hline $18 \%$ & 1.002 & 0.980 & 0.962 & 0.946 & 0.932 & 0.918 & 0.906 & 0.895 \\
\hline \multicolumn{9}{|c|}{ C. 15 percent withdrawal tax rate } \\
\hline $2 \%$ & 1.126 & 1.122 & 1.118 & 1.115 & 1.111 & 1.108 & 1.105 & 1.102 \\
\hline $4 \%$ & 1.122 & 1.115 & 1.108 & 1.102 & 1.096 & 1.091 & 1.085 & 1.080 \\
\hline $6 \%$ & 1.119 & 1.109 & 1.100 & 1.091 & 1.083 & 1.076 & 1.069 & 1.063 \\
\hline $8 \%$ & 1.115 & 1.103 & 1.092 & 1.082 & 1.072 & 1.064 & 1.056 & 1.048 \\
\hline $10 \%$ & 1.112 & 1.098 & 1.085 & 1.073 & 1.063 & 1.053 & 1.044 & 1.035 \\
\hline $12 \%$ & 1.109 & 1.093 & 1.078 & 1.065 & 1.054 & 1.043 & 1.033 & 1.023 \\
\hline $14 \%$ & 1.107 & 1.088 & 1.072 & 1.058 & 1.046 & 1.034 & 1.023 & 1.013 \\
\hline $16 \%$ & 1.104 & 1.084 & 1.067 & 1.052 & 1.038 & 1.026 & 1.014 & 1.003 \\
\hline $18 \%$ & 1.102 & 1.080 & 1.062 & 1.046 & 1.032 & 1.018 & 1.006 & 0.995 \\
\hline
\end{tabular}

Notes: In this example, the investor makes the maximum allowable pretax contribution; non-IRA investments are invested in a typical taxable mutual fund; and dividends and capital gains are taxed at 15 percent through the accumulation phase. Bold numbers indicate approximate indifference points between the traditional IRA and the Roth IRA. 
their pretax contribution. It uses the average distribution rates of mutual funds for ordinary income and capital gains reported by Crain and Austin and Shoven and Sialm (2004) and marginal tax rates established by the JGTRRA of 2003 passed by Congress in May 2003. Values greater (less) than 1 indicate that the traditional IRA (Roth IRA) is more attractive. Investors are indifferent between the two accounts when the ratio is 1 . The algebraic expression for this ratio and its derivation are found in Appendix A.

According to Panel A of Table 2.3, investors maximizing their pretax contribution and staying in the same tax bracket are always better off using a Roth IRA account rather than a traditional IRA. For example, an investor expecting a 10 percent return over a 20-year time horizon would accumulate 94.3 percent as much wealth using a traditional IRA and investing funds in excess of the contribution limit in a typical mutual fund as he or she would using a Roth IRA. Regardless of their initial tax brackets, investors remaining in the same tax bracket will be better off with the Roth IRA because the traditional IRA strategy is disadvantaged by a portion of the pretax investment (i.e., the amount in excess of the contribution limit) being invested in a taxable account. According to Bernheim, Skinner, and Weinberg (2001), however, retirement income is about 64 percent of preretirement income. So, investors are likely to drop into lower tax brackets when they withdraw funds during retirement. Panel B displays value ratios for investors dropping into the 25 percent tax bracket and shows that, although the traditional IRA strategy becomes relatively more attractive, it is more advantageous than the Roth IRA only for relatively short time horizons or low rates of return. But when investors drop to the 15 percent tax bracket, they will almost always favor the traditional IRA strategy (Panel C). Therefore, the traditional IRA becomes relatively more attractive as the withdrawal tax rate decreases.

Notice that the Roth IRA becomes relatively more attractive as the investment horizon increases and as the investment return increases. The taxable investment portion of the traditional IRA strategy creates this trend. For long time horizons and high returns, the taxable investment becomes a larger drag on the traditional IRA strategy, and the more complete tax shelter of the Roth IRA becomes more valuable.

Table 2.4 presents value ratios for taxpayers in the 33 percent tax bracket. The ratios in Panel A are nearly identical to the ratios for taxpayers in the 28 percent tax bracket when the withdrawal tax rate stays constant. Dropping down one tax bracket for the 33 percent tax bracket investor, however, more strongly favors the traditional IRA strategy. In Panel B, the indifference points (i.e., points at which the ratio is equal to 1) shift to the lower right compared with the same panel for the 28 percent taxpayer because dropping down one tax bracket represents a 5 percentage point drop in tax rate rather than a 3 percentage point drop. For a $6-10$ percent return, indifference time horizons extend about 5-10 years. For a 15 -year time horizon, the indifference return increases about 4 percent. Therefore, the traditional IRA is 
optimal in a wider range of circumstances for the 33 percent taxpayer compared with the 28 percent taxpayer. Reverse logic explains why the indifference points in Panel C of Table 2.4 shift to the upper left somewhat compared with those in Panel $\mathrm{C}$ of Table 2.3. Even so, the traditional IRA remains attractive in most situations when an investor drops two tax brackets upon withdrawing funds.

Unreported results indicate that when the non-IRA portion of the IRA strategy is fully taxed as ordinary income, indifference points are about five years shorter than those reported in Table 2.3. The IRA is penalized in these scenarios because the pretax contribution exceeding the contribution limit has a heavier tax burden. The next section provides a sense of this effect. Not maximizing the pretax contribution significantly improves the attractiveness of the traditional IRA. For example, recall that for pretax contributions less than or equal to the contribution limit, investors are indifferent when the tax rate remains the same and prefer the traditional IRA whenever tax rates decrease. These tables are not intended to exhaust all possible scenarios. They are intended to provide a heuristic sense of important factors in choosing between IRA accounts. The financial analyst may use the formulas directly and change the inputs to match an investor's specific circumstances.

A note about an investor's investment horizon is in order. The investment horizon is often deceptively long. It is not necessarily the time until withdrawals from a retirement account begin. Rather, it is conceptually equal to the length of time until the marginal withdrawal created by the proposed investment. For example, consider a 50-year-old investor with $\$ 100,000$ invested in a Roth IRA with an expected return of 10 percent. She plans to begin making withdrawals 15 years from now at age 65 when the Roth IRA is expected to be worth $\$ 417,715$ [i.e., $\$ 100,000(1.10)^{15}$ ]. Because she wishes to make annual after-tax withdrawals of about $\$ 68,000$ at the end of each year, her nest egg can support about 10 years of withdrawals, that is, until age 75.8

She may have three different motivations for making an additional $\$ 3,000$ contribution to a TDA. First, she may intend for the proposed investment to extend past age 75 , the time period over which she makes her $\$ 68,000$ annuitized withdrawals. At age 75, her investment could support almost six months of marginal withdrawals. ${ }^{9}$ Second, she may wish to maintain her 10 -year retirement period but increase the annual $\$ 68,000$ withdrawal. This strategy would permit withdrawals of more than $\$ 70,000$ from the Roth IRA. Third, she may wish to accelerate retirement, commencing withdrawals at, say, age 64.

Each of these scenarios has a different investment horizon. In the first case, the marginal withdrawal created by the investment will occur 25 years hence, which would be the appropriate investment horizon. In the second case, the marginal

$8 \$ 417,725=P M T\left(\mathrm{PVIFA}_{n, r}\right) \approx \$ 68,000\{1 / 0.10-1 /[0.10(1.10) 10]\}$.

$9 \$ 3,000(1.10)^{25}=\$ 32,504$. 
Table 2.4. After-Tax Future Value Ratios of a Traditional IRA and Roth IRA for an Investor in the 33 Percent Tax Bracket

\begin{tabular}{|c|c|c|c|c|c|c|c|c|}
\hline \multirow[b]{2}{*}{$r$} & \multicolumn{8}{|c|}{ Investment Horizon in Years $(n)$} \\
\hline & 5 & 10 & 15 & 20 & 25 & 30 & 35 & 40 \\
\hline \multicolumn{9}{|c|}{ A. 33 percent withdrawal tax rate } \\
\hline $2 \%$ & 0.995 & 0.991 & 0.986 & 0.982 & 0.978 & 0.974 & 0.970 & 0.967 \\
\hline $4 \%$ & 0.991 & 0.982 & 0.974 & 0.967 & 0.960 & 0.954 & 0.947 & 0.941 \\
\hline $6 \%$ & 0.987 & 0.975 & 0.964 & 0.954 & 0.945 & 0.937 & 0.929 & 0.921 \\
\hline $8 \%$ & 0.983 & 0.968 & 0.955 & 0.943 & 0.932 & 0.922 & 0.912 & 0.903 \\
\hline $10 \%$ & 0.979 & 0.962 & 0.947 & 0.933 & 0.921 & 0.909 & 0.898 & 0.888 \\
\hline $12 \%$ & 0.976 & 0.956 & 0.939 & 0.924 & 0.910 & 0.897 & 0.886 & 0.874 \\
\hline $14 \%$ & 0.973 & 0.951 & 0.932 & 0.916 & 0.901 & 0.887 & 0.874 & 0.862 \\
\hline $16 \%$ & 0.970 & 0.946 & 0.926 & 0.908 & 0.892 & 0.877 & 0.864 & 0.851 \\
\hline $18 \%$ & 0.967 & 0.941 & 0.920 & 0.901 & 0.884 & 0.868 & 0.854 & 0.841 \\
\hline \multicolumn{9}{|c|}{ B. 28 percent withdrawal tax rate } \\
\hline $2 \%$ & 1.045 & 1.041 & 1.036 & 1.032 & 1.028 & 1.024 & 1.020 & 1.017 \\
\hline $4 \%$ & 1.041 & 1.032 & 1.024 & 1.017 & 1.010 & 1.004 & 0.997 & 0.991 \\
\hline $6 \%$ & 1.037 & 1.025 & 1.014 & 1.004 & 0.995 & 0.987 & 0.979 & 0.971 \\
\hline $8 \%$ & 1.033 & 1.018 & 1.005 & 0.993 & 0.982 & 0.972 & 0.962 & 0.953 \\
\hline $10 \%$ & 1.029 & 1.012 & 0.997 & 0.983 & 0.971 & 0.959 & 0.948 & 0.938 \\
\hline $12 \%$ & 1.026 & 1.006 & 0.989 & 0.974 & 0.960 & 0.947 & 0.936 & 0.924 \\
\hline $14 \%$ & 1.023 & 1.001 & 0.982 & 0.966 & 0.951 & 0.937 & 0.924 & 0.912 \\
\hline $16 \%$ & 1.020 & 0.996 & 0.976 & 0.958 & 0.942 & 0.927 & 0.914 & 0.901 \\
\hline $18 \%$ & 1.017 & 0.991 & 0.970 & 0.951 & 0.934 & 0.918 & 0.904 & 0.891 \\
\hline \multicolumn{9}{|c|}{ C. 25 percent withdrawal tax rate } \\
\hline $2 \%$ & 1.075 & 1.071 & 1.066 & 1.062 & 1.058 & 1.054 & 1.050 & 1.047 \\
\hline $4 \%$ & 1.071 & 1.062 & 1.054 & 1.047 & 1.040 & 1.034 & 1.027 & 1.021 \\
\hline $6 \%$ & 1.067 & 1.055 & 1.044 & 1.034 & 1.025 & 1.017 & 1.009 & 1.001 \\
\hline $8 \%$ & 1.063 & 1.048 & 1.035 & 1.023 & 1.012 & 1.002 & 0.992 & 0.983 \\
\hline $10 \%$ & 1.059 & 1.042 & 1.027 & 1.013 & 1.001 & 0.989 & 0.978 & 0.968 \\
\hline $12 \%$ & 1.056 & 1.036 & 1.019 & 1.004 & 0.990 & 0.977 & 0.966 & 0.954 \\
\hline $14 \%$ & 1.053 & 1.031 & 1.012 & 0.996 & 0.981 & 0.967 & 0.954 & 0.942 \\
\hline $16 \%$ & 1.050 & 1.026 & 1.006 & 0.988 & 0.972 & 0.957 & 0.944 & 0.931 \\
\hline $18 \%$ & 1.047 & 1.021 & 1.000 & 0.981 & 0.964 & 0.948 & 0.934 & 0.921 \\
\hline
\end{tabular}

Notes: In this example, the investor makes the maximum allowable pretax contribution; non-IRA investments are invested in a typical taxable mutual fund; and dividends and capital gains are taxed at 15 percent through the accumulation phase. Bold numbers indicate approximate indifference points between the traditional IRA and the Roth IRA. 
withdrawal begins in 15 years and is annuitized over 10 years. Research indicates that withdrawal patterns from TDAs affect their after-tax present values, an issue explored in more detail in Chapter 6.10 One may thus infer that the withdrawal pattern would affect the time horizon used in choosing between IRA accounts. But as I will show, the withdrawal pattern affects the value of traditional IRAs and Roth IRAs in identical ways, entering the analysis as a constant that would be multiplied on both the numerator and the denominator of the ratios in Tables 2.3 and 2.4. As such, the relative values of the traditional IRA and Roth are unchanged, leaving the investor's choice between the two unchanged. For the third case in which the investor hopes to commence withdrawals at age 64, the appropriate investment horizon is 14 years. This example shows that an investment's expected effect on an investor's withdrawal pattern determines his or her investment horizon for purposes of this analysis.

\section{Breakeven Withdrawal Tax Rates}

Tables 2.3 and 2.4 illustrate the effect of changing tax rates on the relative attractiveness of traditional and Roth IRAs. Another way to view the importance of the withdrawal tax rate and the impact of the tax structure for the non-IRA investment is to solve for the withdrawal tax rate below which an investor would prefer the traditional IRA strategy. 11 The algebraic solution for this breakeven withdrawal tax can be found in Appendix A, but Figure 2.1 presents breakeven tax rates that maximize the pretax contribution for investors in the 28 percent tax bracket. This examination allows one to investigate the impact of the taxing scheme for the non-IRA portion (i.e., the portion exceeding the contribution limit) of the traditional IRA strategy on the choice between accounts.

Panel A in Figure 2.1 is based on the assumption that the non-IRA investment in excess of the contribution limit is fully taxed each year as ordinary income at 28 percent. 12 This assumption might be appropriate for fixed-income investors or equity traders that exhibit high turnover that results in mostly short-term capital gains. The curved lines across the surface area represent tax rates in 5 percent increments. The breakeven withdrawal tax rates here are quite low, dipping to 5 percent for investors with very long investment horizons and high returns. If an investor expects to withdraw funds at a tax rate below the breakeven point, the traditional IRA will accumulate more wealth. Therefore, low breakeven tax rates, like those in Panel A, favor the Roth IRA. For example, an investor in the 28 percent tax bracket facing a five-year time horizon and expected return of 9 percent has a

10 See, for example, Sibley (2002) and Horan (2002).

11 Several authors have followed this approach, including Krishnan and Lawrence (2001), Horan and Peterson (2001), and Horan (2003).

12 The appropriate model inputs in this case are $p_{o i}=100$ percent, $p_{c g}=0$ percent, and $t_{o i}=28$ percent. 
Figure 2.1. Breakeven Withdrawal Tax Rates for a 28 Percent Tax Bracket Investor: Non-IRA Investment

\section{A. Fully Taxed as Ordinary Income (trader)}

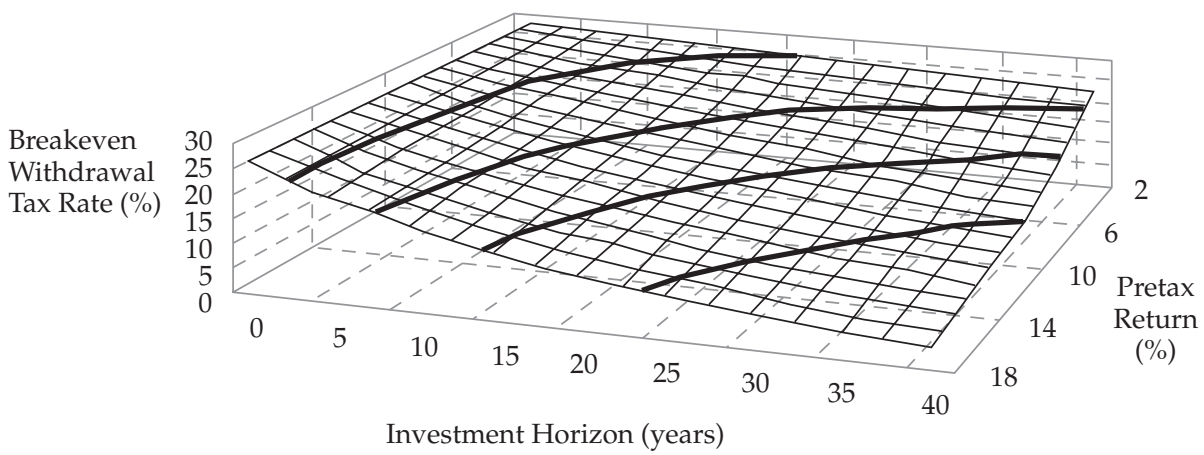

B. Taxed as a Typical Equity Mutual Fund (active investor)

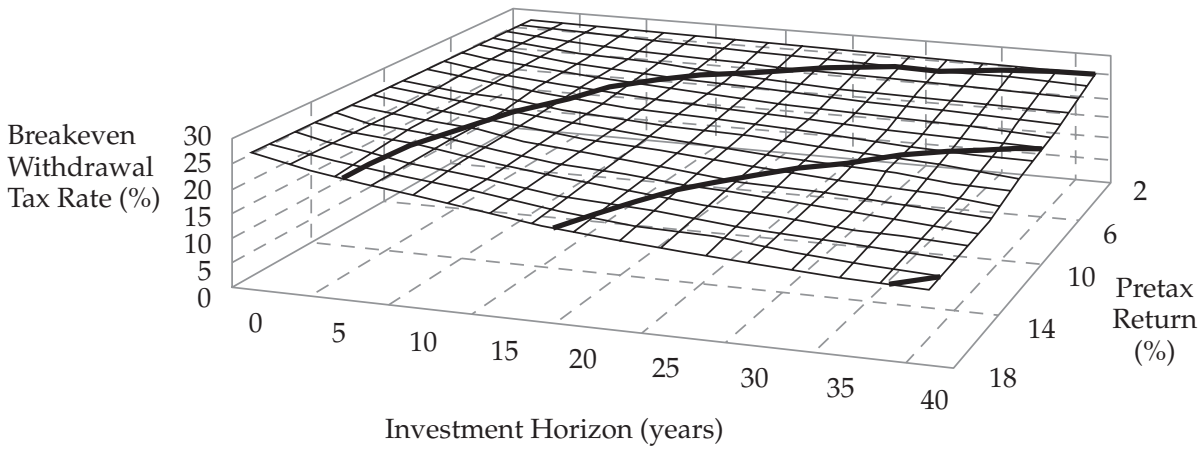

C. Taxed Entirely as Deferred Capital Gain (passive investor)

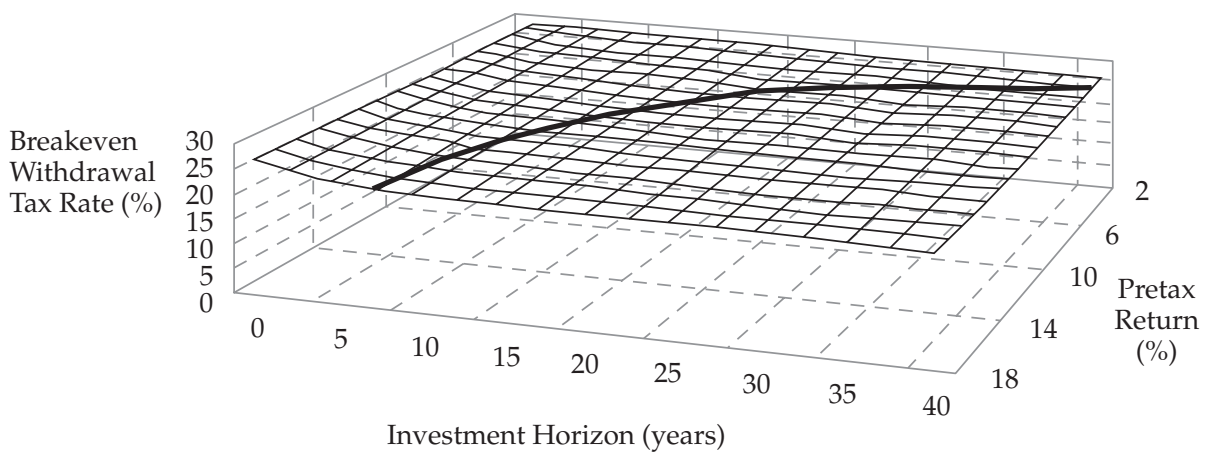


25 percent breakeven tax rate, or a drop of one tax bracket. A withdrawal tax rate below (above) 25 percent indicates that the traditional (Roth) IRA is better. The steepness of the surface area indicates that the choice between IRA accounts is sensitive to the investment horizon and investment return.

Panel $B$ repeats these calculations with the assumption that the non-IRA portion of the traditional IRA strategy is invested in a typical mutual fund. 13 This tax structure might also be appropriate for an active equity investor with modest turnover that generates mostly long-term capital gains. In this case, the breakeven withdrawal tax rates increase substantially, indicating that the traditional IRA becomes much more attractive. Breakeven tax rates fall below 20 percent only for investments with very long time horizons and high returns. In the extreme (Panel C), all the taxable return might be long-term capital gain realized upon withdrawal. 14 This tax structure might be applicable to a passive equity investor with a buy-andhold investment strategy for non-dividend-paying stocks. In this case, the breakeven withdrawal tax rates barely dip below 24 percent, making the traditional IRA strategy much more attractive. The flatness of the surface area in Panel $\mathrm{C}$ indicates that the ideal choice between IRA accounts is insensitive to the investment horizon and investment return when the non-IRA investment is taxed as unrealized capital gain.

Naturally, breakeven tax rates for investors in the 33 percent tax bracket, shown in Figure 2.2, are higher. But the traditional IRA can be relatively more attractive for these taxpayers because the tax rate in the next lower tax bracket is 5 percentage points lower, rather than 2 or 3 percentage points lower as is the case for investors in the 35 percent and 28 percent tax brackets, respectively. The same basic trends from Figure 2.1 hold here. But a single tax bracket drop takes the investor a bit farther down the surface because of the larger increment. Therefore, the traditional IRA may be optimal in a broader range of circumstances. These figures become useful again in the next chapter.

The traditional IRA becomes significantly more attractive as well when an investor does not make pretax investments in excess of the contribution limit. In this case, no taxable investing is necessary with the traditional IRA strategy, which increases its relative attractiveness. It is not possible to review the nearly infinite number of possible scenarios, but this framework allows the analyst to calculate the breakeven withdrawal tax rate for any particular circumstance. These figures also show that the tax structure of the non-IRA investment is important in choosing between TDAs.

As one can see, the optimal choice between a traditional IRA and a Roth IRA depends largely on the tax rate prevailing when the funds are withdrawn from the traditional IRA. Although scenario analyses provide some heuristic sense of the

13 The model inputs in this case are $p_{o i}=20$ percent, $p_{c g}=45$ percent, and $t_{o i}=t_{c g}=15$ percent.

14 The appropriate model inputs in this case are $p_{o i}=p_{c g}=0$. 
Figure 2.2. Breakeven Withdrawal Tax Rates for a 33 Percent Tax Bracket Investor: Non-IRA Investment

\section{A. Fully Taxed as Ordinary Income (trader)}

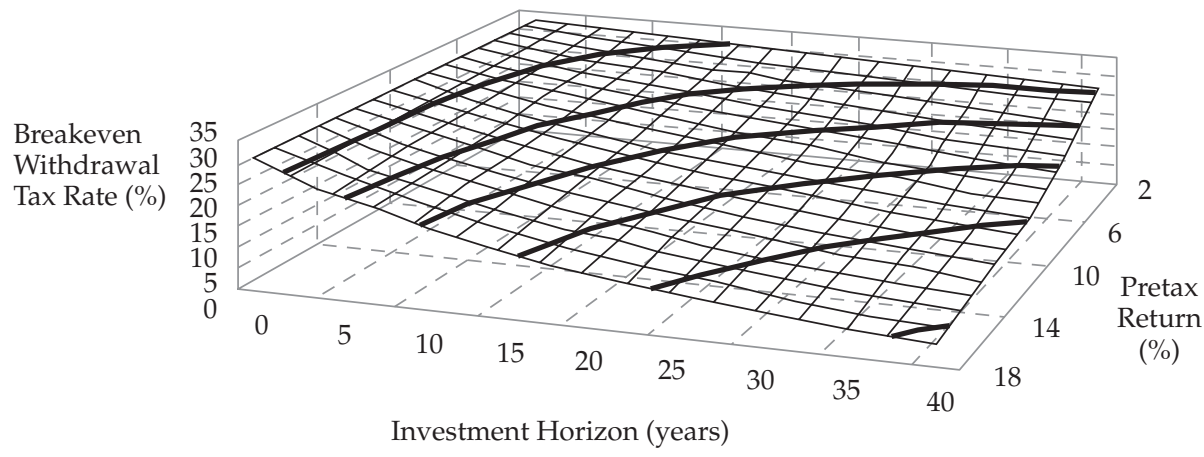

B. Taxed as a Typical Equity Mutual Fund (active investor)

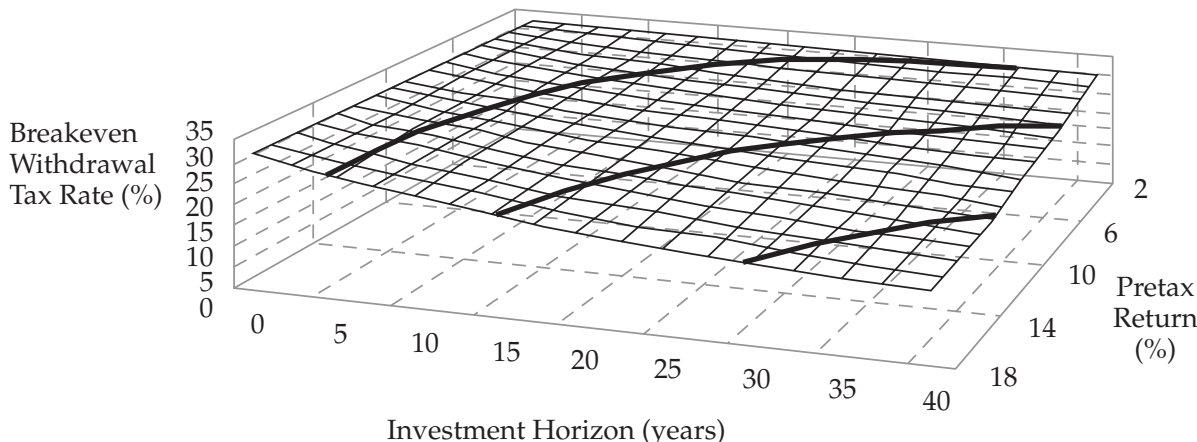

C. Taxed Entirely as Deferred Capital Gain (passive investor)

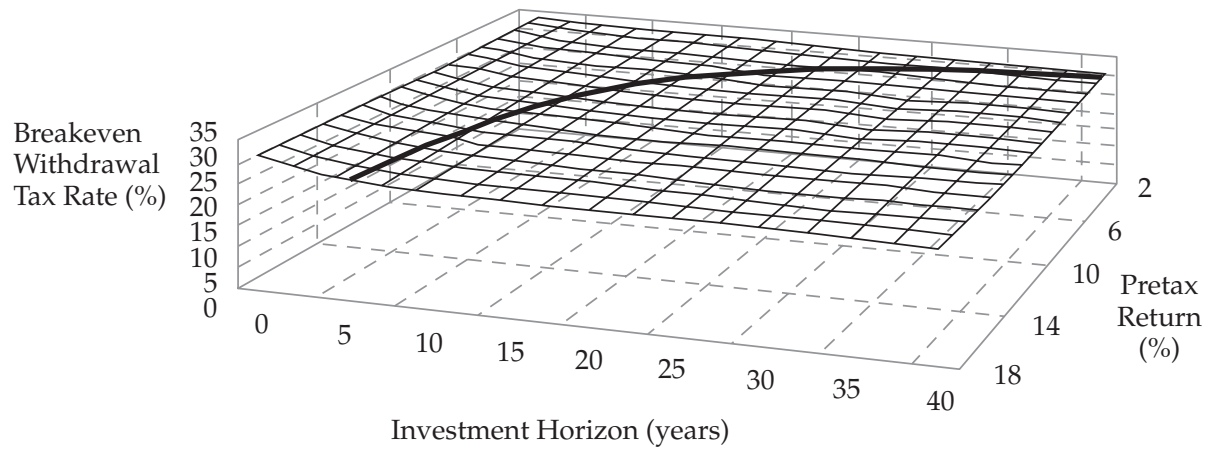


impact of uncertain future tax rates, what more can be said? One argument is that uncertainty about future tax rates cannot favor either type of IRA "because tax rates are just as likely to go up as they are to go down."15 But as I have shown, retirees are likely to be in lower tax brackets when withdrawing retirement funds because retirement income tends to be 64 percent of preretirement income. Future tax rates may also be more likely to decrease (or vice versa) depending on the current and expected political climate. For example, the passage of the EGTRRA of 2001 and JFTRRA of 2003 reflects a secular conservative trend of declining tax rates and portends lower withdrawal tax rates for many investors if it can be sustained. Other pundits see current and future budget deficits as signs of increasing tax rates. In any case, a fair discussion about future fiscal policy and political trends is far beyond the scope of this monograph.

An alternative argument focuses on the effect of uncertainty on the rate used to discount future cash outflows, like taxes. A higher discount rate on a negative future cash flow yields a less-negative present value and is, therefore, a smaller liability than a negative cash flow with a lower discount rate. By this logic, a taxpayer prefers uncertainty about future tax rates because it lowers the present value of his or her tax liability. Disagreement exists about whether this paradoxical analysis is appropriate, but an alternative approach provides similar intuition. Uncertain cash outflows, like taxes on investment returns, essentially have negative systematic risk, which hedges the positive systematic risk of investment inflows. If one views an uncertain after-tax future value of a traditional IRA as a combination of positive cash flows (i.e., pretax accumulation) and negative cash flows (i.e., taxes), the risk (and, hence, discount rate) of the combined cash flows is less than the risk of the pretax value alone and thereby increases the present value. ${ }^{16}$ In other words, by taxing investment returns, the government shares in the risk as well as the return of taxable investments. 17 Consequently, the uncertainty surrounding future tax rates can be thought of as a hedge that tends to favor the traditional IRA.

Finally, it is important to recognize that uncertain future tax rates increase the importance of having the option to choose the type of account from which to make withdrawals upon retirement. For example, an investor with only traditional IRAs or only Roth IRAs at retirement is forced to make withdrawals from only one type of account. But an investor with both types of accounts may choose the account from which withdrawals are made prior to the mandatory withdrawal age of $701 / 2$ years. This choice has value because in low-tax-rate regimes, investors can withdraw from the traditional IRA. In high-tax-rate regimes, the Roth IRA can produce taxfree retirement income. Even if an investor is required to make withdrawals from

15 Krishnan and Lawrence (2001, p.82)

16 Lewellen (1977) proffers a more complete version of this argument.

17 I expand on the notion of the government's sharing investment risk in Chapter 7. 
the traditional IRA, the choice can still have value if voluntary withdrawals exceed the mandatory minimums. Having both types of accounts available when making withdrawals creates tax diversification and valuable flexibility for retirees akin to a real option in a capital budgeting context. To my knowledge, this seemingly valuable flexibility has yet to be analyzed in the literature.

\section{Alternative Minimum Tax}

Established in 1970 to ensure that high-income taxpayers pay some minimum amount of tax, the alternative minimum tax (AMT) has historically affected only a small number of individuals. Over time, an increasing number of taxpayers are covered by the AMT because it is not indexed for inflation. Ironically, recent tax cuts have also increased coverage because they have not been accompanied by similar cuts in the AMT. Under the current law, 95 percent of taxpayers earning between $\$ 100,000$ and $\$ 500,000$ will be subject to the AMT (see Burman, Gale, Rohaly, Harris 2002). It, therefore, makes sense to discuss its impact on the choice between TDAs and the related decisions I discuss hereafter.

A detailed analysis of the AMT is beyond the scope of this monograph, but some of its main features have a bearing on this analysis. Basically, the AMT is a parallel tax system that allows fewer deductions than the standard tax system and has marginal tax rates of 26 percent and 28 percent. Taxpayers calculate their tax liability under both systems and pay the greater of the two tax liabilities. Although the AMT marginal tax rates may be lower than many tax brackets, it often results in a higher tax liability because it disallows certain deductions, such as state tax, property tax, personal exemptions, and dependent exemptions. The first implication of the AMT on this analysis is that the standard tax brackets made permanent by the JGTRRA of 2003 may not be an investor's true marginal tax rate. Rather, marginal tax rates for the AMT taxpayer may be 26 percent or 28 percent. If the AMT reduces an investor's marginal tax rate (even if it increases the overall tax liability), then the Roth IRA becomes relatively more attractive when one holds the withdrawal tax rate constant. Other nuances of the AMT, however, make this implication less straightforward than it initially appears.

The AMT includes initial exemptions that reduce taxable income. The JGTRRA of 2003 increased these exemptions to $\$ 40,250$ for single taxpayers and $\$ 58,000$ for those who are married and filing jointly. These exemptions are phased out, however, if income exceeds an established base level. For example, a couple filing jointly has their exemption phased out at a rate of 25 cents for every dollar of income above $\$ 150,000$. This phase-out effectively increases the marginal tax rate. Each dollar of income above $\$ 150,000$ for a married couple filing jointly has two tax effects. On that dollar, the AMT-taxpaying couple pays 26 cents of tax and has 25 cents of their exemption phased out and subject to tax, creating an additional $6 \frac{1}{2}$ cents of tax (i.e., $0.26 \times 0.25$ ). In this case, the marginal tax rate is $32 \frac{1}{2}$ percent, 
not 26 percent. 18 So, an investor's marginal tax rate can be quite high and a bit illusive under AMT. It is this potentially illusive tax rate that should be used as the initial tax rate, $T_{o}$, in the model. Marginal tax rates this high tend to favor the traditional IRA over the Roth IRA.

The exemption phase-out can also impact the effective tax rate on capital gains. Ostensibly, the tax rate on long-term capital gains is 15 percent under both tax systems. But in some circumstances, a capital gain can reduce or even eliminate the AMT exemption, which effectively increases the tax rate on capital gains. For example, suppose the aforementioned couple has $\$ 150,000$ of income before recognizing a long-term capital gain of $\$ 100,000$ on a piece of investment property. Under the standard tax system, recognizing this gain would create a capital gains tax of $\$ 15,000$. But the $\$ 100,000$ gain reduces their AMT exemption by $\$ 25,000$, exposing that much income to a 26 percent tax, or an extra $\$ 6,500$ tax liability. In other words, the $\$ 100,000$ long-term capital gain created a $\$ 21,500$ (or 21.5 percent) tax liability. The model discussed here can accommodate this situation by setting $t_{c g}$ equal to 21.5 percent, which decreases the value of taxable investments and will disadvantage the traditional IRA strategy in some cases. 19

The AMT can affect the choice between TDAs in other ways as well. Contributions to TDAs with front-end tax benefits decrease a taxpayer's adjusted gross income (AGI), which decreases the potential of being covered by the AMT tax and/or reduces the amount of AMT exemption that would otherwise be phased out. Contributions to TDAs with back-end tax benefits, such as Roth IRAs and 529 plans, do not decrease AGI or reduce AMT coverage. Therefore, the threat of AMT coverage can favor the traditional IRA over the Roth IRA. Because taxpayers can contribute up to $\$ 14,000$ to $401(\mathrm{k})$ plans and 403(b) plans in 2005, these plans can be significant tools in reducing either AMT coverage or the AMT exemption phase-out.

\section{Summary}

Standardizing the pretax investment is equivalent to standardizing the after-tax investment as long as one makes assumptions about investing either the tax savings or the pretax contribution in excess of the contribution limit. The fundamental result is that traditional IRAs become relatively more attractive than Roth IRAs when an investor's withdrawal tax rate declines because the tax shelter of the traditional IRA is greatest when contribution tax rates are high, whereas the tax

18 Income in excess of the base level (e.g., $\$ 175,000$ for a couple filing jointly) is taxed at 28 percent. Therefore, the effective marginal rate on income in the next AMT tax bracket is 35 percent (i.e., 0.28 $+0.28 \times 0.25$ ).

19 Technically, it is a bit higher because a gain of this size will push the taxpayer into the next AMT tax bracket. 
shelter of the Roth IRA is greatest when withdrawal tax rates are high. If the pretax contribution falls below the contribution limit, the choice between the two is dictated by a simple comparison of the contribution and withdrawal tax rates.

When an investor maximizes the pretax contribution, however, part of the traditional IRA strategy includes a taxable investment, which creates a tax drag. If the investor drops two tax brackets during retirement, the traditional IRA is nonetheless optimal because the benefit of the low withdrawal tax rate outweighs the disadvantage of the taxable investment associated with the traditional IRA strategy. When the same investor drops only one tax bracket, the traditional IRA is optimal only for short time horizons or for investments with low rates of return. 


\section{Employer Matching and Converting a Traditional IRA to a Roth IRA}

An additional circumstance that investors may face when investing with TDAs is choosing between a Roth IRA and a 401(k) plan in which the employer matches contributions. The methodology from the previous chapter suggests that an investor facing constant or increasing tax rates during the withdrawal phase of a TDA investment is better off using a TDA with a back-end tax benefit, such as a Roth IRA, than one with a front-end tax benefit. But if the investor's employer matches some or all of the contributions to a $401(\mathrm{k})$ plan, forgoing employer-matching opportunities may be too costly. This chapter analyzes this trade-off and shows that the answer depends on how tax savings from the 401(k) investment are invested. If tax savings are reinvested into the $401(\mathrm{k})$ or another tax-deductible account without employer matching, then the choice between the 401(k) and the Roth IRA reduces to a simple comparison of contribution and withdrawal tax rates. With only modest employer matching, the $401(\mathrm{k})$ is generally optimal even if tax rates increase and even if tax savings are invested in a taxable account. In other words, the employer matching is almost always more valuable than the marginal tax benefits of a Roth IRA.

This chapter also explores the decision to convert a traditional IRA to a Roth IRA. Taxpayers are permitted to make this conversion but are required to pay tax on the converted amount. This situation helps determine when it is worthwhile to convert and how best to satisfy the tax liability. Conversion is more attractive if the tax liability is paid from funds in a highly taxed account rather than a tax-sheltered account, such as the IRA itself. If the tax liability is paid from IRA balances, conversion is generally not optimal unless the investor's tax rate increases by about 11 percent to compensate for the resulting earlier withdrawal penalty. If taxable assets are tapped to pay the conversion tax, then investors facing constant or increasing tax rates benefit from conversion. Regardless, conversion becomes more valuable as the investment horizon and expected return increase because the value of the tax shelter increases as well.

\section{Employer Matching}

Choosing between a 401(k) investment and a traditional IRA investment is straightforward. Because they are taxed similarly, the 401(k) is the better location for an investment as long as the employer matches any of the employee's contri- 
butions. ${ }^{1}$ The choice between an employer-matched 401(k) investment and a Roth IRA is more complicated because it requires an assumption about how tax savings are invested.

Recall from Table 1.2 that the contribution limits for 401(k) plans (e.g., $\$ 13,000$ for 2004) are far greater than contribution limits for Roth IRAs $(\$ 3,000$ for 2004). This difference changes the options available to the investor when he or she is choosing how to invest the tax savings associated with the $401(\mathrm{k})$ contribution. For example, consider from the previous chapter the hypothetical investor in the 25 percent tax bracket facing a $\$ 3,000$ contribution limit on a Roth IRA. I will ignore employer matching for the moment. He or she could contribute up to $\$ 4,000$ pretax. The entire $\$ 4,000$ may be invested in the $401(\mathrm{k})$ plan on an after-tax basis because the contribution limit is $\$ 13,000$. In essence, the tax savings from a $\$ 3,000$ after-tax investment have been invested in a fully deductible TDA. The Roth IRA permits a $\$ 3,000$ after-tax investment. The other $\$ 1,000$ is paid in tax.

Reinvesting Tax Savings into the 401(k). Using the logic presented in the previous chapter, this scenario can be viewed as a $\$ 3,000$ after-tax investment in a Roth IRA. An equivalent investment in the 401(k) generates $\$ 1,000$ worth of tax savings [i.e., $(\$ 3,000 \times 0.25) /(1-0.25)$ ] that can either be reinvested in the $401(\mathrm{k})$ or put in a taxable account. If tax savings are reinvested into the $401(\mathrm{k})$, whereby the individual investor simply increases his or her $401(\mathrm{k})$ contribution in anticipation of a reduced tax liability, then the problem reduces to a scenario in which the pretax investment is less than the contribution limit and the simple rule applies. ${ }^{2}$ In this case, the Roth IRA is preferred if the withdrawal tax rate is greater than the contribution tax rate (the accumulations are equivalent if the tax rates are the same) and the $401(\mathrm{k})$ is preferred otherwise. Remember, I have temporarily assumed away employer matching.

Obviously, the 401(k) becomes more attractive when employers match contributions, thus changing the previously mentioned math. In this case, the $401(\mathrm{k})$ will accumulate more wealth even when contribution and withdrawal tax rates are the same but especially when tax rates decline. The question is whether the Roth IRA can be optimal in the unlikely circumstance that tax rates increase when the investor

1 Taxpayers participating in 401(k) plans were once excluded from making deductible contributions to a traditional IRA. Now, an investor may contribute to both, but there are income limitations on the deductibility of the IRA contribution. Single taxpayers who participate in a qualified employersponsored pension plan, such as a 401(k), and who earn less than $\$ 50,000$ in 2005 can deduct a $\$ 4,000$ annual IRA contribution. Married joint filers must have a combined income of less than $\$ 70,000$ in 2005. Partial deductions on the IRA contribution in 2005 are available to single filers earning between $\$ 50,000$ and $\$ 60,000$ and to married joint filers with combined income between $\$ 70,000$ and $\$ 80,000$. Employees not participating in an available $401(\mathrm{k})$ plan are not subject to income requirements. This information is summarized in Table 1.2.

2 The algebraic expression for this after-tax accumulation is given by Equation 3.1. 
retires. The ratio of accumulations for the employer-matched 401(k) to the Roth IRA in this case has a simple expression. The after-tax accumulation of a pretax 401(k) investment in which the employer matches $\pi$ percent of the employee's investment and the tax savings are reinvested in the $401(\mathrm{k})$ is

$$
\mathrm{FV}_{401(k)^{*}}=(1+\pi) I_{B T}(1+r)^{n}\left(1-T_{n}\right) .
$$

The asterisk denotes the case where tax savings are reinvested in the 401(k). This expression is simply the future value of a traditional IRA in which the pretax contribution is less than or equal to the contribution limit from Equation 2.2 grossed up by the employer's contribution. I can then take the ratio of this expression to the future accumulation of the Roth IRA given in Equation 2.1. After canceling terms, I have a straightforward relationship:

$$
\frac{\mathrm{FV}_{401(k)}}{\mathrm{FV}_{\text {Roth }}}=\frac{(1+\pi)\left(1-T_{n}\right)}{\left(1-T_{0}\right)} \text {. }
$$

In other words, when $(1+\pi)\left(1-T_{n}\right)>\left(1-T_{0}\right)$, the $401(\mathrm{k})$ will accumulate greater after-tax wealth. When $(1+\pi)\left(1-T_{n}\right)<\left(1-T_{o}\right)$, the Roth IRA is better, which can only occur if the withdrawal tax rate is greater than the contribution tax rate. The investor is indifferent otherwise. Table 3.1 examines the case for different levels of employer contribution for some common tax brackets in the current U.S. tax code.

It is clear that only modest levels of employer matching are needed to make the 401(k) a better investment than the Roth IRA even when withdrawal tax rates increase. Table 3.1 provides a valuable rule of thumb: If an investor reinvests $401(\mathrm{k})$ contribution tax savings into the $401(\mathrm{k})$ or some other tax-deductible TDA, then the $401(\mathrm{k})$ accumulates more wealth than the Roth IRA with only modest levels of employer matching. The 401(k) dominates even when withdrawal tax rates increase.

Some employers match a certain percentage of contributions (as I have explicitly assumed), and others match contributions up to a specific dollar amount. Table 3.1 can be used for the latter arrangement, as well, by separating the choice into two decisions. Say, for example, an employer matches contributions up to $\$ 5,000$. According to Table 3.1, the employee should clearly forgo the Roth IRA in favor of the 100 percent matching contribution up to $\$ 5,000$. Additional contributions that receive no matching should be evaluated using the framework presented in the previous chapter for choosing between TDAs with front-end-loaded and back-endloaded tax benefits.

Reinvesting Tax Savings into a Taxable Account. The preceding analysis assumed that tax savings from $401(\mathrm{k})$ contributions were invested in a deductible TDA, such as the 401(k) itself. If one alternatively assumes that expected 401(k) contribution tax savings are invested in a typical taxable mutual fund, the analysis 
Table 3.1. After-Tax Future Value Ratios of a 401(k) and Roth IRA When Tax Rates Increase and Tax Savings Are Reinvested in the 401(k)

\begin{tabular}{|c|c|c|c|c|c|c|}
\hline \multirow{4}{*}{$\begin{array}{l}\text { Employer } \\
\text { Match }(\pi)\end{array}$} & \multicolumn{6}{|c|}{ Contribution Tax Rate $\left(T_{o}\right)$} \\
\hline & \multicolumn{3}{|c|}{25 Percent } & \multicolumn{2}{|c|}{28 Percent } & \multirow[t]{2}{*}{33 Percent } \\
\hline & \multicolumn{5}{|c|}{ Withdrawal Tax Rate $\left(T_{n}\right)$} & \\
\hline & $28 \%$ & $33 \%$ & $35 \%$ & $33 \%$ & $35 \%$ & $35 \%$ \\
\hline $5 \%$ & 1.008 & 0.938 & 0.910 & 0.977 & 0.948 & 1.019 \\
\hline $10 \%$ & 1.056 & 0.983 & 0.953 & 1.024 & 0.993 & 1.067 \\
\hline $15 \%$ & 1.104 & 1.027 & 0.997 & 1.070 & 1.038 & 1.116 \\
\hline $20 \%$ & 1.152 & 1.072 & 1.040 & 1.117 & 1.083 & 1.164 \\
\hline $25 \%$ & 1.200 & 1.117 & 1.083 & 1.163 & 1.128 & 1.213 \\
\hline $30 \%$ & 1.248 & 1.161 & 1.127 & 1.210 & 1.174 & 1.261 \\
\hline $35 \%$ & 1.296 & 1.206 & 1.170 & 1.256 & 1.219 & 1.310 \\
\hline $40 \%$ & 1.344 & 1.251 & 1.213 & 1.303 & 1.264 & 1.358 \\
\hline $45 \%$ & 1.392 & 1.295 & 1.257 & 1.349 & 1.309 & 1.407 \\
\hline $50 \%$ & 1.440 & 1.340 & 1.300 & 1.396 & 1.354 & 1.455 \\
\hline $55 \%$ & 1.488 & 1.385 & 1.343 & 1.442 & 1.399 & 1.504 \\
\hline $60 \%$ & 1.536 & 1.429 & 1.387 & 1.489 & 1.444 & 1.552 \\
\hline $65 \%$ & 1.584 & 1.474 & 1.430 & 1.535 & 1.490 & 1.601 \\
\hline $70 \%$ & 1.632 & 1.519 & 1.473 & 1.582 & 1.535 & 1.649 \\
\hline $75 \%$ & 1.680 & 1.563 & 1.517 & 1.628 & 1.580 & 1.698 \\
\hline $80 \%$ & 1.728 & 1.608 & 1.560 & 1.675 & 1.625 & 1.746 \\
\hline $85 \%$ & 1.776 & 1.653 & 1.603 & 1.722 & 1.670 & 1.795 \\
\hline $90 \%$ & 1.824 & 1.697 & 1.647 & 1.768 & 1.715 & 1.843 \\
\hline $95 \%$ & 1.872 & 1.742 & 1.690 & 1.815 & 1.760 & 1.892 \\
\hline $100 \%$ & 1.920 & 1.787 & 1.733 & 1.861 & 1.806 & 1.940 \\
\hline
\end{tabular}

Note: Bold numbers indicate approximate indifference points between the 401(k) and the Roth IRA.

is less clear. Consider an after-tax Roth IRA investment of $I_{B T}\left(1-T_{o}\right)$. Investing an equal sum into a $401(\mathrm{k})$ generates tax savings of $I_{B T} T_{o}$, which I assume will be invested in a taxable account. ${ }^{3}$ The after-tax accumulation of a $401(\mathrm{k})$ in which the employer matches $\pi$ percent of the employee's investment and the tax savings are invested in a mutual fund is

$$
\mathrm{FV}_{401(k)}=(1+\pi) I_{B T}\left(1-T_{o}\right)(1+r)^{n}\left(1-T_{n}\right)+I_{B T} T_{o}\left[\mathrm{FVIF}_{T X}\right] .
$$

3 The tax savings are based on the pretax investment, not the after-tax investment. For example, a $\$ 750$ after-tax investment for a 25 percent tax bracket investor is associated with a $\$ 1,000$ pretax investment. The tax savings of $\$ 250$ is equal to 25 percent times $\$ 1,000$. 
The first term is the future accumulation of the 401(k) portion of the investment strategy with the employer matching. The second term is the future value of the tax savings using the taxable future value interest factor from Equation 2.4.4

Table 3.2 examines the ratio of the 401(k) accumulation to the Roth IRA accumulation for various levels of employer matching under the assumption that the tax savings are invested in a typical mutual fund. For an investor in the 28 percent tax bracket, it is always better to take advantage of employer matching rather than invest in a Roth IRA even if tax savings are invested in a taxable mutual fund. Unreported results show that neither the tax bracket nor the return affects this

Table 3.2. After-Tax Future Value Ratios of a 401(k) and Roth IRA When Tax Savings Are Invested in a Typical Equity Mutual Fund

\begin{tabular}{|c|c|c|c|c|c|c|c|c|}
\hline \multirow{2}{*}{$\begin{array}{l}\text { Employer } \\
\text { Match }(\pi)\end{array}$} & \multicolumn{8}{|c|}{ Investment Horizon in Years $(n)$} \\
\hline & 5 & 10 & 15 & 20 & 25 & 30 & 35 & 40 \\
\hline $5 \%$ & 1.120 & 1.100 & 1.082 & 1.066 & 1.051 & 1.038 & 1.025 & 1.013 \\
\hline $10 \%$ & 1.156 & 1.136 & 1.118 & 1.102 & 1.087 & 1.074 & 1.061 & 1.049 \\
\hline $15 \%$ & 1.192 & 1.172 & 1.154 & 1.138 & 1.123 & 1.110 & 1.097 & 1.085 \\
\hline $20 \%$ & 1.228 & 1.208 & 1.190 & 1.174 & 1.159 & 1.146 & 1.133 & 1.121 \\
\hline $25 \%$ & 1.264 & 1.244 & 1.226 & 1.210 & 1.195 & 1.182 & 1.169 & 1.157 \\
\hline $30 \%$ & 1.300 & 1.280 & 1.262 & 1.246 & 1.231 & 1.218 & 1.205 & 1.193 \\
\hline $35 \%$ & 1.336 & 1.316 & 1.298 & 1.282 & 1.267 & 1.254 & 1.241 & 1.229 \\
\hline $40 \%$ & 1.372 & 1.352 & 1.334 & 1.318 & 1.303 & 1.290 & 1.277 & 1.265 \\
\hline $45 \%$ & 1.408 & 1.388 & 1.370 & 1.354 & 1.339 & 1.326 & 1.313 & 1.301 \\
\hline $50 \%$ & 1.444 & 1.424 & 1.406 & 1.390 & 1.375 & 1.362 & 1.349 & 1.337 \\
\hline $55 \%$ & 1.480 & 1.460 & 1.442 & 1.426 & 1.411 & 1.398 & 1.385 & 1.373 \\
\hline $60 \%$ & 1.516 & 1.496 & 1.478 & 1.462 & 1.447 & 1.434 & 1.421 & 1.409 \\
\hline $65 \%$ & 1.552 & 1.532 & 1.514 & 1.498 & 1.483 & 1.470 & 1.457 & 1.445 \\
\hline $70 \%$ & 1.588 & 1.568 & 1.550 & 1.534 & 1.519 & 1.506 & 1.493 & 1.481 \\
\hline $75 \%$ & 1.624 & 1.604 & 1.586 & 1.570 & 1.555 & 1.542 & 1.529 & 1.517 \\
\hline $80 \%$ & 1.660 & 1.640 & 1.622 & 1.606 & 1.591 & 1.578 & 1.565 & 1.553 \\
\hline $85 \%$ & 1.696 & 1.676 & 1.658 & 1.642 & 1.627 & 1.614 & 1.601 & 1.589 \\
\hline $90 \%$ & 1.732 & 1.712 & 1.694 & 1.678 & 1.663 & 1.650 & 1.637 & 1.625 \\
\hline $95 \%$ & 1.768 & 1.748 & 1.730 & 1.714 & 1.699 & 1.686 & 1.673 & 1.661 \\
\hline $100 \%$ & 1.804 & 1.784 & 1.766 & 1.750 & 1.735 & 1.722 & 1.709 & 1.697 \\
\hline
\end{tabular}

Notes: The investor is in the 28 percent tax bracket during the contribution and withdrawal phase and earns a 10 percent return. The mutual fund distributes 20 percent of its return as dividends and 45 percent as long-term capital gain. Dividends and capital gains are taxed at 15 percent.

${ }^{4}$ Horan and Peterson (2001) present a similar model in an after-tax investment framework. Appendix B shows how Equation 3.3 reduces to Equation 3.1 when the tax savings are reinvested in the 401(k). 
conclusion. In fact, this rule of thumb remains intact when the investor's withdrawal tax rate increases as I show next.

Even in the unusual circumstance in which an investor has a higher tax rate when withdrawing funds than when making the contribution, the $401(\mathrm{k})$ is generally the better investment. A concise way of demonstrating this result is to calculate the breakeven withdrawal tax rate for different tax brackets and taxing schemes. A derivation of these breakeven withdrawal tax rates is found in Appendix B. Figure 3.1 displays them for an investor in the 28 percent tax bracket who would receive a match on 25 percent of the contributions to the $401(\mathrm{k})$. Withdrawal tax rates below the breakeven tax rate indicate that the employer-matched 401(k) dominates the Roth IRA. In general, the breakeven withdrawal tax rates are quite high (above 28 percent in almost every instance), which indicates that the 401(k) with a modest 25 percent employer matching is a better investment than the Roth IRA. If the taxpayer invests the tax savings in a fully taxable vehicle, such as a fixed-income security, Panel A shows that the investment horizon needs to be quite long and the return quite high for the Roth IRA to be worth forgoing the employer matching of the 401(k) because the breakeven withdrawal tax rates are high. Because fixed-income instruments are fully taxed as ordinary income and tend to have relatively low returns, the Roth IRA is not likely to be more attractive than the 401(k) for fixedincome instruments. An active equity trader with high turnover could have a similar tax structure, however, accompanied by a higher investment return. Even so, the return needs to be quite high for the breakeven withdrawal tax rates to favor the Roth IRA in Panel A.

The Roth IRA becomes even less attractive when the non-401(k) investment of the tax savings is taxed as a typical mutual fund, as in Panel B. In this case, the breakeven withdrawal tax rates are all greater than the highest tax bracket, indicating that forgoing the employer matching associated with the 401(k) would never be optimal. Panel $\mathrm{C}$ presents similar findings when the tax savings are invested in a non-401(k) investment that is taxed entirely as deferred capital gain. The following rule of thumb then provides general guidance in most circumstances: An investor is better off accepting even modest matching of 401( $k$ ) contributions than investing in either a traditional IRA or Roth IRA, even if the withdrawal tax rate increases.

\section{Converting a Traditional IRA to a Roth IRA}

Investors with adjusted gross incomes of no more than $\$ 100,000$ may convert existing traditional IRAs to Roth IRAs. One potential advantage of doing so is that Roth IRAs have no mandatory distribution rule at age $701 / 2$, so investors can potentially enjoy the benefits of tax deferral for an extended period of time. A disadvantage of conversion is that all withdrawals of deductible contributions and earnings from the traditional IRA that are rolled over to the Roth IRA are subject to income tax. Generally, funds that are rolled over in a timely manner are not 
Figure 3.1. Breakeven Withdrawal Tax Rates between a 401(k) with 25 Percent Employer Matching and a Roth IRA for a 28 Percent Taxpayer: Non401(k) Investment

\section{A. Fully Taxed as Ordinary Income (trader)}

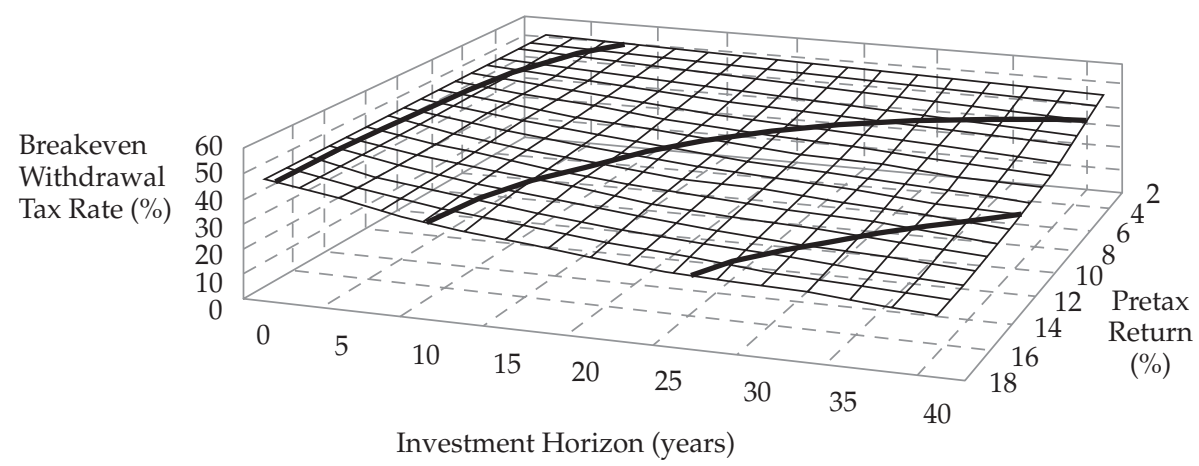

B. Taxed as a Typical Equity Mutual Fund (active investor)

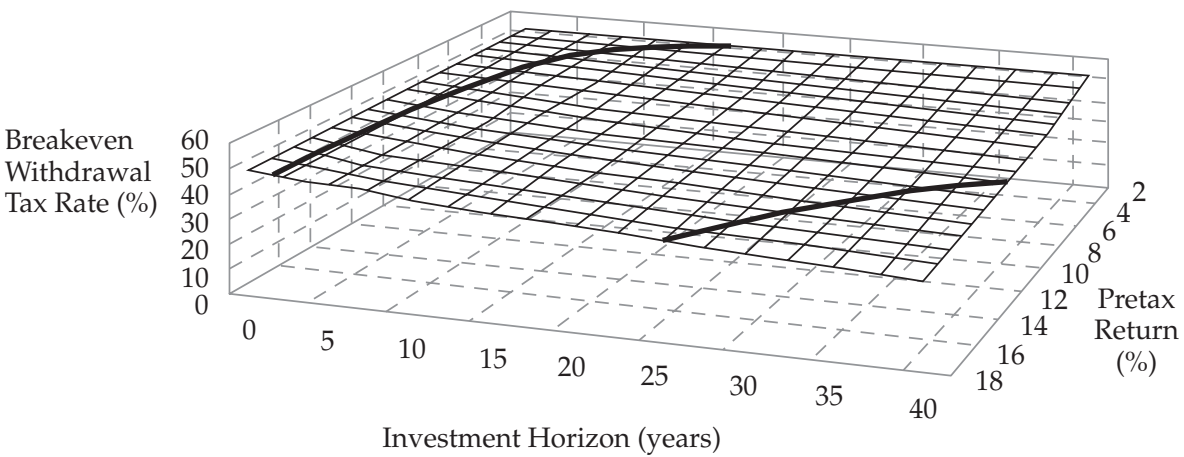

C. Taxed as Deferred Capital Gain (passive investor)




subject to the 10 percent early withdrawal penalty. But if an investor elects to use funds from the traditional IRA to pay the conversion tax, then these funds are not rolled over and are subject to a 10 percent early withdrawal penalty if the conversion occurs before age $591 / 2$. So, conversion is generally a bad idea unless the investor can pay the conversion tax from a taxable savings account. The following analysis illustrates this point.

Using IRA Assets to Pay the Conversion Tax. Assume an investor in the 25 percent tax bracket has a $\$ 10,000$ traditional IRA and wishes to pay the conversion tax and any early withdrawal penalty from the traditional IRA balance. The investor will withhold $\$ 2,500$ from rolling over into the Roth IRA to pay the conversion tax. This holdback, however, is subject to a 10 percent early withdrawal penalty of $\$ 250$. If this amount is also held back from being rolled over to pay the penalty, it too will be subject to an early withdrawal penalty. The total amount to be withheld from the conversion to pay the penalty is about $\$ 278$ [i.e., $\$ 250 /(1-$ $10 \%)$ ] in addition to the $\$ 2,500$ for the conversion tax, leaving $\$ 7,222$ to be rolled over into the Roth IRA and accumulate earnings tax free. Paying the tax liability out of the assets being converted decreases the principal in the new Roth IRA, of course. More generally, if an investor uses IRA funds to pay the conversion tax and penalties, each dollar in the traditional IRA can be converted to $1-T_{o} /(1-\phi)$ dollars in a Roth IRA, where $\phi$ is the early withdrawal penalty, which is 10 percent. A proof is in Appendix B. So, the future value of this converted amount is

$$
\mathrm{FV}_{\text {RothConv }}=\left(1-\frac{T_{0}}{1-\phi}\right)(1+r)^{n}
$$

The asterisk in the subscript denotes the special case in which the conversion tax and penalty are paid from IRA assets. Taking the ratio of this future value to the future value of each dollar in a traditional IRA and solving for a breakeven tax rate yield a simple expression and rule of thumb: The breakeven withdrawal tax rate under these assumptions is $T_{n}=T_{o} /(1-\phi)$. For a 10 percent early withdrawal penalty, the breakeven tax rate is about 11 percent (i.e., 1/0.9) higher than the current tax rate. In other words, an investor wishing to pay the conversion tax and penalties from IRA balances is generally better off staying with his or her traditional IRA unless the withdrawal tax rate is 11 percent higher than his or her current tax rate. 5 Because most retirees have less income in retirement than in their preretirement years, this would be a somewhat unusual circumstance. This analysis assumes that minimum distribution requirements for the traditional IRA are not binding. That is, an investor plans withdrawals beyond the age of $701 / 2$ at least as large as those required by the IRS.

5 Note that an 11 percent increase does not mean an 11 percentage point increase. 
Using Taxable Assets to Pay the Conversion Tax. Conversion opportunities become more attractive when the conversion tax is paid from a taxable account, thus avoiding any early withdrawal penalty and preserving more of the IRA tax shelter. Paying the tax liability from IRA assets is suboptimal if the conversion tax can be paid with dollars that do not qualify for tax-deferred or tax-exempt earnings accumulation. If the tax liability can be paid from assets that would not qualify for tax-deferred status, the principal in the new Roth IRA is unchanged from the traditional IRA. This technique has the effect of lowering the opportunity cost associated with paying the conversion tax. In this case, the future value of a converted IRA dollar is equal to the future value of the new Roth IRA dollar less the after-tax future value of conversion tax, $T_{0}\left[\mathrm{FVIF}_{T X}\right]$, or

$$
\mathrm{FV}_{\text {RothConv }}=(1+r)^{n-T_{0}}\left[\mathrm{FVIF}_{T X}\right] \text {. }
$$

The first term represents the future value of a dollar in the new Roth IRA. The second term represents the lost future value of $T_{0}$ dollars used to pay the conversion tax that would have otherwise accumulated earnings in a taxable account. 6 As usual, one needs to have a sense of the expected return and tax structure of the taxable account from which the funds are taken to pay the conversion tax. By examining the ratio of the traditional IRA to the converted Roth IRA, one can determine whether conversion is worthwhile. A value ratio less than 1 indicates conversion is worthwhile. Panel A and Panel B of Table 3.3 indicate that investors facing constant or increasing tax rates benefit from converting a traditional IRA to a Roth IRA.

The more common scenario, however, is that tax rates fall when withdrawing funds. In this case, Panel $\mathrm{C}$ shows that conversion is optimal only for higher returns or moderately long time horizons. For example, an investor dropping into the 25 percent tax bracket and earning a 10 percent return needs an investment horizon of 10 years to make conversion worthwhile. These tables show that the value ratios decrease as the investment horizon and return increase, demonstrating that conversion is more beneficial for investors with longer investment horizons and higher expected returns.

Breakeven Withdrawal Tax Rate. Another approach for understanding the conversion issue is to examine the breakeven withdrawal tax rate. Perhaps not surprisingly, breakeven withdrawal tax rates for Roth IRA conversions (when the conversion tax is paid from a taxable account) are identical to breakeven withdrawal tax rates for the choice between a traditional IRA and Roth IRA when the pretax contribution is maximized. Appendix $\mathrm{B}$ contains the derivation of the breakeven withdrawal tax rate and its equivalence to the traditional Roth IRA breakeven withdrawal tax rate. So, Figures 2.1 and 2.2 from the previous chapter

6 Equation 3.5 reduces to Equation 3.4 when funds to pay the conversion tax are taken from a frontend-loaded TDA. 
Table 3.3. After-Tax Future Value Ratios of a Traditional IRA to a Converted Roth IRA for an Investor in the 28 Percent Tax Bracket

\begin{tabular}{|c|c|c|c|c|c|c|c|c|}
\hline \multirow[b]{2}{*}{$r$} & \multicolumn{8}{|c|}{ Investment Horizon in Years $(n)$} \\
\hline & 5 & 10 & 15 & 20 & 25 & 30 & 35 & 40 \\
\hline \multicolumn{9}{|c|}{ A. 33 percent withdrawal tax rate } \\
\hline $2 \%$ & 0.925 & 0.920 & 0.916 & 0.911 & 0.907 & 0.903 & 0.899 & 0.895 \\
\hline $4 \%$ & 0.921 & 0.912 & 0.903 & 0.896 & 0.889 & 0.882 & 0.876 & 0.870 \\
\hline $6 \%$ & 0.916 & 0.904 & 0.893 & 0.883 & 0.874 & 0.866 & 0.858 & 0.851 \\
\hline $8 \%$ & 0.912 & 0.897 & 0.884 & 0.872 & 0.862 & 0.852 & 0.844 & 0.836 \\
\hline $10 \%$ & 0.908 & 0.890 & 0.875 & 0.862 & 0.851 & 0.840 & 0.831 & 0.822 \\
\hline $12 \%$ & 0.905 & 0.885 & 0.868 & 0.854 & 0.841 & 0.830 & 0.820 & 0.811 \\
\hline $14 \%$ & 0.901 & 0.879 & 0.862 & 0.846 & 0.833 & 0.821 & 0.810 & 0.800 \\
\hline $16 \%$ & 0.898 & 0.875 & 0.856 & 0.840 & 0.826 & 0.813 & 0.802 & 0.791 \\
\hline $18 \%$ & 0.895 & 0.870 & 0.850 & 0.833 & 0.819 & 0.806 & 0.794 & 0.783 \\
\hline \multicolumn{9}{|c|}{ B. 28 percent withdrawal tax rate } \\
\hline $2 \%$ & 0.994 & 0.989 & 0.984 & 0.979 & 0.975 & 0.970 & 0.966 & 0.962 \\
\hline $4 \%$ & 0.989 & 0.980 & 0.971 & 0.963 & 0.955 & 0.948 & 0.942 & 0.935 \\
\hline $6 \%$ & 0.985 & 0.971 & 0.959 & 0.949 & 0.939 & 0.930 & 0.922 & 0.915 \\
\hline $8 \%$ & 0.980 & 0.964 & 0.949 & 0.937 & 0.926 & 0.916 & 0.906 & 0.898 \\
\hline $10 \%$ & 0.976 & 0.957 & 0.941 & 0.927 & 0.914 & 0.903 & 0.893 & 0.884 \\
\hline $12 \%$ & 0.972 & 0.951 & 0.933 & 0.918 & 0.904 & 0.892 & 0.881 & 0.871 \\
\hline $14 \%$ & 0.969 & 0.945 & 0.926 & 0.910 & 0.895 & 0.882 & 0.871 & 0.860 \\
\hline $16 \%$ & 0.965 & 0.940 & 0.920 & 0.902 & 0.887 & 0.874 & 0.862 & 0.851 \\
\hline $18 \%$ & 0.962 & 0.935 & 0.914 & 0.896 & 0.880 & 0.866 & 0.853 & 0.842 \\
\hline \multicolumn{9}{|c|}{ C. 25 percent withdrawal tax rate } \\
\hline $2 \%$ & 1.036 & 1.030 & 1.025 & 1.020 & 1.015 & 1.011 & 1.006 & 1.002 \\
\hline $4 \%$ & 1.030 & 1.020 & 1.011 & 1.003 & 0.995 & 0.988 & 0.981 & 0.974 \\
\hline $6 \%$ & 1.026 & 1.012 & 0.999 & 0.988 & 0.978 & 0.969 & 0.961 & 0.953 \\
\hline $8 \%$ & 1.021 & 1.004 & 0.989 & 0.976 & 0.964 & 0.954 & 0.944 & 0.935 \\
\hline $10 \%$ & 1.017 & 0.997 & 0.980 & 0.965 & 0.952 & 0.941 & 0.930 & 0.920 \\
\hline $12 \%$ & 1.013 & 0.990 & 0.972 & 0.956 & 0.942 & 0.929 & 0.918 & 0.907 \\
\hline $14 \%$ & 1.009 & 0.984 & 0.965 & 0.947 & 0.933 & 0.919 & 0.907 & 0.896 \\
\hline $16 \%$ & 1.006 & 0.979 & 0.958 & 0.940 & 0.924 & 0.910 & 0.897 & 0.886 \\
\hline $18 \%$ & 1.002 & 0.974 & 0.952 & 0.933 & 0.916 & 0.902 & 0.889 & 0.877 \\
\hline
\end{tabular}

Notes: The conversion tax is assumed to be paid from a taxable account that is invested in a typical equity mutual fund that distributes 20 percent of its return as dividends and 45 percent as long-term capital gain. Dividends and capital gains are taxed at 15 percent. Bold numbers indicate approximate indifference points between the traditional IRA and the converted Roth IRA. 
apply equally well to the conversion decision as they do to the initial investment decision except that the titles should be modified to replace "Non-IRA Investment" with "Conversion Tax Investment." When the conversion tax is taken from an investment that is fully taxed annually as ordinary income, as in Panel A of Figure 2.2, breakeven withdrawal tax rates decrease quickly as the time horizon and return increase. Low breakeven withdrawal tax rates indicate conversion is attractive. For example, an investor in the 33 percent tax bracket expecting a 9 percent return over a 10 -year investment horizon has a 25 percent breakeven withdrawal tax rate. In other words, as long as the investor's withdrawal tax is above 25 percent (a drop of two tax brackets), conversion is optimal. If the account from which the conversion tax is paid is taxed as a typical mutual fund (Panel B), the breakeven withdrawal tax rate increases to about 30 percent. So, if the investor were to drop one tax bracket to 28 percent, she would find that not converting would result in a higher after-tax accumulation. Breakeven tax rates never fall below 28 percent if the conversion tax comes from an investment that would have been entirely taxed as deferred capital gain (Panel C), in which case conversion is optimal only if the investor's withdrawal tax bracket stays the same or increases.

Although the indifference points and breakeven withdrawal tax rates are identical to those in the previous chapter, the conversion value ratios presented earlier are not. The reason why breakeven tax rates are the same but value ratios are not is that paying the conversion tax from a taxable account is akin to making an additional investment in a TDA account. In effect, a converting investor is committing more after-tax dollars to a tax-preferred investment strategy, thereby amplifying the effects of conversion when it is worthwhile and when it is not. An example will illustrate this point.

Consider the hypothetical investor in the 25 percent tax bracket deciding between an initial contribution between a traditional IRA and a Roth IRA. He or she maximizes the pretax investment, which is $\$ 4,000$, and chooses the traditional IRA. In the previous chapter, I showed that the traditional IRA strategy includes a $\$ 3,000$ IRA investment and a $\$ 750$ non-IRA investment in a taxable account. Now, suppose for the time being that the investor immediately converts the traditional IRA to a Roth IRA. The $\$ 3,000$ conversion will generate a conversion tax of $\$ 750$ [i.e., $\$ 3,000 \times 0.25$ ], which can be taken from the taxable, non-IRA investment, and the investor is in exactly the same situation had the Roth IRA been chosen in the first place. In the previous chapter, the future value of the $\$ 750$ was added to the numerator. In this analysis, it is subtracted from the denominator, which changes the ratio.

Now, suppose the investor does not convert immediately but waits five years instead. After five years of earning, say, a 10 percent pretax return, the traditional IRA will be worth $\$ 4,832$. If one assumes that the non-IRA investment is fully taxable as ordinary income, the $\$ 750$ non-IRA investment will grow to $\$ 1,077$ over 
the same time period. Converting to a Roth IRA at this point triggers a conversion tax of $\$ 1,208$ [i.e., $\$ 4,832 \times 25 \%$ ]. Notice that the non-IRA investment is not sufficient to pay the conversion tax because the tax drag prevents it from growing at the same rate as the IRA. The investor must make an additional $\$ 131$ investment in conversion tax to roll over the traditional IRA into a Roth IRA. Therefore, the conversion decision effectively involves making an additional after-tax investment in a Roth IRA.

In any case, the following guidance may help investors considering a conversion from a traditional IRA to a Roth IRA: If the conversion tax is paid from a taxable account, not the traditional IRA, then investors facing increasing or constant tax rates during withdrawal periods will generally benefit from converting. Investors facing decreasing tax rates will not benefit from conversion. As long as the tax is paid from an account with a relatively heavy tax burden, conversion becomes more attractive as the return and time horizon increase. 


\section{Choosing between Nondeductible IRAs and Taxable Investments}

Income limitations prevent some investors from making deductible contributions to a traditional IRA or 401(k) account or after-tax contributions to a Roth IRA (see Table 1.2). Because the income limitations are higher for the Roth IRA than the traditional IRA, some investors may qualify for Roth IRA contributions but not deductible IRA contributions. In this instance, the Roth IRA is at least as good as nondeductible contributions to a traditional IRA, even in the extreme case of a zero tax rate upon withdrawal. Some taxpayers in the 28 percent and higher tax brackets may be precluded from making either a deductible contribution to a traditional IRA account or an after-tax contribution to a Roth IRA. These investors can still choose between a nondeductible IRA contribution (which is not tax deductible but accumulates earnings tax deferred) or a taxable investment. 1

The choice, not surprisingly, depends on the tax structure for the taxable investment. ${ }^{2}$ A different choice dominates in each of the extreme taxing schemes that I have examined thus far - a return taxed entirely as ordinary income or a return taxed entirely as deferred capital gain. If returns are fully taxed as ordinary income, the nondeductible IRA is optimal because it has tax-deferral benefits whereas the taxable investment does not. If returns are taxed entirely as deferred capital gains, the taxable account is optimal because the capital gain tax shelter is more valuable than the tax deferral associated with the nondeductible IRA. Although the choice is less clear when the taxable return has a hybrid taxing scheme, as most mutual funds do, the nondeductible IRA is often the best alternative for investors with very long investment horizons and high returns because the marginal benefit of deferring taxes increases at an increasing rate as time passes.

\footnotetext{
1 Randolph (1994) was among the first to address this question. Crain and Austin (1997) extended his work, allowing for different tax rates on ordinary and capital gains.

2 Gokhale and Kotlikoff (2003) noted that some investors may be better off with taxable accounts rather than a TDA account if applicable tax rates when assets are withdrawn are higher than when funds are contributed.
} 


\section{Analysis}

If the investment under question is a bond, its return (assuming no capital appreciation or depreciation) is fully taxed annually as ordinary income if it is held in a taxable account. The same is true for a trader who exhibits high turnover and realizes return as short-term capital gains. In a nondeductible IRA, tax is deferred until funds are withdrawn. Because the tax deferral is valuable, the nondeductible IRA is better than a taxable account for investments with returns that are taxed entirely as ordinary income.

In contrast, if the return is composed entirely of deferred capital gain (e.g., a buy-and-hold strategy of non-dividend-paying stocks), the entire return is tax deferred until it is liquidated. In a taxable account, the accumulated appreciation receives preferential tax treatment as a capital gain. But a withdrawal from a nondeductible IRA is subject to the higher tax rate on ordinary income. Therefore, the taxable account is better than the nondeductible IRA for investments with returns composed entirely of capital appreciation.

Although the analysis is less clear when the investment has a return with different taxable components, it follows the same basic approach I have developed thus far. The after-tax investment, $I_{B T}\left(1-T_{0}\right)$, is identical for both the nondeductible IRA and the taxable investment. It can, therefore, be ignored. According to Equation 2.4, the future after-tax accumulation of each dollar in a taxable account is

$$
\mathrm{FV}_{T X}=\left(1+r^{*}\right) n\left(1-T^{*}\right)+T^{*}
$$

Although the initial contribution to a nondeductible IRA is taxable, earnings accumulate tax deferred until funds are withdrawn, at which point they are taxed as ordinary income. Therefore, the after-tax accumulation of a dollar invested in a nondeductible IRA is equal to the pretax accumulation less the tax paid on the accumulation, or

$$
\begin{aligned}
\mathrm{FV}_{\text {NonDedIRA }} & =(1+r)^{n}-T_{n}\left[(1+r)^{n}-1\right] \\
& =(1+r)^{n}\left(1-T_{n}\right)+T_{n} .
\end{aligned}
$$

I can then take the ratio of the after-tax accumulations of the taxable account and the nondeductible IRA for different pretax returns and investment horizons to determine under which circumstances one or the other is preferred. Panel A of Table 4.1 shows that the 28 percent taxpayer facing a constant tax rate is generally better off with a taxable investment. For these investors, the benefit of the lower tax rate on dividends and capital gains outweighs the tax deferral offered by the nondeductible IRA account. Interestingly, the relative value of the nondeductible IRA increases as the time horizon and return increase but then begins to decrease. For shorter time horizons and lower returns, the marginal benefit of the preferred capital gains tax outweighs the benefit of deferring taxes until withdrawal. But as 
Table 4.1. After-Tax Future Value Ratios of a Taxable Account and a Nondeductible IRA for an Investor in the 28 Percent Tax Bracket

\begin{tabular}{|c|c|c|c|c|c|c|c|c|}
\hline \multirow[b]{2}{*}{$r$} & \multicolumn{8}{|c|}{ Investment Horizon in Years $(n)$} \\
\hline & 5 & 10 & 15 & 20 & 25 & 30 & 35 & 40 \\
\hline \multicolumn{9}{|c|}{ A. 28 percent withdrawal tax rate } \\
\hline $2 \%$ & 1.012 & 1.023 & 1.033 & 1.041 & 1.048 & 1.054 & 1.058 & 1.061 \\
\hline $4 \%$ & 1.023 & 1.041 & 1.054 & 1.062 & 1.066 & 1.066 & 1.063 & 1.057 \\
\hline $6 \%$ & 1.033 & 1.054 & 1.065 & 1.067 & 1.062 & 1.051 & 1.036 & 1.018 \\
\hline $8 \%$ & 1.041 & 1.063 & 1.068 & 1.060 & 1.044 & 1.021 & 0.994 & 0.965 \\
\hline $10 \%$ & 1.048 & 1.068 & 1.065 & 1.046 & 1.018 & 0.984 & 0.948 & 0.910 \\
\hline $12 \%$ & 1.054 & 1.070 & 1.057 & 1.027 & 0.988 & 0.945 & 0.901 & 0.857 \\
\hline $14 \%$ & 1.060 & 1.069 & 1.046 & 1.005 & 0.957 & 0.906 & 0.856 & 0.807 \\
\hline $16 \%$ & 1.064 & 1.067 & 1.033 & 0.982 & 0.926 & 0.868 & 0.813 & 0.761 \\
\hline $18 \%$ & 1.068 & 1.063 & 1.018 & 0.959 & 0.895 & 0.833 & 0.774 & 0.718 \\
\hline \multicolumn{9}{|c|}{ B. 25 percent withdrawal tax rate } \\
\hline $2 \%$ & 1.009 & 1.017 & 1.024 & 1.030 & 1.034 & 1.038 & 1.040 & 1.041 \\
\hline $4 \%$ & 1.017 & 1.030 & 1.038 & 1.042 & 1.042 & 1.039 & 1.033 & 1.026 \\
\hline $6 \%$ & 1.024 & 1.038 & 1.043 & 1.040 & 1.031 & 1.018 & 1.001 & 0.982 \\
\hline $8 \%$ & 1.030 & 1.043 & 1.041 & 1.029 & 1.010 & 0.985 & 0.958 & 0.929 \\
\hline $10 \%$ & 1.035 & 1.044 & 1.035 & 1.012 & 0.982 & 0.984 & 0.912 & 0.875 \\
\hline $12 \%$ & 1.039 & 1.044 & 1.025 & 0.992 & 0.952 & 0.909 & 0.866 & 0.823 \\
\hline $14 \%$ & 1.042 & 1.041 & 1.012 & 0.969 & 0.921 & 0.871 & 0.822 & 0.775 \\
\hline $16 \%$ & 1.045 & 1.036 & 0.997 & 0.946 & 0.890 & 0.834 & 0.781 & 0.730 \\
\hline $18 \%$ & 1.047 & 1.030 & 0.982 & 0.922 & 0.860 & 0.800 & 0.743 & 0.689 \\
\hline \multicolumn{9}{|c|}{ C. 15 percent withdrawal tax rate } \\
\hline $2 \%$ & 1.000 & 0.999 & 0.997 & 0.994 & 0.991 & 0.988 & 0.984 & 0.979 \\
\hline $4 \%$ & 0.999 & 0.995 & 0.988 & 0.980 & 0.970 & 0.959 & 0.947 & 0.933 \\
\hline $6 \%$ & 0.997 & 0.989 & 0.976 & 0.960 & 0.942 & 0.922 & 0.901 & 0.880 \\
\hline $8 \%$ & 0.996 & 0.982 & 0.962 & 0.938 & 0.911 & 0.883 & 0.854 & 0.826 \\
\hline $10 \%$ & 0.993 & 0.974 & 0.946 & 0.914 & 0.879 & 0.844 & 0.809 & 0.775 \\
\hline $12 \%$ & 0.991 & 0.965 & 0.929 & 0.889 & 0.847 & 0.806 & 0.766 & 0.727 \\
\hline $14 \%$ & 0.988 & 0.955 & 0.912 & 0.865 & 0.817 & 0.771 & 0.726 & 0.684 \\
\hline $16 \%$ & 0.985 & 0.945 & 0.895 & 0.841 & 0.788 & 0.737 & 0.690 & 0.645 \\
\hline $18 \%$ & 0.982 & 0.935 & 0.878 & 0.818 & 0.761 & 0.706 & 0.656 & 0.608 \\
\hline
\end{tabular}

Notes: In this example, non-IRA investments are invested in a typical taxable mutual fund, and dividends and capital gains are taxed at 15 percent through the accumulation phase. Bold numbers indicate approximate indifference points between the taxable account and the nondeductible IRA. 
the time horizon and return increase, the marginal value of deferring taxes increases at an increasing rate. ${ }^{3}$

If the taxpayer drops into the 25 percent tax bracket, as in Panel B, the nondeductible IRA becomes a bit more attractive, but not dramatically. The same trends of increasing then decreasing relative values are present. But if the withdrawal tax rate is 15 percent tax, the nondeductible IRA is always better because the withdrawal tax rate and capital gains tax rate are equal. So, the deferral associated with the nondeductible IRA dominates the taxable investment. This table also shows that for very long time horizons and high returns, the difference in relative values are quite large, indicating that the proper choice between a taxable account and a nondeductible IRA has significant wealth implications.

Table 4.2 displays after-tax value ratios for a taxpayer in the 33 percent tax bracket. The taxable account is relatively more valuable to these investors compared with the investors paying 28 percent because the indifference points have longer time horizons and higher returns in Panel A and Panel B. The taxable account is more attractive to investors in the 33 percent tax bracket because they derive a comparatively larger benefit from the 15 percent tax rate on dividends and capital gains than investors in the 28 percent tax bracket. The same trend of increasing then decreasing relative values with respect to the time horizon and return are also evident. When the 33 percent taxpayer drops two tax brackets to the 25 percent tax bracket (Panel C), the nondeductible IRA becomes attractive for long investment horizons and high returns. In these cases, the preferred tax rate on capital gains is relatively less valuable and the benefit of deferring taxes grows.

Breakeven withdrawal tax rates offer another perspective on the choice between a nondeductible IRA and a taxable account. Appendix $\mathrm{C}$ contains an expression for the breakeven withdrawal tax rate, but an important characteristic is that it is independent of the investor's current tax rate because the after-tax investments for the two types of accounts are the same. Appendix $\mathrm{C}$ also presents the breakeven tax rate for partially deductible IRAs. Figure 4.1 presents breakeven withdrawal tax rates under three different assumptions about how ordinary income distributions from mutual fund returns are taxed. A withdrawal tax rate below the breakeven rate indicates that the nondeductible IRA accumulates more wealth than the taxable account. So, high breakeven withdrawal tax rates favor nondeductible IRAs. Panel A assumes that a mutual fund distributes income in the form of dividends, which are taxed at 15 percent. The breakeven withdrawal tax rates are relatively low, indicating that the taxable account is attractive in many circumstances. Moreover, the breakeven withdrawal tax rate is quite sensitive to the investment horizon and expected return. Nondeductible IRAs become much more attractive than taxable accounts as the

3 A standard comparative statics analysis can identify the maximum points, but it offers little insight to the practicing analyst. 
Table 4.2. After-Tax Future Value Ratios of a Taxable Account and a Nondeductible IRA for an Investor in the 33 Percent Tax Bracket

\begin{tabular}{|c|c|c|c|c|c|c|c|c|}
\hline \multirow[b]{2}{*}{$r$} & \multicolumn{8}{|c|}{ Investment Horizon in Years $(n)$} \\
\hline & 5 & 10 & 15 & 20 & 25 & 30 & 35 & 40 \\
\hline \multicolumn{9}{|c|}{ A. 33 percent withdrawal tax rate } \\
\hline $2 \%$ & 1.017 & 1.033 & 1.047 & 1.060 & 1.071 & 1.081 & 1.090 & 1.097 \\
\hline $4 \%$ & 1.033 & 1.060 & 1.081 & 1.097 & 1.108 & 1.114 & 1.115 & 1.113 \\
\hline $6 \%$ & 1.047 & 1.081 & 1.103 & 1.114 & 1.116 & 1.111 & 1.099 & 1.083 \\
\hline $8 \%$ & 1.060 & 1.097 & 1.115 & 1.117 & 1.106 & 1.086 & 1.016 & 1.032 \\
\hline $10 \%$ & 1.071 & 1.109 & 1.119 & 1.108 & 1.084 & 1.052 & 1.015 & 0.976 \\
\hline $12 \%$ & 1.081 & 1.116 & 1.116 & 1.093 & 1.056 & 1.012 & 0.966 & 0.920 \\
\hline $14 \%$ & 1.090 & 1.121 & 1.109 & 1.073 & 1.024 & 0.972 & 0.918 & 0.866 \\
\hline $16 \%$ & 1.098 & 1.122 & 1.098 & 1.050 & 0.992 & 0.932 & 0.873 & 0.817 \\
\hline $18 \%$ & 1.104 & 1.121 & 1.085 & 1.026 & 0.960 & 0.894 & 0.831 & 0.772 \\
\hline \multicolumn{9}{|c|}{ B. 28 percent withdrawal tax rate } \\
\hline $2 \%$ & 1.012 & 1.023 & 1.033 & 1.041 & 1.048 & 1.054 & 1.058 & 1.061 \\
\hline $4 \%$ & 1.023 & 1.041 & 1.054 & 1.062 & 1.066 & 1.066 & 1.063 & 1.057 \\
\hline $6 \%$ & 1.033 & 1.054 & 1.065 & 1.067 & 1.062 & 1.051 & 1.036 & 1.018 \\
\hline $8 \%$ & 1.041 & 1.063 & 1.068 & 1.060 & 1.044 & 1.021 & 0.994 & 0.965 \\
\hline $10 \%$ & 1.048 & 1.068 & 1.065 & 1.046 & 1.018 & 0.984 & 0.948 & 0.910 \\
\hline $12 \%$ & 1.054 & 1.070 & 1.057 & 1.027 & 0.988 & 0.945 & 0.901 & 0.857 \\
\hline $14 \%$ & 1.060 & 1.069 & 1.046 & 1.005 & 0.957 & 0.906 & 0.856 & 0.807 \\
\hline $16 \%$ & 1.064 & 1.067 & 1.033 & 0.982 & 0.926 & 0.868 & 0.813 & 0.761 \\
\hline $18 \%$ & 1.068 & 1.063 & 1.018 & 0.959 & 0.895 & 0.833 & 0.774 & 0.718 \\
\hline \multicolumn{9}{|c|}{ C. 25 percent withdrawal tax rate } \\
\hline $2 \%$ & 1.009 & 1.017 & 1.024 & 1.030 & 1.034 & 1.038 & 1.040 & 1.041 \\
\hline $4 \%$ & 1.017 & 1.030 & 1.038 & 1.042 & 1.042 & 1.039 & 1.033 & 1.026 \\
\hline $6 \%$ & 1.024 & 1.038 & 1.043 & 1.040 & 1.031 & 1.018 & 1.001 & 0.982 \\
\hline $8 \%$ & 1.030 & 1.043 & 1.041 & 1.029 & 1.010 & 0.985 & 0.958 & 0.929 \\
\hline $10 \%$ & 1.035 & 1.044 & 1.035 & 1.012 & 0.982 & 0.948 & 0.912 & 0.875 \\
\hline $12 \%$ & 1.039 & 1.044 & 1.025 & 0.992 & 0.952 & 0.909 & 0.866 & 0.823 \\
\hline $14 \%$ & 1.042 & 1.041 & 1.012 & 0.969 & 0.921 & 0.871 & 0.822 & 0.775 \\
\hline $16 \%$ & 1.045 & 1.036 & 0.997 & 0.946 & 0.890 & 0.834 & 0.781 & 0.730 \\
\hline $18 \%$ & 1.047 & 1.030 & 0.982 & 0.922 & 0.860 & 0.800 & 0.743 & 0.689 \\
\hline
\end{tabular}

Notes: In this example, non-IRA investments are invested in a typical taxable mutual fund, and dividends and capital gains are taxed at 15 percent through the accumulation phase. Bold numbers indicate approximate indifference points between the taxable account and the nondeductible IRA. 
Figure 4.1. Breakeven Withdrawal Tax Rates between a Taxable Account and a Nondeductible IRA

\section{A. Distributions Taxed as Dividends at 15 Percent}

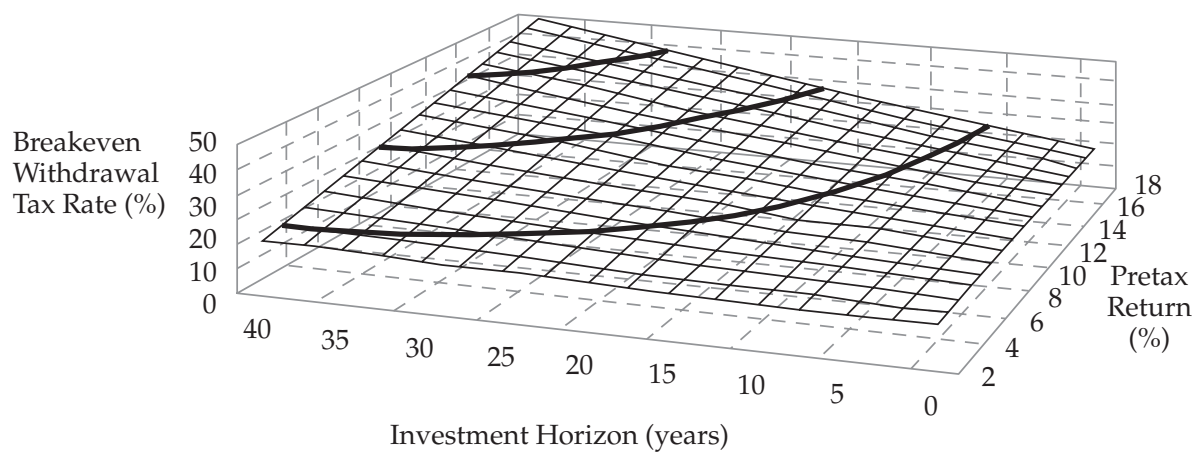

B. Distributions Taxed as Ordinary Income at 28 Percent

Breakeven

Withdrawal

Tax Rate (\%)

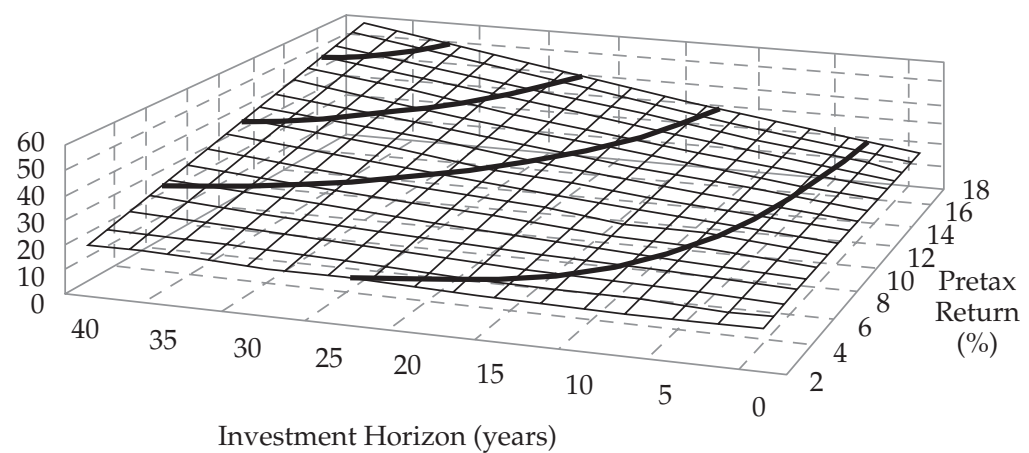

C. Distributions Taxed as Ordinary Income at 33 Percent

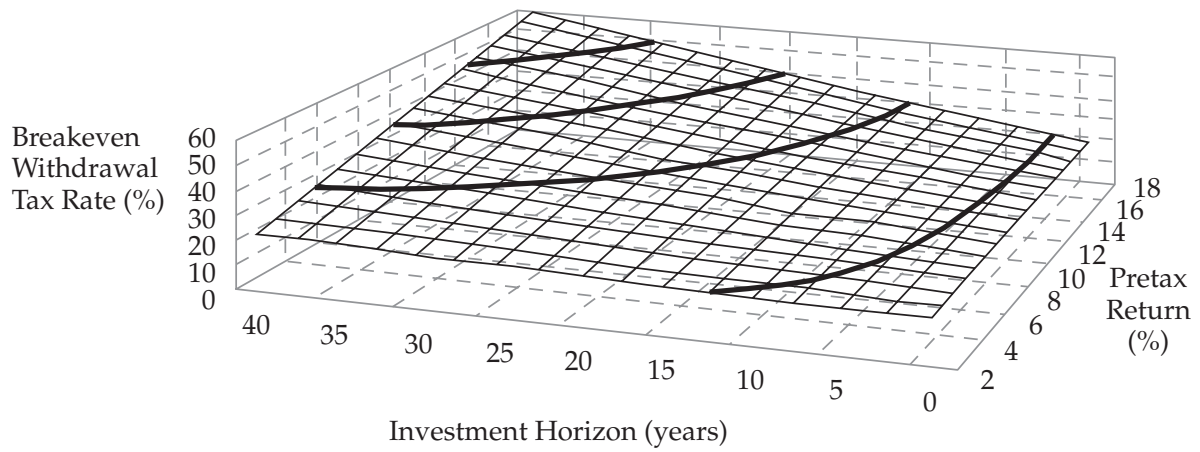


investment horizon and investment return increase. So, investors should estimate these factors carefully when choosing between the two types of accounts.

Panel $\mathrm{B}$ and Panel $\mathrm{C}$ show how the breakeven tax rate changes if the income generated by the mutual fund is taxed as ordinary income rather than taxed as a dividend at 15 percent. This situation is particularly relevant for high-tax-bracket investors who are likely to be subject to the AMT. The AMT affects a small but growing number of taxpayers. Originally targeted to prevent a small number of high-income households from paying no taxes, the AMT is a parallel tax system that functions much like a flat tax of 26 percent or 28 percent on income exceeding a specific amount. Long-term capital gains receive the same preferential tax treatment under the AMT as they do under the ordinary income tax. Large gains, however, may reduce or eliminate the amount of income one can exempt from the AMT. So, indirectly, capital gains can create a marginal tax liability in excess of the 15 percent preferred rate. A detailed analysis of the AMT is far beyond the scope of this monograph, but its potential impact can be incorporated into the discussion.

The breakeven tax rates for ordinary income taxed at 28 percent (Panel B) are 3-7 percentage points higher than in Panel A, in which income is assumed to be taxed at 15 percent. Therefore, the nondeductible IRA becomes attractive in more situations when the preferential tax treatment of dividends associated with the taxable investment is reduced or lost. Breakeven tax rates increase another percentage point or two in Panel C, which assumes ordinary income is taxed at 33 percent. Nonetheless, the taxable account remains a viable investment alternative in many situations.

\section{Summary}

Investors with income limitations on deductible IRA contributions may face the decision of whether to invest using a nondeductible IRA or a taxable account. The following rule of thumb may be useful to investors choosing between a taxable account and a nondeductible IRA: If returns are fully taxed as ordinary income, the nondeductible IRA is optimal because it has tax-shelter benefits. If returns are taxed entirely as deferred capital gains, the taxable account is optimal because the capital gain tax shelter is more valuable than the tax deferral associated with the nondeductible IRA. The nondeductible IRA is often the best alternative except for investors with very long investment horizons and high expected returns. For taxpayers subject to the AMT, the nondeductible IRA alternative becomes increasingly attractive. 


\section{Valuing Tax-Sheltered Assets on an After-Tax Basis}

The proliferation of TDAs (such as pension funds, traditional IRAs, 401(k)s, and Roth IRAs) has increased their significance in investors' portfolios. It has also increased the importance of valuing assets held in TDAs on an after-tax basis. The idea of valuing financial assets held in TDAs can sound a bit confusing to an economist who understands these assets to be denominated in dollars and priced by the marketplace. The marketplace certainly can and does price the assets within a TDA, but the value of a dollar depends on how it is taxed when it is used for consumption purposes. For example, a dollar in a traditional IRA is subject to withdrawal taxes, which decreases the amount of goods and services an investor can buy, whereas a dollar in a Roth IRA is not subject to taxes, barring any unqualified withdrawals. So, in general, a dollar in a Roth IRA is worth more than a dollar held in a traditional IRA. As the reader will see, the after-tax value of a dollar in a TDA is not an objective market value. It is contingent on the particular circumstances and financial plans (e.g., tax profile, investment return, withdrawal patterns) faced by a given investor and, therefore, varies from one investor to the next.

The notion of valuing assets in a TDA on an after-tax basis is based on determining the amount of taxable assets that would produce the same after-tax cash flow as the TDA. For both traditional IRAs and partially deductible IRAs, the after-tax value can be either greater than or less than the pretax accumulation depending on the investment return and time horizon. As the return and investment horizon increase, the after-tax value of the TDA increases because the effect of its tax shelter increases. For Roth IRAs, the after-tax value is always greater than the pretax accumulation as well as the traditional IRA after-tax values because withdrawals from Roth IRAs are free from tax. Although annuitized withdrawal patterns generate higher after-tax values than lump-sum withdrawals at the beginning of the annuity period, the difference is more modest than previous research suggests and can be safely ignored in most cases.

But why would one care about valuing assets held in TDAs on an after-tax basis? Researchers have investigated how the introduction of TDAs has affected savings rates and investors' taxable savings habits. ${ }^{1}$ Most often, however, they treat a dollar in a TDA as equivalent to a dollar in a taxable account when, in fact,

1 See, for example, Engen and Gale (2000), Engen, Gale, and Scholz (1996), and Poterba, Venti, and Wise (1996). 
they might be quite different based on the type of TDA, the taxing scheme of the taxable account, and the withdrawal pattern. Several authors have recognized the need to consider the after-tax value of assets in a TDA arguing that retirees and investors make consumption decisions using after-tax dollars. Retirees and investors, therefore, should make their asset allocation and investment decisions using after-tax dollars. ${ }^{2}$ Researchers have recently developed models of varying sophistication to address this issue so that financial assets within TDAs can be compared on an equal footing with assets in taxable accounts. ${ }^{3}$

Reichenstein (1998), for example, made a first approximation by simply multiplying the pretax value of TDA assets by 1 minus the tax rate. This approach, however, assumes that funds are immediately withdrawn from the TDA in their entirety and, therefore, subject to taxation. Sibley (2002) proposed a more sophisticated framework by deriving a taxable equivalent - that is, the amount of taxable assets that would produce the same after-tax cash flow as a withdrawal from the taxsheltered account at some future date. This approach is useful because it accounts for the value of assets earning tax-deferred or tax-free returns before they are withdrawn. His approach is limited, however, because it focuses on single withdrawals and assumes that returns on the taxable equivalent are fully taxed annually at a single, constant tax rate. Following Horan (2002), I can apply the methods developed in earlier chapters to value assets held in TDAs on an after-tax basis.

Sibley introduced the idea of valuing tax-sheltered accounts by discounting future after-tax withdrawals from the account at an after-tax cost of capital, thereby deriving a taxable equivalent. The taxable equivalent is the amount of taxable assets that would be required to produce the same after-tax cash flows that the TDA produces. ${ }^{4}$ I follow a similar approach but use a model with discount factors based on a typical mutual fund taxing scheme outlined in Chapter 2, whereby a portion of the return is taxed each year as distributed ordinary income, a portion is taxed as distributed dividend or capital gain, and the remainder is taxed as capital gain when the investment is sold. The result is an opportunity cost of capital associated with a typical mutual fund investment, which is appropriate to use if the investor uses a mutual fund or some other taxable portfolio to invest the taxable equivalent in lieu of the tax-sheltered vehicle.

\footnotetext{
2 Reichenstein (1998) and Reichenstein and Jennings (2003), for example.

${ }^{3}$ See Sibley (2002), Horan (2002), and Poterba (2004) for examples.

4 Poterba (2004) also followed a similar approach except that his framework used continuous compounding.
} 


\section{After-Tax Value for a Traditional IRA with a Lump-Sum Withdrawal}

The previous chapter showed that the future after-tax withdrawal after $n$ years of investment return for each dollar in a fully deductible traditional IRA is

$$
\mathrm{FV}_{\text {TradIRA }}=(1+r)^{n}\left(1-T_{n}\right),
$$

where $T_{n}$ is the applicable tax rate upon withdrawal. Using this accumulation, I can determine the taxable equivalent - the amount of money invested today in a taxable account that will produce that same after-tax accumulation as the traditional IRAby taking the present value of this figure. The present value calculation requires a taxable present value interest factor (i.e., $\mathrm{PVIF}_{T X}$ ) that appropriately accommodates the different taxable components of an investment's return: ordinary income, realized capital gains and dividends, and unrealized capital gains. The after-tax present value interest factor is simply the reciprocal of the after-tax future value interest factor introduced in Chapter 2, or

$$
\begin{aligned}
\operatorname{PVIF}_{T X} & =\frac{1}{\operatorname{FVIF}_{T X}} \\
& =\frac{1}{\left(1+r^{*}\right)^{n}\left(1-T^{*}\right)+T^{*}} .
\end{aligned}
$$

Therefore, the taxable equivalent in today's dollars of each dollar invested in a traditional IRA is equal to the product of Equation 5.1 and Equation 5.2, or

$$
\begin{aligned}
\mathrm{PV}_{\text {TradIRA }} & =\frac{(1+r)^{n}\left(1-T_{n}\right)}{\left(1+r^{*}\right)^{n}\left(1-T^{*}\right)+T^{*}} \\
& =(1+r)^{n}\left(1-T_{n}\right)\left[\mathrm{PVIF}_{T X}\right] .
\end{aligned}
$$

Equation 5.3 is essentially the ratio of the after-tax future value of a traditional IRA to the after-tax future value of a taxable account. So, the process of valuing TDAs on an after-tax basis boils down to comparing the after-tax accumulation of the TDA with that of the taxable account.

If an investor has the after-tax equivalent in lieu of the tax-sheltered account, the proceeds might be invested in an investment fully taxed each year as ordinary income, such as a fixed-income instrument or a high turnover portfolio that realizes short-term capital gains. Alternatively, the taxable equivalent might be an investment with a return entirely deferred as unrealized capital gain, such as a passively managed portfolio of non-dividend-paying stocks. The taxable equivalent might more likely be a portfolio of investments with a blended taxing scheme that includes taxable components of ordinary income, realized capital gain, and unrealized capital gain, such as an actively managed portfolio or a mutual fund. Regardless, the inputs 
of Equation 5.3 can be adjusted to reflect these different taxation schemes. The denominator in Equation 5.3 will generally be smaller for fully taxable investments, which will increase the after-tax value of the traditional IRA because the taxsheltering benefits of a TDA increase if the alternative investment has a heavy tax burden. By reverse logic, the after-tax value of the TDA becomes less valuable if the taxable equivalent is invested in a vehicle with a light tax burden because the TDA tax advantages are relatively less valuable.

Table 5.1 displays after-tax valuations for a traditional IRA under various scenarios for an investor in the 28 percent tax bracket during the contribution and withdrawal phase. Panel A shows that the after-tax value increases as the time horizon and return increase and that the after-tax value is quite sensitive as these factors change. For example, the value of each dollar in a traditional IRA for an investor with a five-year investment horizon expecting a 6 percent return is 78 cents. Therefore, the after-tax value of a $\$ 200,000$ traditional IRA would be $\$ 156,000$. By contrast, the after-tax value of a traditional IRA for an investor with a 40-year investment horizon expecting a 12 percent return is 2.44 times the pretax value of the account. In other words, the after-tax value of the same $\$ 200,000$ traditional IRA would then be $\$ 488,000$.

The reason for these dramatic differences is that the value of tax deferral increases as the pretax return increases. The higher the return and time horizon, the greater the tax deferral benefits, especially for a taxable equivalent that is fully taxed as ordinary income. It is interesting to note that the after-tax value of a traditional IRA can be either greater than or less than its pretax value. It depends on the return and when the withdrawal is made. It stands to reason that the value depends on how the withdrawal is made as well. I will address the impact of annuity withdrawal patterns below.

A comparison of the values across the three panels shows that the after-tax values are greatest when the taxable equivalent has a return that is fully taxed as ordinary income. And the difference is quite large for high returns and long investment horizons because the value of the TDA's tax shelter grows under these conditions. In the extreme, a TDA has no value in the absence of taxes.

Panel B of Table 5.1 displays after-tax values assuming the taxable equivalent is a typical equity mutual fund in which a portion of the return is taxed as dividend, realized capital gain, and short-term capital gain. The same basic trends hold, but the after-tax values are lower, especially for long time horizons and high returns. For example, a 20 -year investor expecting a 12 percent return has an after-tax value of about 94 percent of pretax asset value if the taxable equivalent is a typical equity mutual fund. If the taxable equivalent is fully taxable as in Panel A, the after-tax value increases to 132 percent.

In the extreme case in which the return for the taxable equivalent is entirely deferred as a capital gain until the end of the investment period (Panel C), the after- 
Table 5.1. After-Tax Value of a Traditional IRA Withdrawn as a Lump Sum for an Investor in the 28 Percent Bracket

\begin{tabular}{|c|c|c|c|c|c|c|c|c|}
\hline \multirow[b]{2}{*}{$r$} & \multicolumn{8}{|c|}{ Investment Horizon in Years $(n)$} \\
\hline & 5 & 10 & 15 & 20 & 25 & 30 & 35 & 40 \\
\hline \multicolumn{9}{|c|}{ A. Fully taxable discount rate (trader) } \\
\hline $2 \%$ & 0.740 & 0.761 & 0.782 & 0.804 & 0.826 & 0.849 & 0.873 & 0.897 \\
\hline $4 \%$ & 0.760 & 0.802 & 0.847 & 0.894 & 0.944 & 0.996 & 1.052 & 1.110 \\
\hline $6 \%$ & 0.780 & 0.845 & 0.915 & 0.991 & 1.073 & 1.163 & 1.259 & 1.364 \\
\hline $8 \%$ & 0.800 & 0.888 & 0.986 & 1.095 & 1.216 & 1.350 & 1.499 & 1.665 \\
\hline $10 \%$ & 0.819 & 0.932 & 1.060 & 1.206 & 1.372 & 1.561 & 1.775 & 2.020 \\
\hline $12 \%$ & 0.838 & 0.976 & 1.137 & 1.324 & 1.542 & 1.795 & 2.091 & 2.435 \\
\hline $14 \%$ & 0.858 & 1.022 & 1.217 & 1.450 & 1.727 & 2.057 & 2.450 & 2.919 \\
\hline $16 \%$ & 0.877 & 1.068 & 1.300 & 1.583 & 1.927 & 2.347 & 2.858 & 3.480 \\
\hline $18 \%$ & 0.896 & 1.114 & 1.386 & 1.724 & 2.144 & 2.667 & 3.318 & 4.127 \\
\hline \multicolumn{9}{|c|}{ B. Typical equity mutual fund discount rate (active investor) } \\
\hline $2 \%$ & 0.731 & 0.741 & 0.751 & 0.761 & 0.771 & 0.781 & 0.791 & 0.801 \\
\hline $4 \%$ & 0.741 & 0.761 & 0.780 & 0.800 & 0.819 & 0.838 & 0.857 & 0.875 \\
\hline $6 \%$ & 0.750 & 0.780 & 0.808 & 0.836 & 0.864 & 0.891 & 0.919 & 0.947 \\
\hline $8 \%$ & 0.760 & 0.797 & 0.834 & 0.870 & 0.907 & 0.943 & 0.980 & 1.018 \\
\hline $10 \%$ & 0.768 & 0.814 & 0.859 & 0.904 & 0.948 & 0.994 & 1.041 & 1.089 \\
\hline $12 \%$ & 0.777 & 0.831 & 0.883 & 0.936 & 0.989 & 1.045 & 1.102 & 1.162 \\
\hline $14 \%$ & 0.785 & 0.846 & 0.906 & 0.967 & 1.030 & 1.095 & 1.164 & 1.237 \\
\hline $16 \%$ & 0.793 & 0.861 & 0.929 & 0.998 & 1.070 & 1.146 & 1.227 & 1.314 \\
\hline $18 \%$ & 0.801 & 0.876 & 0.951 & 1.028 & 1.110 & 1.198 & 1.291 & 1.392 \\
\hline \multicolumn{9}{|c|}{ C. Completely deferred capital gains discount rate (passive investor) } \\
\hline $2 \%$ & 0.730 & 0.740 & 0.749 & 0.757 & 0.765 & 0.772 & 0.778 & 0.784 \\
\hline $4 \%$ & 0.740 & 0.757 & 0.771 & 0.784 & 0.794 & 0.803 & 0.811 & 0.817 \\
\hline $6 \%$ & 0.748 & 0.771 & 0.789 & 0.803 & 0.814 & 0.822 & 0.828 & 0.833 \\
\hline $8 \%$ & 0.756 & 0.783 & 0.802 & 0.816 & 0.826 & 0.832 & 0.837 & 0.840 \\
\hline $10 \%$ & 0.763 & 0.793 & 0.813 & 0.825 & 0.833 & 0.839 & 0.842 & 0.844 \\
\hline $12 \%$ & 0.770 & 0.802 & 0.821 & 0.832 & 0.838 & 0.842 & 0.844 & 0.845 \\
\hline $14 \%$ & 0.776 & 0.809 & 0.827 & 0.836 & 0.841 & 0.844 & 0.846 & 0.846 \\
\hline $16 \%$ & 0.781 & 0.814 & 0.831 & 0.839 & 0.843 & 0.845 & 0.846 & 0.847 \\
\hline $18 \%$ & 0.786 & 0.819 & 0.835 & 0.842 & 0.845 & 0.846 & 0.847 & 0.847 \\
\hline
\end{tabular}

Notes: The investor maintains the same marginal tax rate throughout the investment horizon. The mutual fund distributes 20 percent of its return as dividends and 45 percent as long-term capital gain. Dividends and capital gains are taxed at 15 percent. Bold numbers correspond approximately to breakeven pretax and after-tax values. 
tax value of a traditional IRA is always less than its pretax value. The intuition is simple. Both the traditional IRA and the taxable equivalent are taxed at the end of the investment period. The former is taxed as ordinary income, and the latter is taxed at the lower capital gains tax rate. In this case, the TDA will always produce a lower after-tax cash flow than the taxable equivalent.

The after-tax values for investors in the 33 percent tax bracket are reported in Table 5.2. The indifference points at which the pretax value equals the after-tax value in Panel $\mathrm{A}$ are about the same as those for the 28 percent taxpayer. But the variance of after-tax values is higher. That is, compared with the 28 percent taxpayer, low after-tax values are lower for the 33 percent taxpayer and high aftertax values are higher. The variance is higher because the TDA's positive tax benefits are relatively more valuable for long time horizons and high returns. For short time horizons and low returns, the tax burden on the taxable equivalent is not terribly onerous, which makes the relative after-tax value of the traditional IRA low.

In Panel B of Table 5.2, the indifference points are about 5-10 years longer and the after-tax values are about 5-10 percent less than those reported for the 28 percent taxpayer. The intuition here is that dividends and realized capital gains are still being taxed at 15 percent for the equity mutual fund in the taxable equivalent. All that is changing is the withdrawal tax rate, which has increased to 33 percent. The higher withdrawal tax rate decreases the after-tax value.

Table 5.3 shows that a decreasing tax rate when funds are withdrawn increases the after-tax value of a traditional IRA, which comes as no surprise. The effect is modest for low returns and short time horizons because the accumulation in these scenarios is modest. Decreasing withdrawal tax rates has a more pronounced effect for high returns and long investment horizons. For example, the after-tax value of a traditional IRA for a taxpayer expecting a 12 percent return over a 40 -year time horizon is more than three times the pretax value if the investor drops from the 33 percent tax bracket to the 28 percent tax bracket. When the marginal tax rate on ordinary income stays constant, the number is 2.2 times. When the investor drops two tax brackets to 25 percent, the after-tax value is 3.17 times the pretax value. Notice that the values in Panel C for Tables 5.1 and Table 5.3 are identical. This is true because all that matters when returns are fully taxed as a deferred capital gain is the withdrawal tax rate, which is 28 percent in both cases.

This analysis indicates that the withdrawal tax rate affects the after-tax value of a traditional IRA. But the return, time horizon, and taxing scheme of the taxable equivalent seem to be more important determinants of the after-tax value for traditional IRAs. 
Table 5.2. After-Tax Value of a Traditional IRA Withdrawn as a Lump Sum for an Investor in the 33 Percent Tax Bracket

\begin{tabular}{|c|c|c|c|c|c|c|c|c|}
\hline \multirow[b]{2}{*}{$r$} & \multicolumn{8}{|c|}{ Investment Horizon in Years $(n)$} \\
\hline & 5 & 10 & 15 & 20 & 25 & 30 & 35 & 40 \\
\hline \multicolumn{9}{|c|}{ A. Fully taxable discount rate (trader) } \\
\hline $2 \%$ & 0.692 & 0.715 & 0.739 & 0.763 & 0.788 & 0.814 & 0.841 & 0.869 \\
\hline $4 \%$ & 0.714 & 0.761 & 0.811 & 0.865 & 0.922 & 0.983 & 1.048 & 1.117 \\
\hline $6 \%$ & 0.736 & 0.809 & 0.889 & 0.977 & 1.073 & 1.180 & 1.296 & 1.424 \\
\hline $8 \%$ & 0.758 & 0.858 & 0.971 & 1.099 & 1.244 & 1.408 & 1.593 & 1.803 \\
\hline $10 \%$ & 0.780 & 0.909 & 1.058 & 1.232 & 1.435 & 1.671 & 1.946 & 2.266 \\
\hline $12 \%$ & 0.802 & 0.960 & 1.150 & 1.376 & 1.648 & 1.973 & 2.362 & 2.828 \\
\hline $14 \%$ & 0.824 & 1.013 & 1.246 & 1.533 & 1.885 & 2.318 & 2.850 & 3.506 \\
\hline $16 \%$ & 0.846 & 1.068 & 1.348 & 1.701 & 2.147 & 2.710 & 3.421 & 4.319 \\
\hline $18 \%$ & 0.867 & 1.123 & 1.454 & 1.882 & 2.437 & 3.155 & 4.085 & 5.288 \\
\hline \multicolumn{9}{|c|}{ B. Typical equity mutual fund discount rate (active investor) } \\
\hline $2 \%$ & 0.680 & 0.690 & 0.699 & 0.709 & 0.718 & 0.727 & 0.736 & 0.745 \\
\hline $4 \%$ & 0.689 & 0.708 & 0.726 & 0.744 & 0.762 & 0.780 & 0.797 & 0.815 \\
\hline $6 \%$ & 0.698 & 0.725 & 0.752 & 0.778 & 0.804 & 0.829 & 0.855 & 0.881 \\
\hline $8 \%$ & 0.707 & 0.742 & 0.776 & 0.810 & 0.844 & 0.877 & 0.912 & 0.947 \\
\hline $10 \%$ & 0.715 & 0.758 & 0.800 & 0.841 & 0.882 & 0.925 & 0.969 & 1.014 \\
\hline $12 \%$ & 0.723 & 0.773 & 0.822 & 0.871 & 0.921 & 0.972 & 1.026 & 1.082 \\
\hline $14 \%$ & 0.731 & 0.788 & 0.844 & 0.900 & 0.958 & 1.019 & 1.083 & 1.151 \\
\hline $16 \%$ & 0.738 & 0.802 & 0.865 & 0.929 & 0.996 & 1.067 & 1.142 & 1.222 \\
\hline $18 \%$ & 0.745 & 0.815 & 0.885 & 0.957 & 1.033 & 1.114 & 1.202 & 1.295 \\
\hline \multicolumn{9}{|c|}{ C. Completely deferred capital gains discount rate (passive investor) } \\
\hline $2 \%$ & 0.680 & 0.689 & 0.697 & 0.705 & 0.712 & 0.718 & 0.724 & 0.730 \\
\hline $4 \%$ & 0.688 & 0.704 & 0.718 & 0.729 & 0.739 & 0.748 & 0.754 & 0.760 \\
\hline $6 \%$ & 0.696 & 0.718 & 0.734 & 0.747 & 0.757 & 0.765 & 0.771 & 0.775 \\
\hline $8 \%$ & 0.704 & 0.729 & 0.747 & 0.759 & 0.768 & 0.775 & 0.779 & 0.782 \\
\hline $10 \%$ & 0.710 & 0.738 & 0.756 & 0.768 & 0.776 & 0.780 & 0.783 & 0.785 \\
\hline $12 \%$ & 0.716 & 0.746 & 0.764 & 0.774 & 0.780 & 0.784 & 0.786 & 0.787 \\
\hline $14 \%$ & 0.722 & 0.752 & 0.769 & 0.778 & 0.783 & 0.786 & 0.787 & 0.787 \\
\hline $16 \%$ & 0.727 & 0.758 & 0.774 & 0.781 & 0.785 & 0.787 & 0.787 & 0.788 \\
\hline $18 \%$ & 0.732 & 0.763 & 0.777 & 0.783 & 0.786 & 0.787 & 0.788 & 0.788 \\
\hline
\end{tabular}

Notes: The investor maintains the same marginal tax rate throughout the investment horizon. The mutual fund distributes 20 percent of its return as dividends and 45 percent as long-term capital gain. Dividends and capital gains are taxed at 15 percent. Bold numbers correspond approximately to breakeven pretax and after-tax values. 
Table 5.3. After-Tax Value of a Traditional IRA Withdrawn as a Lump Sum for an Investor in the 33 Percent Tax Bracket Who Drops One Tax Bracket

\begin{tabular}{|c|c|c|c|c|c|c|c|c|}
\hline \multirow[b]{2}{*}{$r$} & \multicolumn{8}{|c|}{ Investment Horizon in Years $(n)$} \\
\hline & 5 & 10 & 15 & 20 & 25 & 30 & 35 & 40 \\
\hline \multicolumn{9}{|c|}{ A. Fully taxable discount rate (trader) } \\
\hline $2 \%$ & 0.744 & 0.768 & 0.794 & 0.820 & 0.847 & 0.875 & 0.904 & 0.933 \\
\hline $4 \%$ & 0.767 & 0.818 & 0.872 & 0.930 & 0.991 & 1.056 & 1.126 & 1.200 \\
\hline $6 \%$ & 0.791 & 0.869 & 0.955 & 1.050 & 1.154 & 1.268 & 1.393 & 1.531 \\
\hline $8 \%$ & 0.815 & 0.922 & 1.044 & 1.181 & 1.337 & 1.513 & 1.712 & 1.938 \\
\hline $10 \%$ & 0.838 & 0.976 & 1.137 & 1.324 & 1.542 & 1.795 & 2.091 & 2.435 \\
\hline $12 \%$ & 0.862 & 1.032 & 1.235 & 1.479 & 1.771 & 2.120 & 2.538 & 3.039 \\
\hline $14 \%$ & 0.885 & 1.089 & 1.339 & 1.647 & 2.025 & 2.491 & 3.063 & 3.767 \\
\hline $16 \%$ & 0.909 & 1.147 & 1.448 & 1.828 & 2.307 & 2.913 & 3.677 & 4.641 \\
\hline $18 \%$ & 0.932 & 1.207 & 1.562 & 2.023 & 2.619 & 3.391 & 4.390 & 5.683 \\
\hline \multicolumn{9}{|c|}{ B. Typical equity mutual fund discount rate (active investor) } \\
\hline $2 \%$ & 0.733 & 0.746 & 0.759 & 0.772 & 0.785 & 0.798 & 0.811 & 0.824 \\
\hline $4 \%$ & 0.746 & 0.772 & 0.797 & 0.823 & 0.848 & 0.874 & 0.900 & 0.926 \\
\hline $6 \%$ & 0.758 & 0.796 & 0.834 & 0.872 & 0.910 & 0.949 & 0.989 & 1.029 \\
\hline $8 \%$ & 0.770 & 0.819 & 0.869 & 0.919 & 0.971 & 1.024 & 1.079 & 1.136 \\
\hline $10 \%$ & 0.781 & 0.842 & 0.904 & 0.967 & 1.032 & 1.100 & 1.171 & 1.246 \\
\hline $12 \%$ & 0.793 & 0.864 & 0.938 & 1.013 & 1.093 & 1.177 & 1.266 & 1.362 \\
\hline $14 \%$ & 0.803 & 0.886 & 0.971 & 1.060 & 1.154 & 1.256 & 1.365 & 1.484 \\
\hline $16 \%$ & 0.814 & 0.907 & 1.004 & 1.106 & 1.217 & 1.337 & 1.468 & 1.611 \\
\hline $18 \%$ & 0.824 & 0.927 & 1.036 & 1.153 & 1.280 & 1.420 & 1.574 & 1.745 \\
\hline \multicolumn{9}{|c|}{ C. Completely deferred capital gains discount rate (passive investor) } \\
\hline $2 \%$ & 0.730 & 0.740 & 0.749 & 0.757 & 0.765 & 0.772 & 0.778 & 0.784 \\
\hline $4 \%$ & 0.740 & 0.757 & 0.771 & 0.784 & 0.794 & 0.803 & 0.811 & 0.817 \\
\hline $6 \%$ & 0.748 & 0.771 & 0.789 & 0.803 & 0.814 & 0.822 & 0.828 & 0.833 \\
\hline $8 \%$ & 0.756 & 0.783 & 0.802 & 0.816 & 0.826 & 0.832 & 0.837 & 0.840 \\
\hline $10 \%$ & 0.763 & 0.793 & 0.813 & 0.825 & 0.833 & 0.839 & 0.842 & 0.844 \\
\hline $12 \%$ & 0.770 & 0.802 & 0.821 & 0.832 & 0.838 & 0.842 & 0.844 & 0.845 \\
\hline $14 \%$ & 0.776 & 0.809 & 0.827 & 0.836 & 0.841 & 0.844 & 0.846 & 0.846 \\
\hline $16 \%$ & 0.781 & 0.814 & 0.831 & 0.839 & 0.843 & 0.845 & 0.846 & 0.847 \\
\hline $18 \%$ & 0.786 & 0.819 & 0.835 & 0.842 & 0.845 & 0.846 & 0.847 & 0.847 \\
\hline
\end{tabular}

Notes: The investor drops into the next lower tax bracket upon withdrawing funds from the traditional IRA account. The mutual fund distributes 20 percent of its return as dividends and 45 percent as long-term capital gain. Dividends and capital gains are taxed at 15 percent. Bold numbers correspond approximately to breakeven pretax and after-tax values. 


\section{After-Tax Value for a Roth IRA with a Lump-Sum Withdrawal}

I can follow similar logic to find the after-tax value of a lump-sum withdrawal from a Roth IRA. Because withdrawals from Roth IRAs are free from tax and earnings accumulate tax free, the future value of each dollar in a Roth IRA after $n$ years is

$$
\mathrm{FV}_{\text {RothIRA }}=(1+r)^{n} \text {. }
$$

The after-tax value of the lump-sum withdrawal is the after-tax present value of this amount. The after-tax present value interest factor shows that the Roth IRA value is

$$
\begin{aligned}
\mathrm{PV}_{\text {RothIRA }} & =\frac{(1+r)^{n}}{\left(1+r^{*}\right)^{n}\left(1-T^{*}\right)+T^{*}} \\
& =(1+r)^{n}\left[\mathrm{PVIF}_{T X}\right] .
\end{aligned}
$$

Notice that this expression is simply the after-tax value of the traditional IRA in Equation 5.3 divided by $\left(1-T_{n}\right)$, making the effect on the after-tax value quite predictable. After-tax values for Roth IRAs will be greater than those for traditional IRAs, and the difference will be more pronounced for higher values. Furthermore, after-tax values for Roth IRAs will always be greater than 1 because the numerator of Equation 5.5 is always larger than the denominator for positive values of $n$ and $r$.

Table 5.4 displays after-tax values of a dollar invested in a Roth IRA. These values are independent of the contribution and withdrawal tax rates. But they do depend on the rate at which returns on the taxable equivalent are taxed and how those returns are taxed. So, Table 5.4 displays after-tax values when the taxable equivalent is fully taxed as ordinary income at 25 percent and at 33 percent. It also contains after-tax values for taxable equivalents that are taxed as a typical equity mutual fund. As predicted previously, all the values are greater than 1 and are larger than those for traditional IRAs. The difference is magnified for large values. Values are highest for a taxable equivalent fully taxed as ordinary income at 33 percent because the value of the Roth IRA tax shelter is greater when tax rates are high. The relative value is more than four times the pretax value for an investor with a 40-year time horizon and 12 percent expected return.

Values decrease substantially but remain large for taxpayers in the 25 percent tax bracket (Panel B). The tax burden is lightest, however, for a typical equity mutual fund that has a return that is only partially taxed at a preferential rate (Panel C). Nonetheless, the values remain greater than 1 , indicating that a dollar in a Roth IRA is always worth more than a dollar in a taxable account.

Because after-tax values of Roth IRAs are greater than traditional IRAs, one might be tempted to infer that contributions to a Roth IRA are always more beneficial, despite the analysis in Chapter 2. This thinking overlooks the fact that 
Table 5.4. After-Tax Value of a Roth IRA Withdrawn as a Lump Sum

\begin{tabular}{|c|c|c|c|c|c|c|c|c|}
\hline \multirow[b]{2}{*}{$r$} & \multicolumn{8}{|c|}{ Investment Horizon in Years $(n)$} \\
\hline & 5 & 10 & 15 & 20 & 25 & 30 & 35 & 40 \\
\hline \multicolumn{9}{|c|}{ A. Fully taxable discount rate for 33 percent tax bracket } \\
\hline $2 \%$ & 1.033 & 1.067 & 1.102 & 1.139 & 1.176 & 1.215 & 1.255 & 1.296 \\
\hline $4 \%$ & 1.066 & 1.136 & 1.211 & 1.291 & 1.376 & 1.467 & 1.564 & 1.667 \\
\hline $6 \%$ & 1.099 & 1.208 & 1.327 & 1.458 & 1.602 & 1.761 & 1.935 & 2.126 \\
\hline $8 \%$ & 1.132 & 1.281 & 1.450 & 1.640 & 1.857 & 2.101 & 2.378 & 2.691 \\
\hline $10 \%$ & 1.165 & 1.356 & 1.579 & 1.839 & 2.141 & 2.494 & 2.904 & 3.382 \\
\hline $12 \%$ & 1.197 & 1.433 & 1.716 & 2.054 & 2.459 & 2.944 & 3.525 & 4.220 \\
\hline $14 \%$ & 1.230 & 1.512 & 1.860 & 2.287 & 2.813 & 3.459 & 4.254 & 5.232 \\
\hline $16 \%$ & 1.262 & 1.593 & 2.011 & 2.539 & 3.205 & 4.045 & 5.106 & 6.446 \\
\hline $18 \%$ & 1.295 & 1.676 & 2.170 & 2.809 & 3.637 & 4.709 & 6.097 & 7.893 \\
\hline
\end{tabular}

B. Fully taxable discount rate for 25 percent tax bracket

$\begin{array}{rrrrrrrrr}2 \% & 1.025 & 1.050 & 1.076 & 1.103 & 1.131 & 1.159 & 1.188 & 1.217 \\ 4 \% & 1.049 & 1.101 & 1.156 & 1.213 & 1.273 & 1.336 & 1.402 & 1.472 \\ 6 \% & 1.074 & 1.153 & 1.238 & 1.330 & 1.428 & 1.534 & 1.647 & 1.768 \\ 8 \% & 1.098 & 1.206 & 1.324 & 1.453 & 1.596 & 1.752 & 1.924 & 2.112 \\ 10 \% & 1.122 & 1.258 & 1.412 & 1.584 & 1.777 & 1.993 & 2.236 & 2.508 \\ 12 \% & 1.145 & 1.312 & 1.503 & 1.721 & 1.971 & 2.258 & 2.586 & 2.963 \\ 14 \% & 1.169 & 1.366 & 1.596 & 1.866 & 2.181 & 2.548 & 2.978 & 3.481 \\ 16 \% & 1.192 & 1.420 & 1.693 & 2.017 & 2.404 & 2.865 & 3.415 & 4.070 \\ 18 \% & 1.215 & 1.475 & 1.792 & 2.176 & 2.643 & 3.211 & 3.900 & 4.736\end{array}$

C. Typical equity mutual fund discount rate

\begin{tabular}{rrrrrrrrr}
$2 \%$ & 1.015 & 1.029 & 1.043 & 1.058 & 1.071 & 1.085 & 1.099 & 1.113 \\
$4 \%$ & 1.029 & 1.057 & 1.084 & 1.111 & 1.137 & 1.164 & 1.190 & 1.216 \\
$6 \%$ & 1.042 & 1.083 & 1.122 & 1.161 & 1.199 & 1.238 & 1.276 & 1.315 \\
$8 \%$ & 1.055 & 1.108 & 1.159 & 1.209 & 1.259 & 1.310 & 1.361 & 1.414 \\
$10 \%$ & 1.067 & 1.131 & 1.193 & 1.255 & 1.317 & 1.380 & 1.446 & 1.513 \\
$12 \%$ & 1.079 & 1.154 & 1.227 & 1.300 & 1.374 & 1.451 & 1.531 & 1.614 \\
$14 \%$ & 1.091 & 1.176 & 1.259 & 1.343 & 1.430 & 1.521 & 1.617 & 1.718 \\
$16 \%$ & 1.101 & 1.197 & 1.290 & 1.386 & 1.486 & 1.592 & 1.704 & 1.824 \\
$18 \%$ & 1.112 & 1.217 & 1.321 & 1.428 & 1.542 & 1.663 & 1.793 & 1.933 \\
\hline
\end{tabular}

Notes: The mutual fund distributes 20 percent of its return as dividends and 45 percent as long-term capital gain. Dividends and capital gains are taxed at 15 percent.

each dollar contributed to a Roth IRA requires a larger after-tax investment than a contribution to a traditional IRA, which affords an investor the opportunity to invest the tax savings associated with a traditional IRA contribution. That taxable portion of the traditional IRA investment strategy is not considered in the after- 
tax valuation of traditional IRA assets. As a result, one should avoid confusing the after-tax valuation of TDA assets with the analysis for choosing between different types of TDAs.

\section{After-Tax Value for a Partially Deductible IRA with a Lump-Sum Withdrawal}

Income limitations preclude some investors from making fully deductible contributions to a traditional IRA. If investors make contributions to a tax-sheltered account in excess of the allowable deductible limits, they might make partially deductible or nondeductible contributions to an IRA account. The nondeductible portion of an IRA contribution earns returns on a tax-deferred basis until the funds are withdrawn, just like deductible contributions. When nondeductible IRA investments are withdrawn, the funds can be identified as either earnings or the original contribution. The earnings associated with nondeductible contributions are taxed as ordinary income when withdrawn. The original contribution, however, may be withdrawn free of tax. The future value of a dollar, a portion of which represents a nondeductible contribution, in a traditional IRA and withdrawn as a single cash flow can be expressed as

$$
\mathrm{FV}_{\text {PartDedIRA }}=(1+r)^{n}\left(1-T_{n}\right)+a T_{n},
$$

where $a$ is the nondeductible portion of the contribution. If all the contributions to the IRA account are nondeductible, $a$ is equal to 1 and the expression reduces to the future value of a nondeductible IRA in Equation 4.2. The first term is simply the future value of a traditional IRA with fully deductible contributions. The second term represents the basic tax adjustment associated with the nondeductible portion of the contribution when the funds are withdrawn. Once again, I can calculate the present value of this future sum using the after-tax present value interest factor, giving

$$
\begin{aligned}
\mathrm{PV}_{\text {PartDedIRA }} & =\frac{(1+r)^{n}\left(1-T_{n}\right)+a T_{n}}{\left(1+r^{*}\right)^{n}\left(1-T^{*}\right)+T^{*}} \\
& =\left[(1+r)^{n}\left(1-T_{n}\right)+a T_{n}\right]\left[\mathrm{PVIF}_{T X}\right] .
\end{aligned}
$$

A comparison of Equation 5.7 and Equation 5.3 shows that the after-tax value of nondeductible IRAs is greater than after-tax values of deductible IRAs because a portion of the tax was already paid when the contribution was made. The value differential, however, is only appreciable for short investment horizons and low returns because the tax relief from the extra term on the numerator, $a T_{n}$, is fixed and does not grow with the account's value over time. As the account value grows, the relative value of the original nondeductible contribution becomes smaller compared with the overall account value. Table 5.5 demonstrates this relationship for an investor in the 33 percent tax bracket who has made contributions that are 
Table 5.5. After-Tax Value of a Nondeductible IRA Withdrawn as a Lump Sum for an Investor in the 33 Percent Tax Bracket

\begin{tabular}{|c|c|c|c|c|c|c|c|c|}
\hline \multirow[b]{2}{*}{$r$} & \multicolumn{8}{|c|}{ Investment Horizon in Years $(n)$} \\
\hline & 5 & 10 & 15 & 20 & 25 & 30 & 35 & 40 \\
\hline \multicolumn{9}{|c|}{ A. Fully taxable discount rate (trader) } \\
\hline $2 \%$ & 1.001 & 1.004 & 1.009 & 1.016 & 1.025 & 1.035 & 1.048 & 1.062 \\
\hline $4 \%$ & 1.003 & 1.015 & 1.033 & 1.059 & 1.092 & 1.132 & 1.178 & 1.231 \\
\hline $6 \%$ & 1.007 & 1.032 & 1.072 & 1.127 & 1.197 & 1.281 & 1.379 & 1.493 \\
\hline $8 \%$ & 1.012 & 1.054 & 1.122 & 1.215 & 1.333 & 1.477 & 1.646 & 1.844 \\
\hline $10 \%$ & 1.019 & 1.081 & 1.183 & 1.322 & 1.500 & 1.718 & 1.980 & 2.290 \\
\hline $12 \%$ & 1.026 & 1.113 & 1.253 & 1.447 & 1.696 & 2.005 & 2.384 & 2.843 \\
\hline $14 \%$ & 1.035 & 1.148 & 1.332 & 1.587 & 1.920 & 2.340 & 2.865 & 3.515 \\
\hline $16 \%$ & 1.044 & 1.187 & 1.419 & 1.744 & 2.173 & 2.726 & 3.431 & 4.324 \\
\hline $18 \%$ & 1.054 & 1.229 & 1.514 & 1.916 & 2.456 & 3.166 & 4.091 & 5.292 \\
\hline \multicolumn{9}{|c|}{ B. Typical equity mutual fund discount rate (active investor) } \\
\hline $2 \%$ & 0.983 & 0.968 & 0.955 & 0.943 & 0.933 & 0.925 & 0.918 & 0.912 \\
\hline $4 \%$ & 0.968 & 0.944 & 0.925 & 0.912 & 0.903 & 0.898 & 0.897 & 0.898 \\
\hline $6 \%$ & 0.955 & 0.925 & 0.906 & 0.897 & 0.896 & 0.900 & 0.910 & 0.923 \\
\hline $8 \%$ & 0.944 & 0.911 & 0.897 & 0.896 & 0.904 & 0.920 & 0.942 & 0.969 \\
\hline $10 \%$ & 0.934 & 0.902 & 0.894 & 0.902 & 0.923 & 0.951 & 0.986 & 1.025 \\
\hline $12 \%$ & 0.925 & 0.896 & 0.896 & 0.915 & 0.947 & 0.988 & 1.035 & 1.087 \\
\hline $14 \%$ & 0.918 & 0.892 & 0.902 & 0.932 & 0.976 & 1.029 & 1.089 & 1.154 \\
\hline $16 \%$ & 0.911 & 0.891 & 0.910 & 0.952 & 1.008 & 1.073 & 1.145 & 1.224 \\
\hline $18 \%$ & 0.905 & 0.892 & 0.921 & 0.974 & 1.041 & 1.118 & 1.203 & 1.296 \\
\hline \multicolumn{9}{|c|}{ C. Completely deferred capital gains discount rate (passive investor) } \\
\hline $2 \%$ & 0.983 & 0.967 & 0.952 & 0.938 & 0.925 & 0.914 & 0.903 & 0.893 \\
\hline $4 \%$ & 0.967 & 0.939 & 0.914 & 0.893 & 0.876 & 0.861 & 0.849 & 0.838 \\
\hline $6 \%$ & 0.953 & 0.915 & 0.885 & 0.862 & 0.844 & 0.830 & 0.820 & 0.812 \\
\hline $8 \%$ & 0.940 & 0.895 & 0.863 & 0.840 & 0.824 & 0.813 & 0.805 & 0.800 \\
\hline $10 \%$ & 0.928 & 0.878 & 0.845 & 0.824 & 0.811 & 0.802 & 0.797 & 0.794 \\
\hline $12 \%$ & 0.917 & 0.864 & 0.832 & 0.814 & 0.803 & 0.797 & 0.793 & 0.791 \\
\hline $14 \%$ & 0.907 & 0.852 & 0.822 & 0.806 & 0.798 & 0.793 & 0.791 & 0.790 \\
\hline $16 \%$ & 0.898 & 0.843 & 0.815 & 0.801 & 0.794 & 0.791 & 0.790 & 0.789 \\
\hline $18 \%$ & 0.889 & 0.834 & 0.809 & 0.797 & 0.792 & 0.790 & 0.789 & 0.789 \\
\hline
\end{tabular}

Notes: The investor maintains the same marginal tax rate throughout the investment horizon. The mutual fund distributes 20 percent of its return as dividends and 45 percent as long-term capital gain. Dividends and capital gains are taxed at 15 percent. Bold numbers correspond approximately to breakeven pretax and after-tax values.

completely nondeductible. For example, in Panel A, after-tax values for the nondeductible IRA are more than 30 percent larger than after-tax values for the deductible 
IRA for an investor expecting a 4 percent return over a 10-year investment horizon. But for investors expecting a 12 percent return over a 35-year or 40-year investment horizon, the after-tax values are nearly identical. The relationship between these relative values is basically unchanged for the other taxing schemes in Panel B and Panel C. Again, the intuition for this result is that as the nominal value of the account grows over time, the size of the nondeductible contribution (which is exempt from withdrawal tax) decreases in relation to the nominal value of the account.

\section{After-Tax Value for a Traditional IRA Withdrawn as an Annuity}

The preceding analysis derives after-tax values of tax-sheltered accounts for a single withdrawal. Typically, however, investors draw on their retirement assets more evenly over time. One would expect after-tax values to increase if withdrawals are extended over a period of time rather than taken as a lump sum at the beginning of the withdrawal period because the remaining assets are sheltered from taxes for a longer period of time. By contrast, after-tax values for annuitized withdrawals should be less than lump-sum withdrawals at the end of the annuity period. The analysis can be modified to accommodate annuity-style withdrawal patterns that more closely resemble typical retirement behavior. One approach is to calculate the after-tax value for a series of single payments. But this procedure is cumbersome and time consuming. A model that specifically accommodates annuitized withdrawal patterns would yield more expedient results and heuristic guidance for investors and their advisors.

One way to view withdrawing funds as an annuity instead of as a single cash flow is to consider the duration of the cash flow stream. Duration is the weightedaverage timing of the payments using present values as weights. In the case of the single withdrawal, the duration of the cash flow stream is simply the time when the withdrawal occurs. The duration of an annuity having the same time horizon is significantly less than half the time period over which an annuity withdrawal occurs, particularly for long time horizons. Because the weights are larger for nearer term payments, the duration of an annuity is much shorter than the duration of a single cash flow at the end of the annuity period. Therefore, after-tax values of taxsheltered accounts for annuitized withdrawals should be much less than values for single cash flows at the end of the same period.

The first step to valuing an annuitized pattern of withdrawals from a taxsheltered account is to find the annuity payment that can be sustained by the current value of the traditional IRA over $m$ years while earning a pretax return of $r$. The annuity payment is calculated using the standard time-value-of-money techniques involving the present value interest factor of an annuity (PVIFA).

Specifically, the before-tax annuity payment supported by a dollar in a fully deductible IRA over $m$ years is 


$$
\begin{aligned}
\text { PMT } & =\frac{1}{(1 / r)-1 /\left[r(1+r)^{m}\right]} \\
& =\frac{1}{\text { PVIFA }_{r, m}},
\end{aligned}
$$

where the denominator is the well-known present value interest factor for an annuity for return $r$ over $m$ years. This annuity withdrawal is fully taxable as ordinary income at the rate prevailing during retirement or whenever withdrawals are made starting at time $n$. The after-tax annuity payment is determined by multiplying the value in Equation 5.8 by $\left(1-T_{n}\right)$. Knowing the after-tax annuity payment, I can determine the amount of money (held in a taxable account) that would be required to generate the same after-tax payments over $m$ years. This value is the taxable equivalent. An example may help illustrate this point.

Consider a 60 -year old investor with $\$ 1,000,000$ invested in a traditional IRA with an expected return of 10 percent. Her goal is to withdraw funds evenly in the form of an annuity from age 71 to age 90 , a 20-year period. Through age 70 , the traditional IRA will grow in value to $\$ 2,593,742$, which will sustain pretax withdrawals of $\$ 304,660$ over the next 20 years until age 90.5 If she is in the 33 percent tax bracket, the after-tax withdrawals will be $\$ 204,122$. One approach to determining the taxable equivalent (which becomes algebraically necessary with the complex tax structure of a mutual fund or diversified equity portfolio) is to calculate the future value of the after-tax withdrawals as of age 90 using an after-tax future value interest factor of an annuity for a taxable investment over 20 years $\left(\mathrm{FVIFA}_{T X, r, m}\right)$. Appendix $\mathrm{D}$ shows that the future value interest factor of an annuity of a taxable investment at $r$ percent over $m$ years is

$$
\text { FVIFA }_{T X, r, m}=\frac{\left(1+r^{*}\right)^{m}-1}{r^{*}}\left(1-T^{*}\right)+m T^{*} .
$$

Discounting this value back to age 60 using the after-tax present value interest factor for a taxable investment for 30 years $\left(\mathrm{PVIF}_{T X, r, n+m}\right)$ from Equation 5.2 produces the taxable equivalent. Figure 5.1 illustrates this example using a summarized four-step process.

Step 1: Calculate the pretax account value at the beginning of the annuity withdrawal period at time $n$. The $\$ 1,000,000$ corpus for the 60 -year-old investor will grow to $\$ 2,593,742$ by age 70 .

Step 2: Calculate the after-tax annuity payment that supports the pretax account value from Step 1 by multiplying Equation 5.8 by $\left(1-T_{n}\right)$. Her $\$ 2,593,742$ account supports after-tax withdrawals of $\$ 204,122$ from age 71 until age 90 .

$5 \mathrm{FV}_{10}=\$ 1,000,000(1.10) 10=\$ 2,593,742$. Using this figure as the present value of an annuity and solving for the payment, $\$ 2,593,742=$ PMT[PVIFA $\left._{20,10 \%}\right]=$ PMT[8.5136]; PMT $=\$ 304,660$. 
Figure 5.1. Example of Four-Step After-Tax Valuation Method for an Annuity Withdrawal Pattern

Age

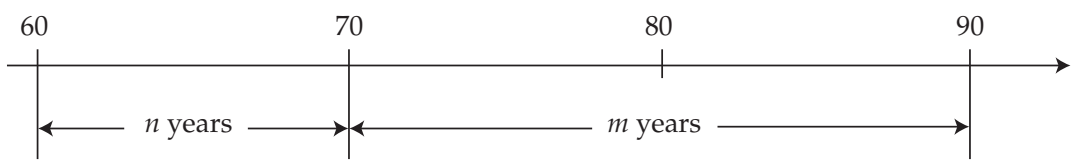

$\$ 1,000,000$

$\$ 2,593,742$

$$
\operatorname{PMT}\left(1-T_{n}\right)
$$

$\$ 204,122 \$ 204,122$

$\$ 204,122 \$ 204,122$

$\stackrel{\mathrm{FVIFATX}, r, m}{\longrightarrow} \$ 8,099,002$

PVIFTX, $r, n+m$

Step 3: Calculate the future value of these withdrawals had they been invested in a taxable account for $m$ years using the $\mathrm{FVIFA}_{T X, r, m}$ from Equation 5.9. The investor's after-tax withdrawals have a future value of $\$ 8,099,002$ as of age 90 .

Step 4: Calculate the present value over $n+m$ years using the after-tax present value interest factor that accommodates different taxable components of an investment's return $\left(\mathrm{PVIF}_{T X, r, n+m}\right)$ from Equation 5.2. If the investor had $\$ 1,157,441$ in a taxable account at age 60 , she could replicate the same after-tax cash flows as the $\$ 1,000,000$ she currently holds in her traditional IRA.

This four-step process can be condensed into a single equation that yields the after-tax value of a traditional IRA if one assumes withdrawals are made as an annuity for $m$ years beginning $n+1$ years from now:

$$
\begin{aligned}
\mathrm{PV}_{\text {TradIRAAnn }} & =(1+r)^{n}\left[\frac{1-T_{n}}{(1 / r)-1 /\left[r(1+r)^{m}\right]}\right]\left[\frac{\frac{\left(1+r^{*}\right)^{m}-1}{r^{*}}\left(1-T^{*}\right)+m T^{*}}{\left(1+r^{*}\right)^{n+m}\left(1-T^{*}\right)+T^{*}}\right] \\
& =(1+r)^{n}\left[\frac{1-T_{n}}{\text { PVIFA }_{r, m}}\right]\left[\operatorname{PVIFA}_{T X, r, m, n}\right] .
\end{aligned}
$$

This equation looks quite onerous, but its individual parts are simply the four steps from the forgoing analysis. The first term is the future value of each dollar in the traditional IRA as of the beginning of the annuity withdrawal period in $n$ years 
as in Step 1. The second term is the annuity payment after-withdrawal taxes that can be generated from each dollar in a traditional IRA starting in $n+1$ years and lasting for $m$ years from Step 2. The numerator of the third term is the future value interest factor of the $m$-year annuity for a taxable investment $\left(\mathrm{FVIFA}_{T X, r, m}\right)$ from Step 3. The denominator of the third term brings this value back to the present over $n+m$ years, according to Step 4 . Taken as a whole, the third term incorporates Step 3 and Step 4. It can, therefore, be interpreted as the present value interest factor of an $m$-year annuity drawn from a taxable investment beginning in $n+1$ years, or PVIFA $_{T X, r, m, n}$.

Table 5.6 presents some examples of after-tax values of a traditional IRA for a typical equity mutual fund investor in the 28 percent tax bracket. Several observations can be made from this table. First, the after-tax values can be either greater than or less than their pretax accumulations. Second, the after-tax values seem to be relatively insensitive to the withdrawal horizon, $m$. For a 10-year withdrawal period, after-tax values in Panel A range from about 74 percent of the pretax accumulation for short investment horizons and low returns to 144 percent of the pretax accumulation for long investment horizons and high returns. The corresponding values for a 20-year withdrawal period in Panel B range from 75 percent to 145 percent, respectively. As expected, the after-tax value increases as the withdrawal period lengthens, but the difference is quite modest because the duration of the annuity increases at a decreasing rate as the withdrawal period increases. Third, the after-tax values are quite similar to those for lump-sum distributions. Comparing the after-tax values in Table 5.6 with the after-tax values for a lumpsum withdrawal in Panel B of Table 5.1, one sees that the values are quite similar. Therefore, the after-tax value of traditional IRAs appears to be insensitive to the withdrawal pattern.

This result appears inconsistent with prior literature showing that annuitized withdrawals significantly decrease the after-tax value of tax-sheltered accounts compared with single withdrawals over the same time period (e.g., Horan 2002). The different conclusions stem from differences in the model. The model presented here is more flexible in that it allows the investment horizon, $n$, to differ from the withdrawal period, $m$. The previous research constrained the investment horizon to be equal to the withdrawal period (i.e., $n=m$ ). It indicated that if an investor has a 20-year investment horizon and commences withdrawals in the first year of the 20-year period, the after-tax value is far less than if the investor withdrew the entire accumulation at the end of 20 years. The results here are different. They show that if assets remain invested in the traditional IRA for 20 years, the after-tax value is insensitive to whether the entire accumulation is withdrawn as a lump sum at the end of 20 years or whether it is withdrawn as an annuity over the following 10 years. When the opportunity cost of capital is fully taxed as ordinary income, after-tax 
Table 5.6. After-Tax Value of a Traditional IRA Withdrawn as an Annuity for an Equity Mutual Fund Investor in the 28 Percent Tax Bracket

\begin{tabular}{|c|c|c|c|c|c|c|c|c|}
\hline \multirow[b]{2}{*}{$r$} & \multicolumn{8}{|c|}{ Investment Horizon in Years $(n)$} \\
\hline & 5 & 10 & 15 & 20 & 25 & 30 & 35 & 40 \\
\hline \multicolumn{9}{|c|}{ A. 10-year withdrawal horizon $(m=10)$} \\
\hline $2 \%$ & 0.741 & 0.751 & 0.761 & 0.771 & 0.781 & 0.790 & 0.800 & 0.810 \\
\hline $4 \%$ & 0.760 & 0.779 & 0.797 & 0.816 & 0.834 & 0.852 & 0.870 & 0.889 \\
\hline $6 \%$ & 0.776 & 0.803 & 0.830 & 0.856 & 0.883 & 0.909 & 0.937 & 0.964 \\
\hline $8 \%$ & 0.791 & 0.825 & 0.859 & 0.894 & 0.929 & 0.965 & 1.001 & 1.039 \\
\hline $10 \%$ & 0.804 & 0.845 & 0.887 & 0.930 & 0.974 & 1.019 & 1.066 & 1.115 \\
\hline $12 \%$ & 0.815 & 0.864 & 0.913 & 0.964 & 1.018 & 1.073 & 1.132 & 1.193 \\
\hline $14 \%$ & 0.826 & 0.882 & 0.939 & 0.998 & 1.061 & 1.128 & 1.198 & 1.272 \\
\hline $16 \%$ & 0.836 & 0.898 & 0.963 & 1.032 & 1.104 & 1.182 & 1.265 & 1.354 \\
\hline $18 \%$ & 0.845 & 0.914 & 0.987 & 1.064 & 1.148 & 1.237 & 1.333 & 1.437 \\
\hline \multicolumn{9}{|c|}{ B. 20-year withdrawal horizon $(m=20)$} \\
\hline $2 \%$ & 0.750 & 0.759 & 0.769 & 0.778 & 0.788 & 0.797 & 0.807 & 0.816 \\
\hline $4 \%$ & 0.773 & 0.791 & 0.808 & 0.826 & 0.844 & 0.861 & 0.879 & 0.897 \\
\hline $6 \%$ & 0.791 & 0.817 & 0.842 & 0.868 & 0.893 & 0.920 & 0.947 & 0.974 \\
\hline $8 \%$ & 0.807 & 0.839 & 0.872 & 0.905 & 0.940 & 0.975 & 1.012 & 1.050 \\
\hline $10 \%$ & 0.819 & 0.859 & 0.899 & 0.941 & 0.985 & 1.030 & 1.077 & 1.126 \\
\hline $12 \%$ & 0.830 & 0.877 & 0.925 & 0.975 & 1.028 & 1.084 & 1.143 & 1.204 \\
\hline $14 \%$ & 0.840 & 0.893 & 0.949 & 1.009 & 1.072 & 1.138 & 1.209 & 1.284 \\
\hline $16 \%$ & 0.848 & 0.909 & 0.973 & 1.041 & 1.114 & 1.192 & 1.276 & 1.365 \\
\hline $18 \%$ & 0.856 & 0.923 & 0.996 & 1.073 & 1.157 & 1.247 & 1.344 & 1.448 \\
\hline
\end{tabular}

Notes: The investor maintains the same marginal tax rate throughout the investment horizon. The mutual fund distributes 20 percent of its return as dividends and 45 percent as long-term capital gain. Dividends and capital gains are taxed at 15 percent. Bold numbers correspond approximately to breakeven pretax and after-tax values.

values remain insensitive to the withdrawal pattern, although the effect of withdrawal patterns is somewhat more pronounced.

\section{After-Tax Value for a Roth IRA Withdrawn as an Annuity}

The after-tax value of a Roth IRA if one assumes annuitized withdrawals follows the same logic used with the traditional IRA with only a slight modification. The pretax annuity payment over $m$ years supported by a Roth IRA account is the same as that for the traditional IRA expressed by Equation 5.8. But because withdrawals from Roth IRAs are not taxed, this value is the after-tax withdrawal as well. Calculating the future value of this annuity over $m$ years and discounting it back $n+m$ years yield 


$$
\mathrm{PV}_{\text {RothIRAAnn }}=\left[\frac{(1+r)^{n}}{\mathrm{PVIFA}_{r, m}}\right]\left[\mathrm{PVIFA}_{T X, r, m, n}\right] .
$$

This expression is quite similar to Equation 5.10. The value is larger, however, because the numerator is not multiplied by $1-T_{n}$. This difference reflects the fact that withdrawals from traditional IRAs are taxable whereas withdrawals from Roth IRAs are not. Therefore, the after-tax values of Roth IRAs and traditional IRAs differ only by the constant $1-T_{n}$. Because Roth IRA withdrawals are not taxed, the after-tax value of a dollar in a Roth IRA is always greater than 1 . The other inferences made previously for traditional IRAs, however, hold for Roth IRAs as well. That is, the length of the withdrawal period does not have a significant effect on the after-tax value of a Roth IRA account as can be seen in Table 5.7. Consequently, the after-tax values for the Roth IRA withdrawn as an annuity are quite similar to those in Table 5.4, Panel C, which assumes a lump-sum withdrawal.

Table 5.7. After-Tax Value of a Roth IRA Withdrawn as an Annuity for an Equity Mutual Fund Investor in the 28 Percent Tax Bracket

\begin{tabular}{|c|c|c|c|c|c|c|c|c|}
\hline \multirow[b]{2}{*}{$r$} & \multicolumn{8}{|c|}{ Investment Horizon in Years $(n)$} \\
\hline & 5 & 10 & 15 & 20 & 25 & 30 & 35 & 40 \\
\hline \multicolumn{9}{|c|}{ A. 10-year withdrawal horizon $(m=10)$} \\
\hline $2 \%$ & 1.029 & 1.043 & 1.057 & 1.071 & 1.084 & 1.098 & 1.111 & 1.124 \\
\hline $4 \%$ & 1.055 & 1.081 & 1.107 & 1.133 & 1.158 & 1.183 & 1.209 & 1.234 \\
\hline $6 \%$ & 1.078 & 1.115 & 1.152 & 1.189 & 1.226 & 1.263 & 1.301 & 1.339 \\
\hline $8 \%$ & 1.098 & 1.146 & 1.193 & 1.241 & 1.290 & 1.340 & 1.391 & 1.443 \\
\hline $10 \%$ & 1.116 & 1.174 & 1.232 & 1.291 & 1.352 & 1.415 & 1.481 & 1.549 \\
\hline $12 \%$ & 1.133 & 1.200 & 1.269 & 1.340 & 1.413 & 1.491 & 1.572 & 1.657 \\
\hline $14 \%$ & 1.148 & 1.224 & 1.304 & 1.387 & 1.474 & 1.566 & 1.664 & 1.767 \\
\hline $16 \%$ & 1.161 & 1.248 & 1.338 & 1.433 & 1.534 & 1.642 & 1.757 & 1.880 \\
\hline $18 \%$ & 1.174 & 1.270 & 1.371 & 1.478 & 1.594 & 1.718 & 1.852 & 1.996 \\
\hline \multicolumn{9}{|c|}{ B. 20-year withdrawal horizon $(m=20)$} \\
\hline $2 \%$ & 1.041 & 1.055 & 1.068 & 1.081 & 1.094 & 1.107 & 1.120 & 1.133 \\
\hline $4 \%$ & 1.073 & 1.098 & 1.123 & 1.147 & 1.172 & 1.196 & 1.221 & 1.246 \\
\hline $6 \%$ & 1.099 & 1.134 & 1.169 & 1.205 & 1.241 & 1.277 & 1.315 & 1.353 \\
\hline $8 \%$ & 1.120 & 1.165 & 1.211 & 1.258 & 1.305 & 1.355 & 1.405 & 1.458 \\
\hline $10 \%$ & 1.138 & 1.193 & 1.249 & 1.307 & 1.368 & 1.431 & 1.496 & 1.564 \\
\hline $12 \%$ & 1.153 & 1.218 & 1.285 & 1.355 & 1.428 & 1.506 & 1.587 & 1.673 \\
\hline $14 \%$ & 1.166 & 1.240 & 1.319 & 1.401 & 1.488 & 1.581 & 1.679 & 1.783 \\
\hline $16 \%$ & 1.178 & 1.262 & 1.351 & 1.446 & 1.548 & 1.656 & 1.772 & 1.896 \\
\hline $18 \%$ & 1.189 & 1.282 & 1.383 & 1.491 & 1.607 & 1.732 & 1.866 & 2.012 \\
\hline
\end{tabular}

Notes: The investor maintains the same marginal tax rate throughout the investment horizon. The mutual fund distributes 20 percent of its return as dividends and 45 percent as long-term capital gain. Dividends and capital gains are taxed at 15 percent. 


\section{After-Tax Value for a Partially Deductible IRA Withdrawn as an Annuity}

A similar process yields the after-tax value of a partially deductible IRA withdrawal in annuity form. The difference is that a portion of the annuitized withdrawals is taxable and a portion is not. The nondeductible portion, $a$, of the initial contribution is not taxed upon withdrawal. If one assumes that the taxable and nontaxable portion of the withdrawals are applied on a pro rata basis to each payment over the life of the annuity, the after-tax value of a partially deductible IRA is

$$
\mathrm{PV}_{\text {PartIRAAnn }}=\left[\frac{(1+r)^{n}\left(1-T_{n}\right)+a T_{n}}{\mathrm{PVIFA}_{r, m}}\right]\left[\mathrm{PVIFA}_{T X, r, m, n}\right] .
$$

The drawback of this formulation is that investors will realistically withdraw the nondeductible contribution first because it is tax free. Investors would typically commence taxable withdrawals only after the tax-free withdrawals have been exhausted. For long time horizons, however, the nondeductible portion of the initial contribution is typically quite small relative to the future accumulation as I discussed earlier in this chapter. Therefore, Equation 5.12 is quite accurate even if actual withdrawals are not taxed on a pro rata basis.

\section{Summary}

Pretax and after-tax values of assets held in tax-deferred accounts can differ substantially. For both traditional IRAs and partially deductible IRAs, the after-tax value can be either greater than or less than the pretax accumulation. For Roth IRAs, the after-tax value is always greater than the pretax accumulation and the traditional IRA after-tax values because withdrawals from Roth IRAs are not taxed. In any case, after-tax values increase with the pretax return and the investment horizon because both these factors increase the value of the tax shield offered by TDAs.

Previous research indicates that withdrawal patterns affect after-tax values significantly. But the more flexible model presented here suggests otherwise. If withdrawals are taken as an annuity over a period of time rather than as a lump sum at the beginning of the withdrawal period, the value of the tax shelter increases. The differential is modest, however, and can be safely ignored in most cases. Valuing tax-sheltered assets on an after-tax basis can be an important factor in appropriately calculating an investor's asset allocation, determining credit limits for loans secured by tax-sheltered assets, and valuing assets for litigious purposes. ${ }^{6}$ I will explore this notion more thoroughly in Chapter 7.

6 Reichenstein (2001) and Horan (2002) provided different methods of calculating an investor's aftertax asset allocation and showed how the asset allocation picture can be dramatically affected by ignoring after-tax values. 


\section{Early Withdrawal Penalties and Breakeven Time Horizons}

The U.S. federal government uses tax-advantaged savings accounts to encourage saving for specific purposes. The different IRA accounts are, of course, designed to encourage retirement savings. More recently, Section 529 plans have been developed as TDAs that encourage saving for education, and President Bush has proposed health care savings accounts to encourage saving for medical expenses. These accounts impose a penalty (typically 10 percent) on nonqualified withdrawals - that is, withdrawals for purposes other than that intended by the specific account. Withdrawals from IRA accounts before age 591/2, for example, are subject to a 10 percent withdrawal penalty. ${ }^{1}$ Although an early withdrawal penalty encourages an investor to keep funds in a retirement account once they have been invested, it may also discourage an investor from saving in the first place.

An important question then for taxpayers considering a tax-advantaged account is: How long must funds be invested in a retirement account for the tax advantages to outweigh the 10 percent penalty should funds need to be withdrawn early? The answer is called the breakeven time horizon or the breakeven holding period. All else being equal, savers facing short breakeven time horizons should be more inclined to commit money to a tax-advantaged savings account, and those with longer breakeven time horizons should be more circumspect about saving via a potentially restrictive investment account. In fact, investors with short breakeven holding periods may even choose to use an IRA purposefully for nonretirement investment goals, knowing they would face an early withdrawal penalty. Similarly, they might choose to use a Section 529 plan for noneducational investment goals.

The breakeven holding period depends in part on the tax structure of the taxable alternative. If the taxable investment option is heavily taxed, then the breakeven point is relatively short because the TDA's tax-sheltering properties become relatively more valuable even in the presence of the early withdrawal penalty. But if the taxable alternative has some inherent tax-sheltering properties (such as an index mutual fund), the breakeven time horizon can be prohibitively long. If tax rates decrease, however, when the funds would be withdrawn from the TDA, breakeven

1 Exceptions do exist. For example, withdrawals for a first-time home purchase or to pay for an education can be exempt from the penalty. See Table 1.2 for more information. 
points can be as short as a few years. Because early withdrawals from Roth IRAs can be taxed as ordinary income in addition to being penalized, their breakeven time horizons are quite long.

Many researchers have investigated the breakeven holding period over the past 25 years. ${ }^{2}$ Early research assumed simplified tax structures. ${ }^{3}$ More recently, authors have noted the need to incorporate more realistic sophistication into the model to capture important complexities of the tax code. 4 This chapter, as those that preceded it, allows portions of the investment return to be taxed separately and closely follows the development set forth in Horan (2004).

\section{Breakeven Investment Horizon for a Traditional IRA}

An investor is indifferent between a taxable investment and a traditional IRA investment with an early withdrawal penalty when the accumulation in the taxable investment equals that for the traditional IRA less an early withdrawal penalty of, say, $\phi$. Recall from Chapter 2 that the future accumulation of a traditional IRA depends in part on whether the pretax contribution is less than or greater than the contribution limit, $L$. I begin by examining the scenario in which the pretax contribution is less than or equal to the contribution limit (i.e., $I_{B T} \leq L$ ). In this case, setting the future value of a taxable investment equal to the future value of a traditional IRA less an early withdrawal penalty of $\phi$ yields

$$
\begin{aligned}
\mathrm{FV}_{T X} & =\mathrm{FV}_{\text {TradIRAPen }} \\
\left(1-T_{o}\right)\left[\left(1+r^{*}\right)^{n}\left(1-T^{*}\right)+T^{*}\right] & =(1+r)^{n}\left(1-T_{n}-\phi\right) .
\end{aligned}
$$

Interestingly, the scenario in which the pretax contribution is maximized, namely $I_{B T}=L /\left(1-T_{o}\right)$, yields the same condition because any investment in excess of the contribution limit is assumed to be invested in a taxable instrument, which is treated in the same manner as the taxable investment option. Treating them differently would not produce a meaningful comparison. Therefore, the size of the contribution does not affect the breakeven time horizon.

Simplified Ordinary Income Tax Structure. Solving for the breakeven time horizon in Equation 6.1 requires an iterative process of trial and error. But when the tax structure is simplified such that the investment returns in the taxable account are fully taxed each year as ordinary income, Equation 6.1 permits a direct solution.

\footnotetext{
2 Burgess and Madeo (1980), Bogan and Bogan (1982), and O'Neil, Saftner, and Dillaway (1983) are among the first to address the breakeven time horizon in the presence of an early withdrawal penalty. 3 For example, Bogan and Bogan (1982), Mano and Burr (1984), and Doyle (1984).

4 Prakash and Smyser (2003) followed an approach identical to Bogan and Bogan (1982). But Benvin (2003) and Kitces (2003) pointed out that the investment return in their model was taxed entirely as ordinary income and could provide misleading results.
} 
If the taxable account is fully taxed, then $p_{o i}=1, p_{c g}=0, T^{*}=0$, and $r^{*}=r\left(1-t_{o i}\right)$, in which case the breakeven time horizon can be expressed as

$$
n^{*}=\ln \left[\frac{\left(1-T_{n}-\phi\right)}{\left(1-T_{o}\right)}\right] / \ln \left[\frac{1+r\left(1-t_{o i}\right)}{1+r}\right] .
$$

See Appendix E for a derivation. This more straightforward expression offers the opportunity for intuitive insight. A withdrawal after time $n^{*}$ results in a higher after-tax accumulation for a traditional IRA with the early withdrawal penalty than for the taxable investment. When the term in brackets in the numerator is equal to 1 , then the breakeven time horizon is zero. In other words, when $\left(1-T_{n}-\phi\right)=(1$ $\left.-T_{o}\right)$, an investor should use a tax-advantaged account even if funds are withdrawn immediately, thereby incurring a penalty. The same is true when $\left(1-T_{n}-\phi\right)>(1$ $-T_{o}$ ). In this case, the breakeven time horizon is negative. (Note that for any positive tax rate, $t_{o i}$, the fraction in brackets in the denominator is less than 1 , making its natural $\log$ negative.) The numerator is positive when the fraction in its brackets is greater than 1 . When the numerator is positive and the denominator is negative, the breakeven time horizon is negative and an investor should use a tax-advantaged account even if funds are withdrawn immediately, thereby incurring a penalty. The breakeven time horizon is positive when $\left(1-T_{n}-\phi\right)<\left(1-T_{0}\right)$.

Another way to interpret this relationship is that the breakeven point depends on the contribution tax rate compared with the withdrawal tax rate. As the withdrawal tax rate decreases, the breakeven point decreases, making the traditional IRA more attractive to investors despite an early withdrawal penalty. This result is reasonable because the traditional IRA allows a taxpayer to avoid taxes now in exchange for paying them later. A declining tax rate works to the taxpayer's advantage in this case. Put differently, when the withdrawal tax rate plus the early withdrawal penalty is less than or equal to the current tax rate (i.e., $T_{n}+\phi \leq T_{\text {o }}$ ), the TDA is always a better investment. When $T_{n}+\phi>T_{0}$ some positive holding period is required to outweigh the early withdrawal penalty.

Another interesting relationship is that as $t_{o i}$ approaches zero, the absolute value of the denominator becomes infinitesimally small and the breakeven holding period becomes infinitely large. This relationship suggests two things. First, the traditional IRA becomes less attractive at low tax rates because its tax advantages become relatively less valuable. Second, for low tax rates, a small change in the tax rate will produce large changes in the breakeven time horizon.

Simplified Capital Gain Tax Structure. A direct solution is also possible when the entire investment return is in the form of capital gain that is realized and taxed at the end of the period. In this case, $p_{o i}=p_{c g}=0$, which makes $r^{*}=r$ and $T^{*}=t_{c g}$. Substituting these values into the breakeven condition in Equation 6.1 and solving for $n$ yields a breakeven time horizon of 


$$
n^{*}=\ln \left[\frac{t_{c g}\left(1-T_{o}\right)}{\left(1-T_{n}-\phi\right)-\left(1-T_{o}\right)\left(1-t_{c g}\right)}\right] / \ln (1+r) .
$$

A derivation is found in Appendix E. This expression produces longer breakeven points than those that assume that investment returns are fully taxed as ordinary income because deferring capital gains tax until the end of the investment period achieves some of the same tax-shelter benefits of the traditional IRA, thereby decreasing some of its comparative advantage.

Table 6.1 displays the breakeven time horizons for a traditional IRA investment with a 10 percent early withdrawal penalty for various tax rates and annual returns. Tax rates are assumed to be constant over the investment period from contribution to withdrawal. It uses average distribution rates of mutual funds for ordinary income and capital gains reported by Crain and Austin (1997) and Shoven and Sialm (2003) and marginal tax rates established by the JGTRRA of 2003 passed by Congress in May 2003. Several trends are apparent. According to Panel A, which assumes the taxable return is fully taxed as ordinary income, the breakeven time horizon is quite sensitive to the annual return and decreases at a decreasing rate as the investment return increases. The reasoning is that the value of the tax deferral associated with an IRA is greater as the pretax return increases. This panel is appropriate for individuals investing in fixed-income securities or equity portfolios with high turnover that create short-term capital gains. Another trend evident in Panel A is that breakeven time horizons are much shorter for investors in high tax brackets. It decreases rapidly as the investor's initial tax rate increases because the initial tax deduction of the traditional IRA is more valuable for high-tax-bracket investors.

Similar trends exist in Panel B, which assumes the taxable return is taxed as a typical mutual fund, which might be appropriate for active investors. The breakeven points are substantially higher than those in Panel A, doubling and tripling in some scenarios, suggesting that the breakeven time horizon is quite sensitive to the taxing scheme. The breakeven points are longer because the relative advantage of the IRA tax shelter is greater when the investment is fully taxed as ordinary income as compared with a mutual fund investment that has some inherent tax advantages. It should be noted that if an investor stays in the 10 percent or 15 percent tax brackets, dividends and capital gains are taxed at only 5 percent.

It is also important to note that IRA withdrawals after the age of $591 / 2$ are penalty free. Consequently, very high breakeven holding periods in Table 6.1 have no practical significance because the early withdrawal penalty disappears at age 591/2. In such cases, the IRA account without the penalty dominates the taxable investment, but the taxable investment dominates if IRA funds are withdrawn early. One may be surprised to find that the breakeven time horizons in Panel B increase slightly for investors in the 35 percent tax bracket. The reason is that for investors 
Table 6.1. Breakeven Time Horizon for a Traditional IRA with Early Withdrawal Penalty for Constant Tax Rates

\begin{tabular}{lrrrrrrr}
\hline \multicolumn{7}{c}{ Annual Return $(r)$} \\
\cline { 2 - 8 }$T_{o}=T_{n}$ & $4 \%$ & $6 \%$ & $8 \%$ & $10 \%$ & $12 \%$ & $14 \%$ & $16 \%$ \\
\hline A. Return fully taxed & as & ordinary & income & at $t_{\text {oi }}=$ & $T_{0}$ (trader) \\
$15 \%$ a & 65.0 & 44.2 & 33.7 & 27.5 & 23.3 & 20.3 & 18.1 \\
$25 \%$ & 14.8 & 10.0 & 7.7 & 6.2 & 5.3 & 4.6 & 4.1 \\
$28 \%$ & 13.8 & 9.4 & 7.1 & 5.8 & 4.9 & 4.3 & 3.8 \\
$33 \%$ & 12.7 & 8.6 & 6.5 & 5.3 & 4.5 & 3.9 & 3.5 \\
$35 \%$ & 12.3 & 8.3 & 6.4 & 5.2 & 4.4 & 3.8 & 3.4
\end{tabular}

B. Tax structure for a typical growth mutual fund (active investor)

$\begin{array}{lrrrrrrr}15 \% \mathrm{a} & 86.0 & 58.4 & 44.6 & 36.3 & 30.8 & 26.9 & 23.9 \\ 25 \% & 28.1 & 19.1 & 14.5 & 11.8 & 10.0 & 8.7 & 7.7 \\ 28 \% & 29.6 & 20.0 & 15.3 & 12.4 & 10.5 & 9.1 & 8.1 \\ 33 \% & 32.3 & 21.9 & 16.7 & 13.6 & 11.5 & 10.0 & 8.9 \\ 35 \% & 33.5 & 22.7 & 17.3 & 14.1 & 11.9 & 14.0 & 9.2\end{array}$

C. Return fully taxed as deferred capital gain (passive investor)

\begin{tabular}{lccccccc}
$15 \% \mathrm{a}, \mathrm{b}$ & - & - & - & - & - & - & - \\
$25 \%$ & 56.0 & 37.7 & 28.5 & 23.1 & 19.4 & 16.8 & 14.8 \\
$28 \%$ & 66.4 & 44.7 & 33.8 & 27.3 & 23.0 & 19.9 & 17.5 \\
$33 \%$ & 135.2 & 91.0 & 68.9 & 55.6 & 46.8 & 40.5 & 35.7 \\
$35 \% \mathrm{~b}$ & - & - & - & - & - & - & - \\
\hline
\end{tabular}

Notes: The investor maintains the same marginal tax rate throughout the investment horizon. The mutual fund distributes 20 percent of its return as dividends and 45 percent as long-term capital gain. Dividends and capital gains are taxed at 15 percent.

aFor taxpayers in the 10 percent and 15 percent tax brackets, the JGTRRA of 2003 reduces the tax rate on dividends and capital gains to 5 percent.

$\mathrm{b}$ Breakeven time horizons in this row are undefined because the natural $\log$ of a negative number is undefined.

Source: This table follows the model and design of Horan (2004).

facing high tax rates, mutual funds offer relatively effective tax shields, which decrease the relative advantage of the traditional IRA.

When returns are taxed only as capital gain at the end of the investment period, as in Panel C, the breakeven points become even longer and, in some cases, approach infinity because the tax deferral characteristics of the traditional IRA are replicated somewhat by the tax deferral of the unrealized capital gain in the taxable investment. Passive investors implementing a buy-and-hold strategy of non-dividend-paying 
stocks would find themselves in this situation. In any case, the breakeven points are sensitive to the assumed tax structure.

By comparing the breakeven holding periods in Table 6.2 with those in Table 6.1 , one can see the impact that declining tax rates have on breakeven time horizons. Table 6.2 presents breakeven time horizons when investors drop into the next lower tax bracket when withdrawing funds and illustrates that the impact of declining tax rates is quite substantial. According to Panel $\mathrm{A}$, the breakeven holding periods can be short when the taxable investment is fully taxed as ordinary income at the investor's initial tax rate, $T_{o}$, which is the case for interest income on fixed-income investments. For investors in high tax brackets facing a 10 percent expected return, the tax shelter of the IRA is relatively valuable and the breakeven time horizons decrease substantially to four years or less. For investors in the 25 percent tax bracket dropping to the 15 percent tax bracket, a traditional IRA with an early withdrawal penalty is a superior investment vehicle for any time horizon as indicated by the zero breakeven time horizon. 5 The zero breakeven points for taxpayers in the 35 percent tax bracket indicate that such an investor is always better off using a traditional IRA and paying an early withdrawal penalty.

The reader may notice that breakeven points in Table 6.2 do not monotonically decrease as the initial tax rate increases as in the previous table. Rather, they "jump around" as one peruses down each column. The reason is that the value of the traditional IRA and its ability to overcome the cost of the early withdrawal penalty is driven more by the change in the tax rate than the level of the tax rate. For example, an investor initially in the 35 percent tax bracket dropping to the 33 percent tax bracket (the last row of Panel A) has breakeven time horizons that are about 60 percent longer than an investor initially in the 33 percent tax bracket dropping to the 28 percent tax bracket (the second to last row of Panel A). The difference becomes more pronounced for the other taxing schemes in the following two panels. It stems from the fact that the former investor experiences a 2 percentage point decrease in the tax rate, and the latter investor experiences a 5 percentage point decrease in the tax rate, demonstrating that the change in the tax rate is more important than the level of the tax rate.

Panel B contains the results under the assumption the investment is a mutual fund with average distribution rates for ordinary income and capital gains. Again, breakeven points in this panel are longer than those in Panel A, suggesting that the tax structure of the non-IRA investment is important in determining the breakeven point. They are, however, about half the length, assuming that tax rates remain constant. The breakeven investment horizons for investors in the 15 percent tax bracket are much longer because dividends and capital gains are taxed at only 5 percent

5 The algebraic reason for these zero breakeven points is that the first coefficient in Equation 6.2 becomes zero in this instance. 
Table 6.2. Breakeven Time Horizon for a Traditional IRA with Early Withdrawal Penalty for an Investor Dropping One Tax Bracket

\begin{tabular}{|c|c|c|c|c|c|c|c|}
\hline \multirow[b]{2}{*}{$T_{0}$} & \multicolumn{7}{|c|}{ Annual Return $(r)$} \\
\hline & $4 \%$ & $6 \%$ & $8 \%$ & $10 \%$ & $12 \%$ & $14 \%$ & $16 \%$ \\
\hline \multicolumn{8}{|c|}{ A. Return fully taxed as ordinary income at $t_{o i}=T_{0}$ (trader) } \\
\hline $15 \% \mathrm{a}$ & 31.5 & 21.4 & 16.3 & 13.3 & 11.3 & 9.8 & 8.8 \\
\hline $25 \%$ & 0.0 & 0.0 & 0.0 & 0.0 & 0.0 & 0.0 & 0.0 \\
\hline $28 \%$ & 9.4 & 6.4 & 4.9 & 4.0 & 3.4 & 2.9 & 2.6 \\
\hline $33 \%$ & 6.1 & 4.1 & 3.1 & 2.5 & 2.2 & 1.9 & 1.7 \\
\hline $35 \%$ & 9.7 & 6.6 & 5.0 & 4.1 & 3.4 & 3.0 & 2.7 \\
\hline
\end{tabular}

B. Tax structure for a typical growth mutual fund (active investor)

$\begin{array}{lrrrrrrr}15 \% \text { a } & 37.4 & 25.4 & 19.4 & 15.8 & 13.4 & 11.6 & 10.4 \\ 25 \% & 0.0 & 0.0 & 0.0 & 0.0 & 0.0 & 0.0 & 0.0 \\ 28 \% & 19.4 & 13.1 & 10.0 & 8.1 & 6.9 & 6.0 & 5.3 \\ 33 \% & 14.4 & 9.7 & 7.4 & 6.0 & 5.1 & 4.4 & 3.9 \\ 35 \% & 25.6 & 17.3 & 13.2 & 10.7 & 9.1 & 7.9 & 7.0\end{array}$

C. Return fully taxed as deferred capital gain (passive investor)

\begin{tabular}{lrrrrrrr}
$15 \% \mathrm{a}, \mathrm{b}$ & \multicolumn{1}{c}{-} & \multicolumn{1}{c}{-} & \multicolumn{1}{c}{-} & - & - & - & - \\
$25 \%$ & 0.0 & 0.0 & 0.0 & 0.0 & 0.0 & 0.0 & 0.0 \\
$28 \%$ & 26.6 & 17.9 & 13.6 & 11.0 & 9.2 & 8.0 & 7.0 \\
$33 \%$ & 17.5 & 11.8 & 8.9 & 7.2 & 6.1 & 5.3 & 4.6 \\
$35 \%$ & 43.8 & 29.5 & 22.3 & 18.0 & 15.2 & 13.1 & 11.6 \\
\hline
\end{tabular}

Notes: The investor drops one tax bracket when funds are withdrawn. The mutual fund distributes 20 percent of its return as dividends and 45 percent as long-term capital gain. Dividends and capital gains are taxed at 15 percent. a For taxpayers in the 10 percent and 15 percent tax brackets, the JGTRRA of 2003 reduces the tax rate on dividends and capital gains to 5 percent. $\mathrm{b}$ Breakeven time horizons in this row are undefined because the natural $\log$ of a negative number is undefined.

Source: This table follows the model and design of Horan (2004).

for these investors, substantially decreasing the value of the tax deferral associated with the traditional IRA. Breakeven time horizons when the investment return is fully taxed as a capital gain at the end of the investment period are displayed in Panel C. They are slightly longer than those in Panel B because the taxable investment in this case offers significant tax-deferral characteristics. The differences are not large, however. Panel A and Panel $\mathrm{C}$ represent different extremes for the taxable investment. For most investors, the actual taxing scheme would fall somewhere between these two extremes. These tables indicate that two important factors in the breakeven 
investment horizon are the taxing scheme for the taxable alternative and the relationship between the prevailing tax rates upon contribution and withdrawal.

\section{Breakeven Investment Horizon for a Roth IRA}

When examining the breakeven time horizon for Roth IRA investments with an early withdrawal penalty, one must recognize that the early withdrawal penalty for the Roth IRA applies only to earnings, not the initial contribution. Therefore, if the early withdrawal is less than the initial contribution, no early withdrawal penalty applies and the breakeven time horizon is effectively zero. But withdrawals in excess of the initial contribution are subject not only to the 10 percent early withdrawal penalty but also ordinary income tax. This nonqualified distribution tax creates a double tax when earnings are withdrawn early-once when funds are contributed and again when they are withdrawn — and can create long breakeven points when withdrawals exceed the initial contribution.

For a Roth IRA, the after-tax accumulation after paying ordinary income tax and a penalty for early withdrawal on earnings is

$$
\begin{aligned}
\mathrm{FV}_{\text {RothP }} & =I_{B T}\left(1-T_{o}\right)\left\{\left[(1+r)^{n}-1\right]\left(1-T_{n}-\phi\right)+1\right\} \\
& =I_{B T}\left(1-T_{0}\right)\left[(1+r)^{n}\left(1-T_{n}-\phi\right)+T_{n}+\phi\right] .
\end{aligned}
$$

Setting this expression equal to the future value of a taxable investment and solving for $n$ yields the breakeven condition, which can be rearranged as

$$
\left[\frac{1+r^{*}}{1+r}\right]^{n}=\frac{1-T_{n}-\phi}{1-T^{*}}+\frac{\phi+T_{n}-T^{*}}{(1+r)^{n}\left(1-T^{*}\right)} .
$$

A proof is in Appendix E. This analysis is similar in spirit to Terry and Goolsby (2003), who analyze the usefulness of Section 529 plans for retirement savings. The tax structures of Section 529 plans and Roth IRAs are nearly equivalent, and Section 529 withdrawals for purposes other than education are subject to a similar penalty and income tax as are early withdrawals from a Roth IRA.

If one assumes a simplified tax structure for the Roth IRA in which investment returns are taxed each year as ordinary income, it does not yield a closed-form solution for $n$. But if one assumes the returns are taxed as capital gains at the end of the period, it does. In this circumstance, $p_{o i}=p_{c g}=0$, which makes $r^{*}=r$ and $T^{*}$ $=t_{c g}$. Substituting these values into Equation 6.5 and solving for $n$ yields a breakeven time horizon of zero in all cases. In other words, an investor is always better off with an investment taxed entirely as tax-deferred capital gains rather than a Roth IRA with a withdrawal penalty if all funds in the Roth IRA are withdrawn early. Recall that withdrawals of initial contributions are neither penalized nor taxed as a nonqualified distribution, making the breakeven time horizon for early withdrawals of only initial contributions effectively zero. But there are many similarities when 
comparing a complete early withdrawal from a Roth IRA with a taxable investment taxed as deferred capital gain. The initial investment of both alternatives is initially taxed. Both alternatives offer tax deferral during the accumulation phase. And both are taxed at the end of the investment period. The only difference is the early withdrawal penalty on earnings associated with the Roth IRA, making the Roth IRA less desirable than the taxable investment. Therefore, when the taxable alternative is taxed entirely as deferred capital gain, a taxable account is always better than making a complete withdrawal from a Roth IRA that would be subject to the early withdrawal penalty.

The breakeven point is less obvious with other taxing schemes. One relationship to note is that the breakeven time horizon for a Roth IRA does not depend on the investor's initial tax rate because the investment in both the taxable investment and the Roth IRA is taxed identically. Table 6.3 displays breakeven holding periods for a Roth IRA if one assumes a complete early withdrawal of contribution and earnings. The table assumes that early withdrawals less than the initial contribution are not penalized or taxed but that earnings are subject to the 10 percent early withdrawal penalty as well as income tax as a nonqualified distribution. In Panel A, returns are assumed to be fully taxed as ordinary income at a rate of $T_{n}$ during the accumulation phase. The breakeven time horizons are significantly longer than those associated with traditional IRAs because earnings associated with early withdrawals from Roth IRAs are taxed as ordinary income in addition to being penalized, whereas qualified withdrawals are neither taxed nor penalized.

Panel B presents some very long breakeven points for returns taxed as typical growth mutual fund returns, especially for investors in high tax brackets. Recall that IRA withdrawals after the age of $591 / 2$ are penalty free. Consequently, very high breakeven holding periods in Table 6.3 have no practical significance. The breakeven points are significantly longer than in Panel A because the benefits of tax deferral associated with the Roth IRA are relatively less valuable when compared with a mutual fund investment. The breakeven points increase with the withdrawal tax rate because the early withdrawal of earnings from a Roth IRA is taxed as ordinary income. Although not displayed in this table, one could use different tax rates for the accumulation and withdrawal phases.

Taken at face value, these results suggest that, in most instances, using Roth IRAs exclusively for nonretirement investment goals is not advantageous. But the early withdrawal penalty and the nonqualified distribution income tax only apply to withdrawals greater than the initial contribution. The previous analysis assumes a total withdrawal rather than a partial withdrawal. For a partial withdrawal not exceeding total contributions, the breakeven period for a Roth IRA is essentially zero. In contrast, withdrawals that exceed the initial contribution have longer breakeven points. If withdrawals are made over time, whereby early withdrawals are less than the initial contributions, then the early withdrawal penalty may disappear for later 
Table 6.3. Breakeven Time Horizon for a Roth IRA with Early Withdrawal Penalty for Constant Tax Rates

\begin{tabular}{lccccccc}
\hline \multicolumn{7}{c}{ Annual Return $(r)$} \\
\cline { 2 - 8 }$T_{n}$ & $4 \%$ & $6 \%$ & $8 \%$ & $10 \%$ & $12 \%$ & $14 \%$ & $16 \%$ \\
\hline A. Return fully taxed & as ordinary income & at $t_{\text {oi }}$ & $T_{n}$ (trader) \\
$10 \%$ a & 48.3 & 33.0 & 25.3 & 20.7 & 17.6 & 15.4 & 13.8 \\
$15 \%^{\mathrm{a}}$ & 36.5 & 24.9 & 19.2 & 15.7 & 13.4 & 11.8 & 10.5 \\
$25 \%$ & 26.6 & 18.3 & 14.1 & 11.6 & 9.9 & 8.7 & 7.9 \\
$28 \%$ & 25.1 & 17.3 & 13.3 & 11.0 & 9.4 & 8.3 & 7.4 \\
$33 \%$ & 23.4 & 16.1 & 12.4 & 10.2 & 8.8 & 7.7 & 7.0 \\
$35 \%$ & 22.9 & 15.7 & 12.2 & 10.0 & 8.6 & 7.6 & 6.8 \\
B. Tax structure for a typical growth mutual fund (active investor) & \\
$10 \%$ a & 124.1 & 84.3 & 64.4 & 52.5 & 44.5 & 38.8 & 34.6 \\
$15 \%$ a & 132.3 & 89.8 & 68.6 & 55.9 & 47.4 & 41.4 & 36.8 \\
$25 \%$ & 95.9 & 65.2 & 49.8 & 40.6 & 34.5 & 30.1 & 26.8 \\
$28 \%$ & 109.4 & 74.3 & 56.8 & 46.3 & 39.2 & 34.2 & 30.5 \\
$33 \%$ & 132.7 & 90.1 & 68.8 & 56.1 & 47.5 & 41.5 & 36.9 \\
$35 \%$ & 142.5 & 96.7 & 73.9 & 60.2 & 51.0 & 44.5 & 39.6 \\
\hline
\end{tabular}

Notes: The investor maintains the same marginal tax rate throughout the investment horizon. The mutual fund distributes 20 percent of its return as dividends and 45 percent as long-term capital gain. Dividends and capital gains are taxed at 15 percent.

a For taxpayers in the 10 percent and 15 percent tax brackets, the JGTRRA of 2003 reduces the tax rate on dividends and capital gains to 5 percent.

Source: This table follows the model and design of Horan (2004).

withdrawals of earnings if they occur after age 591/2. Therefore, an optimal ordering exists of withdrawals from Roth IRAs. Nontaxable contributions should be withdrawn first. Contributions from converted traditional IRA contributions are treated a bit differently and should come next. Finally, earnings should be withdrawn last.

\section{Summary}

This chapter shows that the breakeven holding period is sensitive to the annual return and decreases at a decreasing rate as the return increases. Moreover, the tax structure for the non-IRA investment greatly influences the attractiveness of using an IRA for nonretirement purposes. For example, breakeven points are substantially longer when a significant proportion of the return on the taxable investment is in the form of either realized or unrealized capital gains, as is the case with many equity mutual funds. 
For the traditional IRA, the breakeven point is also sensitive to whether tax rates increase or decrease from the time of contribution to withdrawal. Breakeven points can be short (a few years) when investors drop into the next lower tax bracket and returns are high. In contrast, the breakeven investment horizons for the Roth IRA are not dependent on the initial tax rate. They are substantially higher than traditional IRA breakeven points, however, because earnings associated with early withdrawals are taxed as nonqualified distributions in addition to being subject to an early withdrawal penalty. 


\section{Asset Location between Taxable and Tax-Deferred Savings Accounts}

The previous chapter examined conditions under which an investor accumulates more after-tax wealth by using a tax-advantaged account with an early withdrawal penalty than by using a taxable account. And Chapter 4 analyzed the choice between nondeductible IRAs and taxable accounts. These chapters investigated whether an investor should use a taxable account or a tax-deferred account. But what if an investor has a portfolio of stocks and bonds that are to be located in taxable and taxdeferred accounts? In which account - the tax deferred or the taxable- should the investor locate the stocks, and where should the investor locate the bonds? This choice is called the asset location decision and is distinct from the asset allocation decision, which determines the mix of stocks and bonds in the aggregate portfolio. Moreover, does the location of assets affect the investor's overall asset allocation? If so, how? This chapter examines the asset location decision and how it interacts with the asset allocation decision.

The asset location decision has recently attracted the attention of researchers who have examined the issue theoretically and empirically. ${ }^{1}$ Although some of the theoretical models overlook many tax code nuances that were considered in previous chapters, they are nonetheless quite sophisticated and do not lend themselves to easy application. Incorporating additional complexities of the tax code is not likely to ameliorate that problem. Fortunately, one can extract valuable intuition and heuristic guidance from the literature.

Much of the intuition is based on an arbitrage argument developed for corporate pension fund policy by Black (1980) and Tepper (1981). For a company, contributions to a pension plan are tax deductible and the returns on pension assets are exempt from tax, much like a traditional IRA for an individual investor. The basic idea behind the arbitrage argument is that a company should place what would otherwise be highly taxed assets (e.g., fixed-income securities) within the tax shelter of the pension fund and locate securities with less tax burden in the form of, say, deferred capital gains (e.g., equities) outside the pension fund. A fair question might be: How would this policy be implemented if the ideal asset allocation does not call

1 Some of the more comprehensive examples include Shoven and Sialm (2003), Dammon, Spatt, and Zhang (2004), and Huang (2000). 
for high-taxed assets, such as bonds, in the absence of taxes? Black and Tepper prescribed that borrowing outside the pension fund can offset any excessive fixedincome investment in the pension fund. The proceeds from borrowing can then be invested in equities. In this way, lending in the pension fund offsets borrowing outside the pension fund, leaving the company with only equity exposure on net. The exact amount of borrowing required to offset the fixed-income investment in the pension depends on the tax rate and how assets are taxed, but the concept remains the same.

Since then many authors have applied this logic to individual investors and the tax-advantaged retirement accounts available to them. ${ }^{2}$ That is, investors should place fixed-income securities in their tax-deferred accounts and any equities in their taxable accounts. If filling the tax-deferred account with bonds overweights the asset allocation too heavily toward fixed income, investors can borrow money to offset the lending in the tax-deferred account and use the proceeds to purchase additional equity in the taxable account.

Several considerations can complicate this basic arbitrage argument. First, when considering an individual's asset allocation, Reichenstein (2001) argued that the traditional approach fails to distinguish between pretax and after-tax values. In Chapter 5, I discussed methods for valuing tax-sheltered assets on an after-tax basis, showing that a TDA's pretax value can differ substantially from its after-tax value. Because goods and services are purchased with after-tax dollars, a more accurate treatment of asset allocation would rely on after-tax values rather than pretax values. Recall that the after-tax value of a dollar in a TDA can be either greater than or less than a dollar, depending on the type of account, return, time horizon, and withdrawal pattern from the account. Therefore, the leverage in the taxable account needed to offset lending in the tax-deferred account can be either greater than or less than its bond investment. Furthermore, an investor's trading behavior affects the effective tax burden of some investments. Active investors with high turnover realize more short-term capital gains, which are taxed as ordinary income, than passive buy-and-hold investors, who defer realizing capital gains, which are taxed at a lower rate.

Second, including municipal bonds, which are exempt from state and local taxes, in the set of possible investment opportunities may make shifting stock to a TDA optimal. Although stock tends to be more tax efficient than corporate and government bonds, municipal bonds are more tax efficient than both. A third complication to the basic arbitrage argument for asset location is that investors may be constrained from borrowing or face other portfolio constraints that make executing the arbitrage strategy costly or impossible. Finally, investors may face

2 For example, Auerbach and King (1983), Huang (2003), Shoven and Sialm (2003), and Dammon, Spatt, and Zhang (2004). 
liquidity constraints that make the arbitrage strategy costly. For example, if the equity in a taxable account suffers a substantial decline in value, an investor may be forced to liquidate assets in the tax-deferred account to finance consumption, which may trigger an early withdrawal penalty for some investors. I will address each of these issues in turn.

It is important to remember that the asset location decision involves a series of trade-offs. On the one hand, the higher expected return associated with equity investments increases the value of deferring taxes on their return (as opposed to bond returns), as I have shown in previous chapters, suggesting stocks might be optimally located in tax-deferred accounts. On the other hand, the effective tax rate on equities is lower than on fixed-income instruments, suggesting stocks might be optimally located in taxable accounts. The asset location decision should balance these considerations.

A complicating factor in this trade-off, however, is the effect of asset location on portfolio risk. Holding stock in a taxable account produces less after-tax portfolio risk than holding stock in a tax-deferred account because the government shares in some of the risk (not just the return) of the equities when they are held in a taxable account. Although lending or borrowing can be adjusted to offset this change in risk associated with the asset location decision, this asset allocation change can, in turn, affect asset location, which creates a recursive process that does not lend itself to a direct solution. Therefore, the two decisions affect each and, in a technical sense, must be solved jointly.

\section{After-Tax Asset Allocation}

Conventional methods of examining asset allocation use pretax values. That is, a dollar held in a taxable account is treated in the same way as a dollar held in a TDA. I showed in Chapter 5, however, that the after-tax value of a tax-sheltered dollar can be either greater than or less than the value of a dollar held in a taxable account, depending on the type of tax-sheltered account (e.g., traditional IRA versus Roth IRA), the type of asset in which the dollar is invested (e.g., stocks versus bonds), how those assets are turned over, the length of time the money is held in the tax-deferred account, and how the funds are withdrawn. Because consumption is based on after-tax dollars, an asset allocation measure that uses after-tax values would be more accurate.

Consider a hypothetical investor who is retired, 50 years old, in the 28 percent tax bracket, and planning withdrawals over 30 years. This investor has just purchased $\$ 100,000$ of a mutual fund in a taxable account. In addition, he has $\$ 200,000$ invested in an equity mutual fund located in a traditional IRA and $\$ 300,000$ invested in fixed income in a Roth IRA. These pretax values are displayed in Table 7.1, Panel A. Stocks and bonds are expected to return 12 percent and 6 percent, respectively. On a pretax basis, asset allocation is one-half stock and one-half bonds. Using the 
Table 7.1. After-Tax Asset Allocation for an Investor in the 33 Percent Tax Bracket with a 30-Year Horizon

\begin{tabular}{|c|c|c|c|c|}
\hline Item & $\begin{array}{c}\text { After-Tax } \\
\text { Value Factor }\end{array}$ & Dollar Value & Proportion & $\begin{array}{c}\text { Stock } \\
\text { Proportion }\end{array}$ \\
\hline \multicolumn{5}{|l|}{ A. Pretax values } \\
\hline Taxable mutual fund (stock) & & $\$ 100,000$ & $16.7 \%$ & $50.0 \%$ \\
\hline Fully deductible IRA (stock) & & 200,000 & 33.3 & \\
\hline Roth IRA (bond) & & 300,000 & 50.0 & \\
\hline Total & & $\$ 600,000$ & & \\
\hline \multicolumn{5}{|c|}{ B. After-tax values (lump-sum withdrawal) } \\
\hline Taxable mutual fund (stock) & 1 & $\$ 100,000$ & $12.2 \%$ & $35.8 \%$ \\
\hline Fully deductible IRA (stock) & 0.972 & 194,400 & 23.6 & \\
\hline Roth IRA (bond) & 1.761 & 528,300 & 64.2 & \\
\hline Total & & $\$ 822,700$ & & \\
\hline \multicolumn{5}{|c|}{ C. After-tax values (annuity withdrawal) } \\
\hline Taxable mutual fund (stock) & 1 & $\$ 100,000$ & $14.5 \%$ & $38.1 \%$ \\
\hline Fully deductible IRA (stock) & 0.816 & 163,200 & 23.6 & \\
\hline Roth IRA (bond) & 1.428 & 428,400 & 61.9 & \\
\hline Total & & $\$ 691,600$ & & \\
\hline \multicolumn{5}{|c|}{ D. Post-arbitrage after-tax values (annuity withdrawal) } \\
\hline Taxable mutual fund (stock) & 1 & $\$ 273,933$ & $38.1 \%$ & $38.1 \%$ \\
\hline Taxable borrowing (short bond) & 1 & $(173,933)$ & $(24.2)$ & \\
\hline Fully deductible IRA (bond) & 0.957 & 191,400 & 26.6 & \\
\hline Roth IRA (bond) & 1.428 & 428,400 & 59.5 & \\
\hline Total & & $\$ 719,800$ & & \\
\hline
\end{tabular}

after-tax valuation tables in Chapter 5 , I can convert these pretax values to aftertax values, which vary dramatically. If funds are withdrawn from the TDAs as a lump sum in 30 years, the after-tax value of the equity in the traditional IRA is $\$ 194,400$ (shown in Panel B). This value comes from multiplying the $\$ 200,000$ pretax value by 0.972 , which is the after-tax value factor from Table 5.2, Panel B, for a 12 percent investment and a 30-year investment horizon. The after-tax value of the Roth IRA is calculated using the after-tax value factor from Table 5.4, Panel A, for a 6 percent return over 30 years. Using these after-tax values changes the equity exposure from 50 percent to 35.8 percent.

If funds are withdrawn from the TDAs as an annuity over 20 years beginning 10 years hence (as shown in Panel C), the change is less dramatic but still substantial. The after-tax value factors are not reported in this monograph, but the factors for the traditional IRA and the Roth IRA are 0.816 and 1.428, respectively. In this case, after-tax equity exposure is 38.1 percent. Reichenstein (2001) and others have argued that properly assessing portfolio risk requires the use of after- 
tax values because by taxing returns or withdrawals, the government shares in investment risk as well as return. Therefore, an investor substituting bonds for stock in a traditional IRA needs to use after-tax values to determine the appropriate amount of borrowing used to finance an offsetting equity purchase in the taxable account to keep portfolio risk constant.

For example, suppose the current investor sells the $\$ 200,000$ of stock mutual funds in the traditional IRA and purchases bonds in the same account with the proceeds. With an annuitized withdrawal pattern, the after-tax value of the stock sold is $\$ 163,200$ and the after-tax value of the bonds purchased is $\$ 191,400 .^{3}$ The difference of $\$ 28,200$ represents the value gain from the asset location shift. To maintain the same 38.1 percent equity exposure, the investor must borrow $\$ 173,933$ in a taxable account at 6 percent and use the proceeds to purchase additional shares of the stock mutual fund for a total of $\$ 273,933$ of equity in the taxable account. ${ }^{4}$ As Table 7.1, Panel D, indicates, this shift maintains the same after-tax asset allocation and hence the same level of risk. Notice, however, that the after-tax value of the portfolio increased to $\$ 719,800$ without affecting after-tax asset allocation. This example illustrates the potential importance of asset location on the after-tax value of a portfolio of tax-advantaged savings account. It suggests that investors should place bonds, which have a heavy tax burden, in TDAs and use taxable accounts to gain equity exposure and to borrow or lend to adjust the risk of the overall portfolio. This basic advice seems to hold even in relatively more complex environments as described in the following section.

The literature on the asset location decision is still developing. As yet, I am unaware of asset location research that distinguishes between TDAs with front-end tax benefits and TDAs with back-end tax benefits. Nor has the literature on asset location recognized that an investor's investment horizon and withdrawal pattern affect the after-tax value of tax-sheltered assets and thus after-tax asset allocation. By affecting after-tax asset allocation, these factors can affect the asset location decision as well.

\section{Borrowing Constraints}

The preceding tax arbitrage example is illustrative, but for many investors, implementing it is not practical because they face restrictions on the amount and form of borrowing. For instance, the tax arbitrage argument assumes that investors can borrow and lend at the same rate in whatever amounts they wish. In reality, such is not the case. Investors using margin accounts for their investment borrowing

\footnotetext{
3 The after-tax value factor in this case is 0.957 .

4 The amount of borrowing that is used to purchase additional equity is equal to the after-tax value of the stock sold in the traditional IRA plus the preshift equity exposure times the value gain. In other words, $\$ 173,933=\$ 163,200+0.381(\$ 28,200)$.
} 
typically pay the broker call rate or a premium above it, which is undoubtedly greater than the yield on a bond of similar risk. Some or all of the tax gains from the arbitrage are, therefore, consumed by this rate differential. Furthermore, investors are typically restricted from initially borrowing more than 50 percent of the value of their equity portfolio, potentially limiting the extent to which one might be able to carry out this strategy.

Some defined-contribution plans permit participants to borrow against a portion of their accumulations. The amount of borrowing is typically restricted, however, and the collateralized assets must oftentimes be held in a low-risk investment vehicle with a low yield, far less than the interest rate on the loan. Therefore, many researchers have investigated the asset location decision with the assumption that investors are unable to borrow. I will proceed from here using that assumption as well. The tax arbitrage argument with borrowing constraints dictates that, to the extent possible, bonds should be held in TDAs subject to the investor's after-tax asset allocation dictated by his or her risk tolerances.

One may then ask which type of TDA - a traditional IRA or Roth IRA-is best suited to carry the bonds should the investor's after-tax asset allocation accommodate equity and bonds in TDAs? The answer depends, of course, on many factors, but the Roth IRA is best in many instances because the after-tax value factor for heavy tax burden investments is typically greater for Roth IRAs than for traditional IRAs.

Consider, for example, an investor with a 33 percent tax rate through the investment and withdrawal phases with 10 years to retirement $(n=10)$, at which time she will commence 20 years of annuitized withdrawals $(m=20)$. Table 7.2, Panel A, displays the after-tax value factors for stocks and bonds in a traditional IRA and a Roth IRA, under the assumption stocks have a 10 percent return and bonds a 6 percent return. For each dollar shifted from stocks to bonds in the traditional IRA, the after-tax value increases by 11 cents. The same shift in the Roth IRA produces a 16 cent increase, suggesting that this investor might best place bonds in the Roth IRA first. If the desired after-tax asset allocation calls for more bonds, they should then be placed in the traditional IRA. A more pronounced effect is noticed for investors with longer investment horizons. Panel B shows that the same investor with a 30-year investment horizon and withdrawal horizon can realize a greater increase in after-tax value by locating bonds in the Roth IRA rather than the traditional IRA.

It must be noted that, for simplicity, I have ignored in this simple exercise how the after-tax asset allocation is affected by this change in asset location. Nonetheless, it provides heuristic guidance. More research is needed to incorporate an investor's utility function and risk aversion into the analysis. 
Table 7.2. After-Tax Value Factors for an Investor in the 28 Percent Tax Bracket

\begin{tabular}{lccc}
\hline \multicolumn{1}{c}{$\begin{array}{c}r=10 \% \\
\text { Item }\end{array}$} & $\begin{array}{c}r=6 \% \\
\text { Equity Mutual Fund }\end{array}$ & $\begin{array}{c}\text { Gain from } \\
\text { Bonds }\end{array}$ & $\begin{array}{l}\text { Stocks to Bonds } \\
\text { A. 10-year investment horizon and 20-year withdrawal horizon }\end{array}$ \\
Traditional IRA & 0.859 & 0.973 & $\$ 0.114$ \\
Roth IRA & 1.193 & 1.352 & $\$ 0.159$ \\
B. 30-year investment horizon and 30-year withdrawal horizon \\
Traditional IRA & 1.036 & 1.406 & $\$ 0.370$ \\
Roth IRA & 1.439 & 1.952 & $\$ 0.523$ \\
\hline
\end{tabular}

\section{Municipal Bonds}

The basic tax arbitrage example introduced earlier considers only taxable bonds and equity as possible asset classes. The interest on municipal bonds, however, is exempt from state and federal taxes. Because investors are willing to accept a lower yield to have this benefit, the pretax return on municipal bonds is typically lower than that on taxable bonds such that $r_{m}=r_{b}\left(1-t_{m}\right)$, where $r_{m}$ is the return on a tax-exempt municipal bond, $r_{b}$ is the return on a taxable bond of similar risk, and $t_{m}$ is the implied tax rate of municipal bonds. Using data from bond mutual funds, Shoven and Sialm (2003) reported that the ex post implied tax rate from 1979 to 1998 was 26 percent, which is smaller than the tax rate on ordinary income for many investors. In addition, the municipal bond funds seem to be considerably more risky than the corporate bond funds. Shoven and Sialm also examined the asset location decision when municipal bonds were part of the investment opportunity set.

When investors are constrained from borrowing or short selling and cannot hold more than 50 percent of their wealth in a TDA, Shoven and Sialm (2003) showed that high-income investors in the 40 percent tax bracket generally are better off holding stock in taxable accounts and taxable bonds in TDAs if the mutual fund tax burden is relatively light. As the stock fund becomes more tax inefficient (i.e., distributes more of its return as dividends or capital gains), the investor should increase his or her stock holdings in the TDA, thereby increasing the investor's pretax exposure to equities. The intuition for increasing the pretax stock allocation as the tax burden increases is that the government shares in the risk and return of the equity investment as its tax burden increases, thereby decreasing the investor's after-tax exposure to that asset class. To hold the after-tax asset allocation constant, the investor increases his or her pretax equity exposure.

At some point, however, if the tax inefficiency of equities becomes sufficiently onerous such that 68.6 percent or more of the annual returns are distributed, the investor is better off shifting the equities from the taxable account to the TDA and buying municipal bonds in the taxable account. Interestingly, this break point is close to the mean total distribution rates reported in Table 2.2. For a medium- 
income individual in the 30 percent tax bracket, the optimal asset location is similar. When distribution rates of the stock fund are low, investors should hold stock in the taxable account and favor bonds in the TDA. But as the stock fund distributes more than 88.5 percent of its return (i.e., is highly tax inefficient), stocks are better placed in the TDA and the taxable account should hold municipal bonds.

In this context, the usefulness of tax-exempt bonds comes with several caveats. First, the Shoven and Sialm study incorporated a preferred tax rate of 20 percent on long-term capital gains. It did not, however, incorporate the new tax realities of the JGTRRA of 2003, which lowers the capital gains tax rate to 15 percent and lowers the tax rate on dividends from the ordinary income tax rate to 15 percent. The new tax law increases the tax efficiency of stock mutual funds and decreases the relative attractiveness of holding municipal bonds in a taxable account for an investor's equity exposure. Second, actively managed equity funds tend to be less tax efficient than passively managed index funds. In addition, index funds tend to have higher risk-adjusted returns, on average, than actively managed funds. Investors using index funds benefit from their higher risk-adjusted return and improved tax efficiency, which together mitigate the usefulness of locating stock in a TDA and tax-exempt bonds in a taxable account.

Therefore, the opportunity to use municipal bonds to optimize asset location is limited to investors using actively managed equity. In fact, Dammon, Spatt, and Zhang (2004) found that the opportunity to invest in tax-exempt bonds did not alter the general advice of locating bonds, to the extent possible, in TDAs and stock in taxable accounts provided that equity can be held in a relatively tax-efficient form, such as an index fund.

\section{Trading Behavior}

The tax burden for many asset classes, such as equities, depends on an investor's trading behavior or that of the mutual fund held by the investor. Therefore, gains from optimal asset location and perhaps the optimal asset location itself will depend on the trading behavior of an individual investor. Reichenstein (2001) considered three types of investors. In his model, all gains for a trader are short term and taxed as ordinary income each year. For an active investor, all gains are realized annually as long-term gains and taxed at the capital gains tax rate, which at the time of his writing was 20 percent. The passive investor buys and holds stock, never paying capital gains tax via charitable contributions or the step-up in cost basis at the owner's death or the death of his or her spouse. ${ }^{5}$

For the trader, stock and bonds are taxed similarly. In Reichenstein's model, stocks can be located in either the TDA or the taxable account. The optimal asset

5 Although Reichensten (2001) used similar terminology as that in previous chapters of this monograph, his definitions differ slightly from mine. They are, however, conceptually similar. 
allocation in each case, however, calls for a relatively large pretax exposure to the asset held in the taxable account because the after-tax value of each dollar in the taxable account is typically less than the after-tax value of a dollar in the TDA in his model.6 Therefore, the after-tax asset allocation to the asset in the taxable account is too low unless more is allocated to that asset. For the active investor, bonds should be located, to the degree possible, in TDAs, but the improvement in the investors' utility is modest. For the passive investor, not locating bonds in TDAs can have a much larger effect on utility. But Reichenstein found that a proper investment management strategy remains more important than the proper asset location strategy. That is, avoiding mutual funds that are tax inefficient and that produce negative pretax alpha has a greater impact on investor utility than optimally locating assets in TDAs and taxable accounts.

On average, active managers have difficulty matching the risk-adjusted returns of passively managed index funds on a pretax basis. The additional tax liabilities created through active management create an even higher hurdle for managers. Reichenstein (2001) found that even if active managers produce identical riskadjusted pretax returns as index funds, investors stand to gain more from pursuing a passive investment strategy with a low tax drag than optimally locating assets among TDAs and taxable accounts.

\section{Liquidity Constraints}

The strategy of locating bonds in TDAs, to the extent that borrowing constraints allow, may maximize a portfolio's tax efficiency, but it also increases the risk of the taxable portion of the portfolio because the taxable account will have a disproportionately large allocation of equity relative to the TDA. The added risk in the taxable account can be important to investors in the presence of borrowing constraints because it increases the risk that an investor's taxable investments fall short of providing the investor's minimum level of consumption. If a large shock to consumption were to arise whereby consumption exceeded the value of the assets held in the taxable account, it could become necessary to withdraw funds from a TDA prior to age $591 / 2$, thereby imposing an early withdrawal penalty on the investor.

Dammon, Spatt, and Zhang (2004) analyzed this situation and found that the impact of liquidity constraints on the optimal asset location decision depends on the magnitude and likelihood of consumption shocks and their correlation with equity returns. Deviating from the traditional admonition to locate bonds in TDAs requires a large likelihood of a large consumption shock that would have to be strongly negatively correlated with equity returns. Therefore, liquidity constraints

6 The after-tax value tables in Chapter 5 demonstrate that this is not always the case. Reichenstein (2001) focuses on returns rather than after-tax accumulations and therefore ignores the withdrawal tax for the TDA. Therefore, his model works for Roth IRAs but not for traditional IRAs. 
associated with holding equity in taxable accounts do not appear to have a significant effect on the asset location decision.

Up to this point, the general advice for investors seems to be to hold heavily taxed assets, such as bonds, in TDAs and favor equities in taxable accounts. Amromin (2002) argued that the asset location decision can be affected not only by tax efficiency considerations but also by precautionary liquidity considerations. He posited that households that are more likely to suffer a catastrophic shortfall in labor income are more likely to abandon tax-efficient investing in favor of having less risk in their taxable account. He posited further that households with less accumulated wealth or a high share of their wealth in TDAs are likely to behave similarly to avoid the costs associated with accessing funds in TDAs early. In addition, investors facing greater restrictions on accessing TDA assets should hold less equity in their taxable accounts, all else being equal.

\section{Empirical Evidence of Investor Behavior}

I demonstrated in Chapter 5 that the after-tax value of tax-preferred savings accounts is an increasing function of the marginal tax rate an investor pays on returns in an otherwise taxable account. Intuitively, this result is sensible because tax shelters would be worthless in the absence of taxes. Auerbach and King (1983) predicted that under certain conditions, portfolio clienteles will form such that investors will hold assets that have a lower tax burden for them. By extension, location clienteles should form as investors hold highly taxed assets in TDAs, to the extent possible, and more lightly taxed assets in taxable accounts.

Evidence suggests that investors deviate from this predicted behavior. Generally, the prescriptions described previously indicate that investors should locate their taxable bonds in TDAs subject to their desired after-tax asset allocation. In the presence of borrowing constraints, if taxable bonds are held in taxable accounts, the investor should have filled the TDA entirely with taxable bonds and should want to hold more. Therefore, investors with taxable bonds in taxable accounts should not be holding equity in TDAs. Poterba and Samwick (2003) reported, however, that 56.9 percent of investors who hold taxable bonds in taxable accounts also hold equity in tax-deferred accounts. Similarly, investors holding equity in TDAs should be doing so because they have already satisfied their bond holdings in TDAs and should not, therefore, be holding taxable bonds in taxable accounts. Poterba and Samwick reported that 35.1 percent of investors holding tax-deferred equity also hold taxable bonds in taxable accounts.

As discussed previously, Shoven and Sialm showed that municipal bonds can play a useful role in the asset location decision for certain highly taxed investors so long as the distribution rates on equity investments are sufficiently high. Their model suggests that investors holding municipal bonds (in taxable accounts, of course) should generally not be holding equity in taxable accounts but rather in 
TDAs. But 53.9 percent of investors holding tax-exempt bonds also hold equity in taxable accounts. It could be, of course, that investors hold a variety of equity vehicles with different tax burdens. They could be holding tax-efficient equity in taxable accounts and more heavily taxed equity in TDAs. Amromin reported similar findings but suggested that this apparent deviation from optimal asset location behavior is the result of the early withdrawal penalty and other TDA-accessibility restrictions that might prove costly to an investor who experiences an unexpectedly large shock to consumption or shortfall in income. Investors may, therefore, choose to sacrifice tax efficiency in favor of greater liquidity in their taxable account.

\section{Summary}

In making the asset allocation decision, it is important to use asset allocation proportions that are based on after-tax values and to consider the effect that the location decision has on these after-tax proportions. Differences between pretax and after-tax asset allocations can be substantial. In a world characterized by unlimited borrowing and equal borrowing and lending rates, investors should hold taxable bonds in TDAs. Their taxable accounts should be used to hold more lightly taxed equity and to borrow or lend to adjust their after-tax asset allocation to match their risk tolerances. In the presence of borrowing constraints, the general advice of holding highly taxed assets, such as fixed income, in TDAs to the extent possible is robust in many circumstances. As of now, there seems to be two caveats to this directive.

First, highly taxed investors holding heavily taxed equity may benefit from getting their bond exposure from municipal bonds held in taxable accounts. If so, then equity might optimally be held in TDAs. But holding more tax-efficient equity in a taxable account would obviate the need to do this and tends to make the investor better off. Because one's trading behavior affects the tax drag of equity, a way to lighten the tax burden of equity may be to pursue a passive buy-and-hold strategy rather than a high-turnover, active short-term trading strategy. Another deviation from the general rule can result from investors wishing to maintain lower investment risk levels in their taxable accounts to preserve their liquidity. When it is costly to access funds held in the TDA, investors wishing to insulate themselves from unexpectedly high consumption needs or unexpected shortfalls in labor income may rationally forgo tax efficiency in favor of greater liquidity. It is fair to say, however, that investors and researchers have more to learn regarding the optimal asset location. 


\section{Implications for Financial Analysts}

Most modern portfolio theory that financial analysts rely on is grounded in a pretax framework. Recently, researchers have advanced the understanding of the impact of tax structure, the value of tax-timing options, and how the effect of taxes interacts with trading behavior. 1 They have developed models to help investors make optimal decisions in a taxable environment characterized by somewhat complex tax structures in which taxation depends on the type of asset and the account in which it is held. Many of these advances have yet to find their way into mainstream financial analysis, in part because of their complexity. This monograph is designed to package salient tax considerations into a tractable framework that requires of the analyst only a basic understanding of algebra and time-value-of-money concepts. The purpose of this approach is to provide analysts with tools that they can reasonably incorporate into their analyses. Although this compendium focuses largely on how investors might optimally use tax-advantaged savings accounts, the fundamental framework has broader applications. It has significant implications that permeate the entire portfolio management process and the approach that analysts use in developing portfolio optimization techniques.

\section{Portfolio Management and Investment Objectives}

Many financial institutions market their services by offering to help prospective clients navigate the many TDA options available to investors. These efforts create an onus for the financial advisor to be aware of the salient characteristics of TDAs and perhaps more importantly to use them effectively to a client's advantage in the portfolio management process. Knowing how TDAs might be used to accumulate wealth in a tax-efficient manner can have an impact on the financial analyst's approach in establishing return objectives and risk tolerances for clients. When a financial analyst synthesizes a client's particular circumstances and investment goals into a set of return objectives, the objectives are typically expressed in pretax terms and often without regard for the tax structure of the account(s) in which the portfolio is held. Moreover, the notion that the risk of a security or a portfolio from an investor's perspective is greater when held in a tax-sheltered account versus a taxable

1 Dammon and Spatt (1996) and Dammon, Spatt, and Zhang (2001) have examined optimal trading, security pricing, consumption, and portfolio decisions in the context of capital gains tax but outside the context of tax-deferred savings accounts. 
account (because the government shares more fully in the risk of the latter) has yet to find its way into the collective consciousness of the financial analyst profession. Yet, this understanding can affect a financial advisor's assessment of an investor's return requirements, risk tolerances, and investment constraints.

For example, suppose Mrs. Klondike, a 60-year-old widow with a $\$ 2$ million portfolio, wishes to draw out $\$ 50,000$ annually on a pretax basis indefinitely. She hopes further that her withdrawals grow by the rate of inflation, which is expected to be 3 percent indefinitely, so that she maintains her purchasing power. Mrs. Klondike also wishes to protect and grow the corpus of her portfolio so that it might be bequeathed to the local YWCA upon her death. A typical advisor would determine her spending rate to be $2 \frac{1}{2}$ percent per year and her return requirement to be $5 \frac{1}{2}$ percent per year. If her portfolio consists of taxable bonds yielding $5 \frac{1}{2}$ percent held in a taxable account, she will meet her spending needs in the near term. But over time, she will be unable to meet her spending needs and grow the corpus of her portfolio. Why? Suppose the portfolio's entire return will be taxed at 30 percent. In the near term, the portfolio will generate more than enough income to meet her needs. But the portfolio's after-tax return is 3.85 percent [i.e., $0.055 \times(1$ $-0.30)$ ], which over time will be insufficient to maintain the purchasing power of Mrs. Klondike's withdrawals and to grow the corpus of the portfolio.

If, however, the portfolio of bonds is held in a traditional IRA, all of Mrs. Klondike's investment goals will be met. Her $\$ 50,000$ pretax withdrawals will still grow by the rate of inflation because only her withdrawals will be taxed. ${ }^{2}$ The remaining portion of the annual return will be compounded on a tax-deferred basis. Furthermore, the assets may pass to the charitable organization free of tax if the account and estate are properly structured. The picture looks even better if the assets are held in a Roth IRA. In this case, none of Mrs. Klondike's withdrawals are taxed, decreasing her spending rate from $2 \frac{1}{2} 2$ percent to $1 \frac{3 / 4}{4}$ percent [i.e., $\$ 50,000 \times(1-$ $0.30) / \$ 2,000,000]$. All of her withdrawals and earnings will accrue free of tax, allowing her corpus to grow.

As this simplified example illustrates, the tax structure of an account can affect an investor's pretax return objectives, which serve as the foundation for properly constructing portfolios that meet investors' needs. Because different asset classes have different tax structures (e.g., fixed-income instruments are taxed more heavily than equity when held in a taxable account), proper asset allocation must also consider the accounts in which different asset classes are held and how they are taxed.

This example also helps illustrate the notion that Mrs. Klondike's risk exposure is not identical for the three scenarios. Her risk exposure in the Roth IRA account is greatest because she is the residual claimant on all of the investment gains and losses. The government shares in a portion of her investment risk when the portfolio is held in a traditional IRA because withdrawals from the account are taxed. The

2 For expositional ease, I am assuming away mandatory distribution requirements. 
government may share in an even greater proportion of portfolio risk if the portfolio is held in a taxable account, depending on the tax structure of the assets. This insight is important because if the financial advisor recognizes that the taxable account will not satisfy Mrs. Klondike's long-term financial goals, he may increase the risk of the portfolio by introducing equities, knowing that the government will share in some of the risk. Conceptually, he could add equity until the after-tax portfolio risk is equal to that of the all-bond portfolio if it were held in a Roth IRA.

This example also highlights the importance of viewing asset allocation on an after-tax basis. Chapter 5 showed that a dollar in a TDA does not necessarily have the same value as a dollar in a taxable account. As a result, if an investor's aggregate portfolio is held in a series of taxable and TDA accounts, pretax asset allocation measures can be misleading, as I demonstrated in the previous chapter. Measuring a portfolio's exposure to different asset classes on an after-tax basis provides a more accurate picture of an investor's asset allocation. Yet, financial advisors routinely ignore this approach and risk creating portfolios that do not match the return requirements and risk tolerances of their clients.

To this point, the discussion has taken the type of investment account as a given in the portfolio management process. And I have argued that analysts may not be adequately considering this factor in their work. Financial analysts and financial advisors should include the choice of investment account (e.g., traditional IRA, Roth IRA, 401(k), taxable account) as a decision variable in the portfolio management process. That is, investors should be advised on whether to use TDAs in their investment strategy and which TDAs might be best given their current and expected tax situation. Unlike trusts, TDAs are relatively straightforward and do not require an extensive understanding of tax and estate law. It is reasonable then to expect financial advisors to be well versed in their proper use. For example, a financial advisor should be able to recommend whether it is beneficial to use a TDA in meeting investment objectives, to choose between TDAs with front-end tax benefits and back-end tax benefits, to convert or refrain from converting a traditional IRA to a Roth IRA, and to hold bonds in either TDAs or taxable accounts. That is, the financial advisor should provide guidance regarding asset location as well as asset allocation.

\section{Portfolio Management and Investment Constraints}

In addition to affecting the development of investment objectives (i.e., return requirements and risk tolerances), a focus on tax-efficient wealth accumulation also affects an investor's investment constraints. Investment constraints are commonly thought to consist of tax considerations, time horizon, liquidity requirements, legal and regulatory factors, and unique circumstances. A common example of how tax considerations might affect asset allocation is that tax-exempt investors should avoid municipal bonds, which have lower yields because of their tax-favored status but from which tax-exempt organizations do not benefit. A more holistic view of tax- 
efficient wealth accumulation recognizes that tax considerations interact with the other investment constraints, the investment objectives, and even the portfolio management strategy.

For example, the tax status of an investor's account might affect the investor's time horizon. An investor with a greater proportion of assets held in TDAs may be able to reach her retirement goals more quickly than one with a greater percentage of assets held in taxable accounts. Interestingly, the time horizon may also affect tax considerations. As Chapter 6 investigated, investors with sufficiently long preretirement investment horizons may find it beneficial to use TDAs and incur an early withdrawal penalty rather than use a taxable account. The same holds true for using 529 plans for noneducational investment purposes. Often, the breakeven time horizon is quite short, in which case a TDA may be an efficient investment tool in spite of the early withdrawal penalty. If so, this decision will affect the return requirements, risk tolerances, and asset allocation as described previously.

Tax considerations may also affect liquidity requirements and vice versa. The possibility of early withdrawal penalties can place a liquidity constraint on the portfolio. Conversely, as the previous chapter showed, liquidity requirements may discourage investors from placing more volatile assets, such as equity with a relatively light tax burden, in taxable accounts where they might otherwise be optimally placed from a tax perspective. Because a precipitous decline in the value of equity in a taxable account may necessitate withdrawing assets from a TDA, which may be subject to an early withdrawal penalty, holding bonds (perhaps municipal bonds) in a taxable account may be advisable. In this way, liquidity requirements may affect tax considerations, which may, in turn, affect asset allocation.

A deeper understanding of the tax considerations and investment constraints can also affect asset allocation strategy, portfolio rebalancing, and trading behavior. A buy-and-hold investment strategy is a passive asset allocation strategy in which the initial mix of asset classes is allowed to drift with price movements. Because it entails no rebalancing, and hence no turnover, it is efficient from a tax perspective and may be well suited for assets held in taxable accounts. In contrast, constant mix and constant proportion portfolio insurance strategies require rebalancing to maintain the proper proportion of assets among asset classes, depending on whether there is a minimum floor value below which the value of the portfolio should not drop. Rebalancing generally creates a heavier tax burden than a buy-and-hold strategy and may, therefore, be more attractive in TDAs that negate the tax consequences of frequent rebalancing. Of course, the tax implications for a rebalancing strategy will depend heavily on the parameters that dictate how often rebalancing is required.

Similarly, tax considerations can affect equity investment strategy. Active portfolio management for the equity portion of a portfolio requires some degree of turnover. Some strategies entail higher trading levels than others. Active investment strategies with high turnover are generally less tax efficient than passive strategies 
with little or no turnover. Therefore, all else being equal, high-turnover active management investment strategies might best be pursued in TDAs, and lowturnover passive equity strategies might best be pursued in taxable accounts. The interaction of asset allocation strategy, equity investment strategy, and the tax status of different accounts has not been fully investigated. But this monograph provides some heuristic guidance and highlights the importance of tax-efficient wealth accumulation on the portfolio management process.

\section{Portfolio Optimization}

Beyond the portfolio management process, this research has implications for portfolio optimization. Traditional portfolio optimization techniques create an efficient set of portfolios that have different levels of expected return and risk. But the expected returns and covariance matrix used in this process are almost always based on pretax returns. This monograph shows that tax structure and trading behavior can dramatically affect terminal wealth accumulations, which by implication suggests that pretax efficient frontiers may not be reasonable proxies for aftertax efficient frontiers. A seemingly simple solution is to substitute after-tax returns for pretax returns as inputs into the optimization process. The problem with this approach, however, is that determining an annual after-tax return for an investment that has a large taxable event when it is liquidated or withdrawn from an account is difficult. Most likely, the analyst knows neither the timing nor the size of that tax liability. So, translating this information into annual after-tax returns for individual assets or asset classes for use as input in a portfolio optimization process is not straightforward. One alternative is to redefine the objective function to maximize expected terminal wealth (rather than expected annual return) subject to various risk constraints. This approach forces the analyst to think about wealth accumulation rather than annual return and may be useful only if the investor can identify a specific investment horizon.

Another approach is to use simulation techniques that incorporate after-tax account values. Simulations might incorporate variability in an investor's tax rate and investment return over time. In any case, the significance of taxes in the investing environment creates an impetus for the financial analyst to focus on aftertax wealth accumulation and incorporate tax considerations into the portfolio optimization process.

Many of the implications for portfolio management and portfolio optimization deserve more research before they can be properly incorporated into financial analysts' common body of knowledge. And this monograph falls short of doing that. But it hopefully introduces important concepts, provides useful techniques that can help guide analysts and investors, and creates an impetus for analysts to focus on tax-efficient wealth accumulation in the disposition of their duties. 


\section{Appendix A. Proof of Equivalency for Standardized Pretax and After-Tax Investments}

To compare the future accumulations of a traditional IRA and a Roth IRA, one must hold the investment constant. The analysis is unaffected whether the pretax investment for the two accounts is standardized or the after-tax investment is standardized. Consider a standardized pretax investment of $I_{B T}$ and an after-tax investment of $I_{B T}\left(1-T_{o}\right)$. In either case, the amount of money invested in the Roth IRA is $I_{B T}\left(1-T_{0}\right)$.

The investment in the traditional IRA requires some explanation. Consider first pretax investments $\left(I_{B T}\right)$ less than the contribution limit $(L)$. If one standardizes the pretax investment $\left(I_{B T}\right)$ for both accounts, the amount invested in the traditional IRA is simply $I_{B T}$ because the investment is tax deductible. If one standardizes the after-tax investment at $I_{B T}\left(1-T_{0}\right)$ for both accounts, the traditional IRA investment of $I_{B T}\left(1-T_{0}\right)$ generates tax savings of $I_{B T} T_{0}$ if tax savings are invested in the traditional IRA. Adding these two values yields $I_{B T}$, which is the same investment in the pretax scenario.

Now consider pretax investments greater than the after-tax contribution limit but less that the maximum pretax Roth IRA investment, such that $L<I_{B T}<L /(1-$ $\left.T_{0}\right)$. The Roth IRA is still $I_{B T}\left(1-T_{0}\right)$ whether the pretax or after-tax investment is held constant. The allocation for the traditional IRA strategy has two components, however: the IRA contribution up to the contribution limit $(L)$ and a non-IRA contribution for any investment in excess of the limit. This total can be expressed as

$$
I_{\text {Trad }}=\min \left(I_{B T}, L\right)+\max \left[0\left(I_{B T}-L\right)\left(1-T_{0}\right)\right] .
$$

The first term of Equation A1 represents the after-tax investment in the deductible IRA up to the IRA contribution limit, $L$. The second term represents the amount, if any, applied in a non-IRA, nondeductible investment. When $I_{B T}>L$, standardizing the pretax investment at $I_{B T}$ yields $L+\left(I_{B T}-L\right)\left(1-T_{0}\right)$. If the after-tax investment is standardized at $I_{B T}\left(1-T_{0}\right)$, only the portion up to $L$ can be invested in the traditional IRA. This portion, however, will generate tax savings of $L T_{0}$. Rearranging terms shows that the sum of these two values, $I_{B T}\left(1-T_{0}\right)+L T_{0}$, equals the standardize pretax investment, $L+\left(I_{B T}-L\right)\left(1-T_{0}\right)$. Therefore, the investment in both accounts is unaffected by the choice of standardizing the pretax investment or standardizing the after-tax investment. 


\section{Development of the Future Value of a Taxable Investment}

Crain and Austin (1997) showed that for a taxable mutual fund investment, a dollar invested for $n$ years has a before-withdrawal tax future value of

$$
\mathrm{FV}_{T X b}=\left(1+r-r p_{o i} t_{o i}-r p_{c g} t_{c g}\right)^{n} \text {, }
$$

where $r-r p_{o i} t_{o i}-r p_{c g} t_{c g}$ is the annual after-tax return. Although the investor pays tax annually on the portion of the annual return that is distributed as ordinary income or capital gain, he or she must also recognize a capital gain when the mutual fund shares are sold at time $n$ and pay capital gain tax. The capital gain is equal to the value in Equation A2 less the adjusted basis, which is composed of the initial investment plus ordinary income and capital gain distributions (on which tax has already been paid) less the income tax on those distributions. The adjusted basis can be expressed as

$$
\begin{aligned}
\text { Adjusted basis }= & 1+r p_{o i}\left(1-t_{o i}\right) \frac{\left(1+r-r p_{o i} t_{o i}-r p_{c g} t_{c g}\right)^{n}-1}{\left(r-r p_{o i} t_{o i}-r p_{c g} t_{c g}\right)} \\
& +r p_{c g}\left(1-t_{c g}\right) \frac{\left(1+r-r p_{o i} t_{o i}-r p_{c g} t_{c g}\right)^{n}-1}{\left(r-r p_{o i} t_{o i}-r p_{c g} t_{c g}\right)} .
\end{aligned}
$$

The first term of this expression is the original $\$ 1.00$ investment. The second term is the accumulated ordinary income distributions over the life of the investment and has two parts. The first part is the after-tax portion of the return distributed as ordinary income. The second part of the second term is an after-tax future value factor that determines the accumulated value of the after-tax ordinary income distributions. The third term is analogous to the second except that it pertains to the capital gain distributions.

Taking the before-tax accumulation in Equation A2 and subtracting capital gains tax on the adjusted basis in Equation A3 yields

$$
\begin{aligned}
\mathrm{FVIF}_{T X}= & \left(1+r-r p_{o i} t_{o i}-r p_{c g} t_{c g}\right)^{n}-t_{c g}\left[\left(1+r-r p_{o i} t_{o i}-r p_{c g} t_{c g}\right)^{n}-1\right. \\
& -r p_{o i}\left(1-t_{o i}\right) \frac{\left(1+r-r p_{o i} t_{o i}-r p_{c g} t_{c g}\right)^{n}-1}{\left(r-r p_{o i} t_{o i}-r p_{c g} t_{c g}\right)} \\
& \left.-r p_{c g}\left(1-t_{c g}\right) \frac{\left(1+r-r p_{o i} t_{o i}-r p_{c g} t_{c g}\right)^{n}-1}{\left(r-r p_{o i} t_{o i}-r p_{c g} t_{c g}\right)}\right] .
\end{aligned}
$$


This unwieldy equation can be simplified by setting $r^{*}=r-r p_{o i} t_{o i}-r p_{c g} t_{c g}$ and $T^{*}$ $=t_{c g}\left(1-p_{o i}-p_{c g}\right) /\left(1-p_{o i} t_{o i}-p_{c g} t_{c g}\right)$. Rearranging terms produces

$$
\mathrm{FVIF}_{T X}=\left(1+r^{*}\right)^{n}\left(1-T^{*}\right)+T^{*} .
$$

When the investment is taxed entirely as capital gain at the end of the investment period, $p_{o i}=p_{c g}=0$. Substituting these values reduces to $r^{*}=r$ and $T^{*}=$ $t_{c g}$. Equation A5 then simplifies to $(1+r)^{n}\left(1-t_{c g}\right)+t_{c g}$. When the investment is taxed entirely as ordinary income each year, then $p_{o i}=1$ and $p_{c g}=0$. Substituting these values makes $r^{*}=r\left(1-t_{o i}\right)$ and $T^{*}=0$. Equation A5 then simplifies to $[1+$ $\left.r\left(1-t_{o i}\right)\right] n$, which is a familiar after-tax future value formula.

\section{Derivation of Relative Values of Traditional IRAs and Roth IRAs}

The relative future value of the traditional IRA and the Roth IRA is the ratio of Equation 2.5 to Equation 2.1, or

$$
\frac{\mathrm{FV}_{\text {Trad }}}{\mathrm{FV}_{\text {Roth }}}=\frac{L(1+r)^{n}\left(1-T_{n}\right)+\left(I_{B T}-L\right)\left(1-T_{o}\right)\left[\left(1+r^{*}\right)^{n}\left(1-T^{*}\right)+T^{*}\right]}{I_{B T}\left(1-T_{o}\right)(1+r)^{n}} .
$$

Dividing the first term of the numerator through by $(1+r)^{n}$, distributing $\left(1-T_{0}\right)$ in the second term of the numerator, and dividing through by $\left(1-T_{0}\right)$ yields

$$
\begin{aligned}
\frac{\mathrm{FV}_{\text {Trad }}}{\mathrm{FV}_{\text {Roth }}}= & \frac{L\left(1-T_{n}\right)}{I_{B T}\left(1-T_{0}\right)}+\frac{I_{B T}\left[\left(1+r^{*}\right)^{n}\left(1-T^{*}\right)+T^{*}\right]}{I_{B T}(1+r)^{n}} \\
& -\frac{L\left[\left(1+r^{*}\right)^{n}\left(1-T^{*}\right)+T^{*}\right]}{I_{B T}(1+r)^{n}} .
\end{aligned}
$$

Dividing to unity and collecting terms yields

$$
\begin{aligned}
\frac{\mathrm{FV}_{\text {Trad }}}{\mathrm{FV}_{\text {Roth }}}= & \frac{L\left(1-T_{n}\right)}{I_{B T}\left(1-T_{o}\right)} \\
& +\left(1-\frac{L}{I_{B T}}\right) \frac{\left(1+r^{*}\right)^{n}\left(1-T^{*}\right)+T^{*}}{(1+r)^{n}} .
\end{aligned}
$$




\section{Derivation of the Breakeven Withdrawal Tax Rate}

The breakeven withdrawal tax rate is found by setting Equation A8 to 1 and solving for $T_{n}$. Doing so and subtracting 1 from both sides gives

$$
\begin{aligned}
0= & \frac{L\left(1-T_{n}\right)}{I_{B T}\left(1-T_{o}\right)} \\
& -1+\left(1-\frac{L}{I_{B T}}\right) \frac{\left(1+r^{*}\right)^{n}\left(1-T^{*}\right)+T^{*}}{(1+r)^{n}} .
\end{aligned}
$$

Dividing through by $L$, multiplying through by $I_{B T}\left(1-T_{o}\right)$, and distributing $I_{B T}$ ' $L$ through the third term results in

$$
\begin{aligned}
0= & \left(1-T_{n}\right)-\frac{I_{B T}\left(1-T_{0}\right)}{L} \\
& +\left(1-T_{0}\right)\left(\frac{I_{B T}}{L}-1\right) \frac{\left(1+r^{*}\right)^{n}\left(1-T^{*}\right)+T^{*}}{(1+r)^{n}} .
\end{aligned}
$$

Adding $T_{n}$ to both sides and canceling $T_{o}$ on the right-hand side produces

$$
\begin{aligned}
T_{n}= & T_{o}+\left(1-T_{o}\right)-\frac{I_{B T}\left(1-T_{o}\right)}{L} \\
& +\left(1-T_{o}\right)\left(\frac{I_{B T}}{L}-1\right) \frac{\left(1+r^{*}\right)^{n}\left(1-T^{*}\right)+T^{*}}{(1+r)^{n}} .
\end{aligned}
$$

Finally, collecting terms around $-\left(1-T_{o}\right)$ and $\left(I_{B T} / L-1\right)$ yields Equation A12:

$$
T_{n}=T_{o}-\left(1-T_{o}\right)\left(\frac{I_{B T}}{L}-1\right)\left[1-\frac{\left(1+r^{*}\right)^{n}\left(1-T^{*}\right)+T^{*}}{(1+r)^{n}}\right] .
$$




\section{Appendix B. Simplification When Tax Savings Are Reinvested in 401(k)}

The after-tax accumulation of a 401(k) in which the employer matches $\pi$ percent of the employee's investment and the tax savings are invested in a mutual fund is

$$
\mathrm{FV}_{401(k)}=(1+\pi) I_{B T}\left(1-T_{o}\right)(1+r)^{n}\left(1-T_{n}\right)+I_{B T} T_{0}\left[\mathrm{FVIF}_{T X}\right] .
$$

If the tax savings in the second term are reinvested in the $401(\mathrm{k})$, then $\mathrm{FVIF}_{T X}$ reduces to $(1+r)^{n}$ and the investment is grossed up to $(1+\pi)$ by the employer's contribution. Therefore, the expression becomes

$$
\mathrm{FV}_{401(k)^{*}}=(1+\pi) I_{B T}\left(1-T_{0}\right)(1+r)^{n}\left(1-T_{n}\right)+(1+\pi) I_{B T} T_{0}(1+r)^{n} .
$$

Collecting terms around $(1+\pi) I_{B T}(1+r)^{n}$ produces

$$
\mathrm{FV}_{401(k)^{*}}=(1+\pi) I_{B T}(1+r)^{n}\left(1-T_{n}\right) .
$$

\section{Breakeven Withdrawal Tax Rate Between a 401(k) and a Roth IRA}

Setting the future accumulation of an employer-matched 401(k) to that of a Roth IRA and solving for $T_{n}$ determines the breakeven withdrawal tax rate between the two types of accounts. Therefore, setting Equation B1 to Equation 2.1 yields

$$
\begin{aligned}
\mathrm{FV}_{\text {Roth }} & =\mathrm{FV}_{401(k)} \\
I_{B T}\left(1-T_{0}\right)(1+r)^{n} & =(1+\pi) I_{B T}\left(1-T_{0}\right)(1+r)^{n}\left(1-T_{n}\right)+I_{B T} T_{0}\left[\mathrm{FVIF}_{T X}\right] .
\end{aligned}
$$

Dividing through by $I_{B T}$, subtracting $I_{B T} T_{0}\left[\mathrm{FVIF}_{T X}\right]$ from both sides, dividing both sides by $(1+\pi) I_{B T}\left(1-T_{o}\right)(1+r)^{n}$, subtracting 1 from both sides, and multiplying through by -1 yields

$$
T_{n}=1-\frac{\left(1-T_{o}\right)(1+r)^{n}-T_{o}\left[\mathrm{FVIF}_{T X}\right]}{(1+\pi)\left(1-T_{o}\right)(1+r)^{n}} .
$$


Substituting for $\mathrm{FVIF}_{T X}$, separating terms, canceling terms, and factoring out -1 / $(1+\pi)$ yields

$$
T_{n}=1-\frac{1}{1+\pi}\left[1-\frac{T_{0}\left[\left(1+r^{*}\right)^{n}\left(1-T^{*}\right)+T^{*}\right]}{(1+\pi)\left(1-T_{o}\right)(1+r)^{n}}\right] .
$$

\section{Future Value of Roth IRA Conversion}

An investor converting a traditional IRA to a Roth IRA must pay a withdrawal (or conversion) tax on funds coming from the traditional IRA. An investor wishing to pay this conversion tax from IRA assets must pay an early withdrawal penalty as well on the amount not rolled over into the Roth IRA. Under this scenario, for each dollar rolled over from the traditional IRA, $\left(1-T_{0}\right)$ dollars get rolled over into the Roth IRA because $T_{o}$ dollars are held back to pay the conversion tax. Each of the $T_{o}$ dollars held back and not rolled over is subject to an early withdrawal penalty of $T_{o} \phi$ dollars, where $\phi$ is the percentage early withdrawal penalty. To hold back enough funds from the traditional IRA to cover the withdrawal tax and early withdrawal penalty, the investor must withhold a total of $T_{o} \phi /(1-\phi)$ dollars from the Roth IRA for each dollar rolled over from the traditional IRA. Therefore, the future value of each dollar rolled over from a traditional IRA into a Roth IRA is

$$
\mathrm{FV}_{\text {RothConv* }}=\left[1-T_{0}-\frac{T_{0} \phi}{1-\phi}\right](1+r)^{n} .
$$

The first term in the brackets represents each dollar withdrawn from the traditional IRA to be converted into the Roth IRA. The second term in the brackets is the tax withheld on each dollar rolled over from the traditional IRA. The third term in the brackets is the additional amount withheld to pay the conversion tax. Multiplying the numerator and the denominator of the second term by $1-\phi$ and canceling terms yields

$$
\mathrm{FV}_{\text {RothConv* }}=\left[1-\frac{T_{0}}{1-\phi}\right](1+r)^{n} .
$$

\section{Breakeven Withdrawal Tax Rate for a Roth IRA Conversion}

The future value of each dollar held in a traditional IRA is $(1+r) n\left(1-T_{n}\right)$. By setting this value equal to Equation 2.5, the future value of a dollar converted to a Roth IRA becomes

$$
(1+r)^{n}\left(1-T_{n}\right)=(1+r)^{n}-T_{o}\left[\mathrm{FVIF}_{T X}\right] .
$$


Distributing $(1+r)^{n}$ on the left-hand side, subtracting $(1+r)^{n}$ from both sides, and manipulating yields

$$
T_{n}=T_{o} \frac{\mathrm{FVIF}_{T X}}{(1+r)^{n}} .
$$

\section{Equivalence to Breakeven Withdrawal Tax Rate for Initial Investment}

The breakeven withdrawal tax rate previously mentioned is equal to that for the choice between a traditional IRA and a Roth IRA when the investment decision is initially made as long as the pretax investment is maximized. In this case, $I_{B T}(1-$ $\left.T_{o}\right)=L$. Substituting this expression into the breakeven Equation A12 produces

$$
T_{n}=T_{\circ}-\left(1-T_{o}\right)\left(\frac{I_{B T}}{I_{B T}\left(1-T_{0}\right)}-1\right)\left\{1-\frac{\left(1+r^{*}\right)^{n}\left(1-T^{*}\right)+T^{*}}{(1+r)^{n}}\right\} .
$$

Setting 1 in the large parentheses equal to $I_{B T}\left(1-T_{o}\right) / I_{B T}\left(1-T_{o}\right)$, distributing terms, and canceling terms yields Equation B10. Therefore, the breakeven withdrawal tax rates are equal. 


\section{Appendix C. Derivation of Breakeven \\ Withdrawal Tax Rate for Nondeductible IRA}

The withdrawal tax rate at which an investor is indifferent between a taxable account and a nondeductible IRA satisfies the condition that Equation 4.1 equals Equation 4.2. Setting them equal to each other yields

$$
\begin{aligned}
\mathrm{FV}_{T X} & =\mathrm{FV}_{\text {NonDedIRA }} \\
\left(1+r^{*}\right)^{n}\left(1-T^{*}\right)+T^{*} & =(1+r)^{n}\left(1-T_{n}\right)+T_{n} .
\end{aligned}
$$

Rearranging and solving yields

$$
T_{n}=\frac{(1+r)^{n}-\left(1+r^{*}\right)^{n}\left(1-T^{*}\right)-T^{*}}{(1+r)^{n}-1} .
$$

When a portion of the IRA contribution is deductible and another portion is nondeductible, the future value of a dollar withdrawn as a single cash flow can be expressed as

$$
\mathrm{FV}_{\text {PartDedIRA }}=(1+r)^{n}\left(1-T_{n}\right)+a T_{n},
$$

where $a$ is the nondeductible portion of the contribution. If all the contributions to the IRA account are nondeductible, $a$ is equal to 1 . Following the identical logic as previously mentioned, the breakeven withdrawal tax rate for a partially deductible IRA is

$$
T_{n}=\frac{(1+r)^{n}-\left(1+r^{*}\right)^{n}\left(1-T^{*}\right)-T^{*}}{(1+r)^{n}-a} .
$$




\section{Appendix D. Derivation of Future Value Interest Factor of a Taxable Annuity}

Consider an annuity investment in which an after-tax dollar is invested each year for $m$ years into a taxable investment. In this case, the future value of this accumulation can be expressed as the sum of the future values of each annual investment, or

$$
\text { FVIFA }_{T X, r, m}=\sum_{t=0}^{m-1}\left[\left(1+r^{*}\right)^{t}\left(1-T^{*}\right)+T^{*}\right] .
$$

Distributing the summation operator and factoring out $\left(1-T^{*}\right)$ yields

$$
\text { FVIFA }_{T X, r, m}=\left(1-T^{*}\right) \sum_{t=0}^{m-1}\left(1+r^{*}\right)^{t}+\sum_{t=0}^{m-1} T^{*} .
$$

Substituting the well-known expression for the future value of an annuity yields

$$
\mathrm{FVIFA}_{T X, r, m}=\left(1-T^{*}\right) \frac{\left(1+r^{*}\right)^{m}-1}{r^{*}}+m T^{*} .
$$




\section{Appendix E. Breakeven Investment Horizon for a Traditional IRA and a Roth IRA}

Beginning with Equation 6.1 as a breakeven condition, I can divide both sides by $(1+r)^{n}$ and $\left(1-T_{o}\right)$, distribute the terms, and divide through by $\left(1-T^{*}\right)$, yielding

$$
\left[\frac{1+r^{*}}{1+r}\right]^{n}=\frac{\left(1-T_{n}-\phi\right)}{\left(1-T_{0}\right)\left(1-T^{*}\right)}-\frac{T^{*}}{(1+r)^{n}\left(1-T^{*}\right)} .
$$

Because $n$ is an exponent on both sides, no closed-form solution exists and solving for $n$ requires an iterative process of trial and error. If the investment return is fully taxed as ordinary income, the simplified tax structure sets $p_{o i}=1$ and $p_{c g}=0$. In this case, $T^{*}=0$ and $r^{*}=r\left(1-t_{o i}\right)$ and the previous equation simplifies the breakeven condition to

$$
\left[\frac{1+r\left(1-t_{o i}\right)}{1+r}\right]^{n}=\frac{\left(1-T_{n}-\phi\right)}{\left(1-T_{o}\right)} .
$$

Taking the natural log of both sides and solving for $n$ produces

$$
n=\ln \left[\frac{\left(1-T_{n}-\phi\right)}{\left(1-T_{o}\right)}\right] / \ln \left[\frac{1+r\left(1-t_{o i}\right)}{1+r}\right] .
$$

If the investment is taxed entirely as capital gain, then $p_{o i}=p_{c g}=0$, which makes $r^{*}=r$ and $T^{*}=t_{c g}$. The breakeven condition in Equation 6.1 then reduces to

$$
\left(1-T_{o}\right)\left[(1+r)^{n}\left(1-t_{c g}\right)+t_{c g}\right]=(1+r)^{n}\left(1-T_{n}-\phi\right) .
$$

Distributing $\left(1-T_{0}\right)$ and factoring out $(1+r)^{n}$ yields

$$
(1+r)^{n}=\frac{t_{c g}\left(1-T_{o}\right)}{\left(1-T_{n}-\phi\right)-\left(1-T_{o}\right)\left(1-t_{c g}\right)} .
$$


Taking the natural log of both sides and solving for $n$ produces

$$
n=\ln \left[\frac{t_{c g}\left(1-T_{o}\right)}{\left(1-T_{n}-\phi\right)-\left(1-T_{o}\right)\left(1-t_{c g}\right)}\right] / \ln (1+r) .
$$

To solve for the breakeven investment horizon for a Roth IRA, set the after-tax and after-penalty future value of a Roth IRA in Equation 6.4 to the future value of a taxable investment yields

$$
\left(1-T_{o}\right)\left[\left(1+r^{*}\right)^{n}\left(1-T^{*}\right)+T^{*}\right]=\left(1-T_{o}\right)\left[(1+r)^{n}\left(1-T_{n}-\phi\right)+T_{n}+\phi\right] .
$$

I can divide both sides by $\left(1-T_{0}\right)$ and rearrange terms to produce

$$
\left(1+r^{*}\right)^{n}\left(1-T^{*}\right)=(1+r)^{n}\left(1-T_{n}-\phi\right)+T_{n}+\phi-T^{*}
$$

Dividing both sides by $\left(1-T^{*}\right)$ and by $(1+r)^{n}$ yields

$$
\left[\frac{1+r^{*}}{1+r}\right]^{n}=\frac{1-T_{n}-\phi}{1-T^{*}}+\frac{\phi+T_{n}-T^{*}}{(1+r)^{n}\left(1-T^{*}\right)} .
$$




\section{References}

Amromin, Gene. 2002. "Portfolio Allocation Choices in Taxable and Tax-Deferred Accounts: An Empirical Analysis of Tax Efficiency." Unpublished manuscript, Board of Governors of the Federal Reserve System.

Auerbach, Alan. J., and Mervyn A. King. 1983. "Taxation, Portfolio Choice, and Debt-Equity Ratios: A General Equilibrium Model.” Quarterly Journal of Economics, vol. 98, no. 4 (November):587-610.

Benvin, Anthony B. 2003. "On 'The Break-Even Frontier for Early Withdrawal from a Tax Deferred Account.” Journal of Financial Planning, vol. 16, no. 11 (November):20.

Bernheim, B. Douglas., Jonathan S. Skinner, and Steven Weinberg. 2001. "What Accounts for the Variation in Retirement Wealth among U.S. Households?" American Economic Review, vol. 91, no. 4 (September):832-857.

Black, Fischer. 1980. "The Tax Consequences of Long-Run Pension Policy." Financial Analysts Journal, vol. 36, no. 4 (July/August):21-28.

Bogan, Elizabeth C., and Thomas R. Bogan. 1982. "Individual Retirement Accounts and Preretirement Savings Goals." Financial Analysts Journal, vol. 38, no. 6 (November/December):45-47.

Burgess, Richard D., and Silvia A. Madeo. 1980. "A Simulation Study of Tax Sheltered Retirement Plans." Journal of the American Taxation Association, vol. 1, no. 2:34-41.

Burman, Leonard E., William G. Gale, Jeffrey Rohaly, and Benjamin Harris. 2002. "The Individual AMT: Problems and Potential Solutions." National Tax Journal, vol. 55, no. 3 (September):555-596.

Crain, Terry L., and Jeffrey R. Austin. 1997. "An Analysis of the Tradeoff between Tax Deferred Earnings in IRAs and Preferential Capital Gains." Financial Services Review, no. 6, vol. 4 (Winter):227-242.

Dammon, Robert M., and Chester S. Spatt. 1996. "The Optimal Pricing of Securities with Asymmetric Capital Gains Taxes and Transaction Costs." Review of Financial Studies, vol. 9, no. 3 (Fall):921-952. 
Dammon, Robert M., Chester S. Spatt, and Harold H. Zhang. 2001. "Optimal Consumption and Investment with Capital Gains Taxes." Review of Financial Studies, vol. 14, no. 3 (Fall):583-616.

- 2004. "Optimal Asset Location and Allocation with Taxable and TaxDeferred Investing." Journal of Finance, vol. 59, no. 3 (June):999-1037.

Doyle, Robert J. 1984. "IRAs and the Capital-Gains Tax Effect." Financial Analysts Journal, no. 40, vol. 3 (May/June):60-65.

Engen, Eric, and William Gale. 2000. "The Effect of 401(k) Plans on Household Wealth: Differences across Earnings Groups.” Working Paper 8032, National Bureau of Economic Research.

Engen, Eric, William Gale, and J. Karl Scholz. 1996. "The Illusory Effects of Saving Incentives on Saving." Journal of Economic Perspectives, vol. 10., no. 4 (Fall):113138.

Gokhale, Jagadeesh, and Laurence Kotlikoff. 2003. "Who Gets Paid to Save?" In Tax Policy and the Economy, vol. 17 (September). Edited by James Poterba. Cambridge, MA: MIT Press.

Horan, Stephen M. 2002. "After-Tax Valuation of Tax-Sheltered Assets." Financial Services Review, vol. 11, no. 3 (Fall):253-276.

—. 2003. "Choosing between Tax-Advantaged Savings Accounts: A Reconciliation of Standardized Pretax and After-Tax Frameworks." Financial Services Review, vol. 12, no. 4 (Winter):339-357.

_. 2004. "Breakeven Holding Periods for Tax Advantaged Savings Accounts with Early Withdrawal Penalties." Financial Services Review, vol. 13, no. 3 (Fall):233-247.

Horan, Stephen M., and Jeffrey H. Peterson. 2001. "A Reexamination of TaxDeductible IRAs, Roth IRAs, and 401(k) Investments.” Financial Services Review, vol. 10, no. 1 (Spring):87-100.

Horan, Stephen M., Jeffrey H. Peterson, and Robert McLeod. 1997. "An Analysis of Non-Deductible IRA Contributions and Roth IRA Conversions." Financial Services Review, vol. 6, no. 4 (Winter):243-256.

Huang, Jennifer. 2000. "Taxable or Tax-Deferred Account? Portfolio Decisions with Multiple Investment Goals." Unpublished manuscript, Massachusetts Institute of Technology, Cambridge, MA. 
2003. "Portfolio Decisions with Taxable and Tax-Deferred Accounts: A Tax-Arbitrage Approach." Unpublished manuscript, Massachusetts Institute of Technology, Cambridge, MA.

Hubbard, Glenn R., and Jonathan S. Skinner. 1996. "Assessing the Effectiveness of Saving Incentives.” Journal of Economic Perspectives, vol. 10, no. 4 (Fall):73-90.

Kitces, Michael E. 2003. "More on Early Withdrawals and the Breakeven Frontier." Journal of Financial Planning, vol. 16, no. 11 (May):20-21.

Krishnan, V. Sivarama, and Shari Lawrence. 2001. "Analysis of Investment Choices for Retirement: A New Approach and Perspective.” Financial Services Review, vol. 10, no. 1 (Spring):75-86.

Lewellen, Wilbur G. 1977. "Some Observations on Risk-Adjusted Discount Rates.” Journal of Finance, vol. 31, no. 4 (September):1331-37.

Mano, Ronald M., and Ted Burr. 1984. "IRAs versus Nonsheltered Alternatives for Retirement Savings Goals.” Financial Analysts Journal, vol. 40, no. 3 (May/ June):67-75.

O’Neil, Cherie J., Donald V. Saftner, and Peter M. Dillaway. 1983. "Premature Withdrawals from Retirement Accounts: A Break-Even Analysis." Journal of the American Taxation Association, vol. 4, no. 2 (Spring):35-43.

Poterba, James M. 2004. "Valuing Assets in Retirement Accounts.” Working Paper CRR WP 2004-11, Center for Retirement Research at Boston College (March).

Poterba, James M., and James A. Samwick. 2003. "Taxation and Household Portfolio Composition: US Evidence from the 1980s and 1990s." Journal of Public Economics, vol. 87, no. 1 (January):5-38.

Poterba, James M., Steven F. Venti, and David A. Wise. 1996. "How Retirement Saving Programs Increase Saving." Journal of Economic Perspectives, vol. 10, no. 4 (Fall):91-112.

Prakash, Arun. J., and Michael W. Smyser. 2003. "The Break-Even Frontier for Early Withdrawal from a Tax Deferred Account." Journal of Financial Planning, vol. 16 , no. 8 (November):56-61.

Randolph, William L. 1994. "The Impact of Mutual Fund Distributions on AfterTax Returns.” Financial Services Revierw, vol. 3, no. 2 (Summer):127-141. 
Reichenstein, William. 1998. “Calculating a Family's Asset Mix.” Financial Services Review, vol. 7, no. 3 (Fall):195-206.

- 2001. “Asset Allocation and Asset Location Decisions Revisited.” Journal of Wealth Management, vol. 4, no. 1 (Summer):16-26.

Reichenstein, William, and William Jennings. 2003. Integrating Investments and the Tax Code. Hoboken, NJ: John Wiley \& Sons.

Shoven, John B., and Clemens Sialm. 2003. "Asset Location in Tax-Deferred and Conventional Savings Accounts." Journal of Public Economics, vol. 88, no. 1/2 (January):23-38.

Sibley, Michael. 2002. "On the Valuation of Tax-Advantaged Retirement Accounts.” Financial Services Review, vol. 11, no. 3 (Fall):233-251.

Stout, Gary R., and Robert L. Barker. 1998. "Roth IRA Planning." Journal of Accountancy, vol. 186, no. 2 (August):59-69.

Tepper, Irwin. 1981. "Taxation and Corporate Pension Policy." Journal of Finance, vol. 34, no. 1 (March):1-13.

Terry, Andy, and William C. Goolsby. 2003. "Section 529 Plans as Retirement Accounts.” Financial Services Review, vol. 12, no. 4 (Winter):309-318. 